\title{
UC-NRLF
}

|| || || || ||||||||||||||||||||||||||||||

||C||||||||||||||||||||||||||||||||||||||||||.||||

B 3888243 


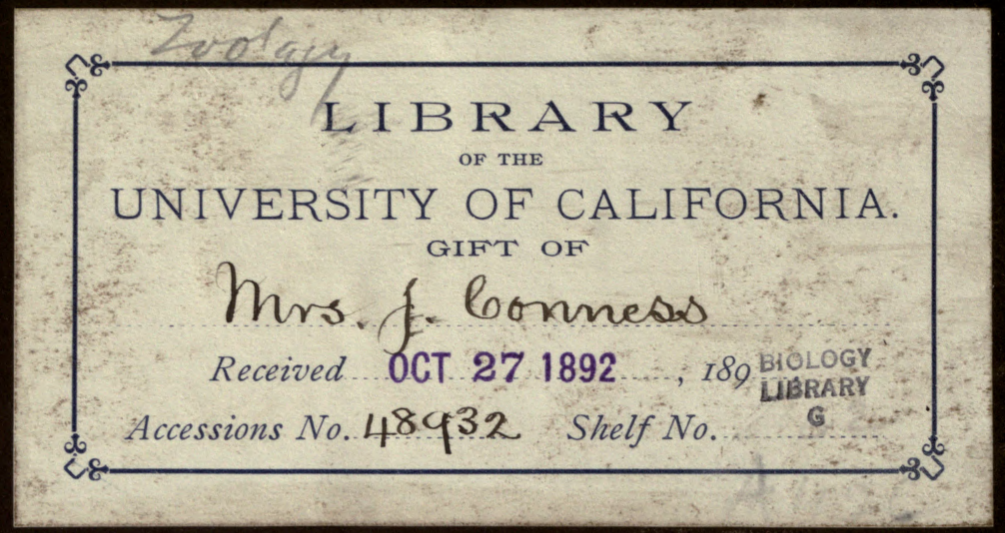




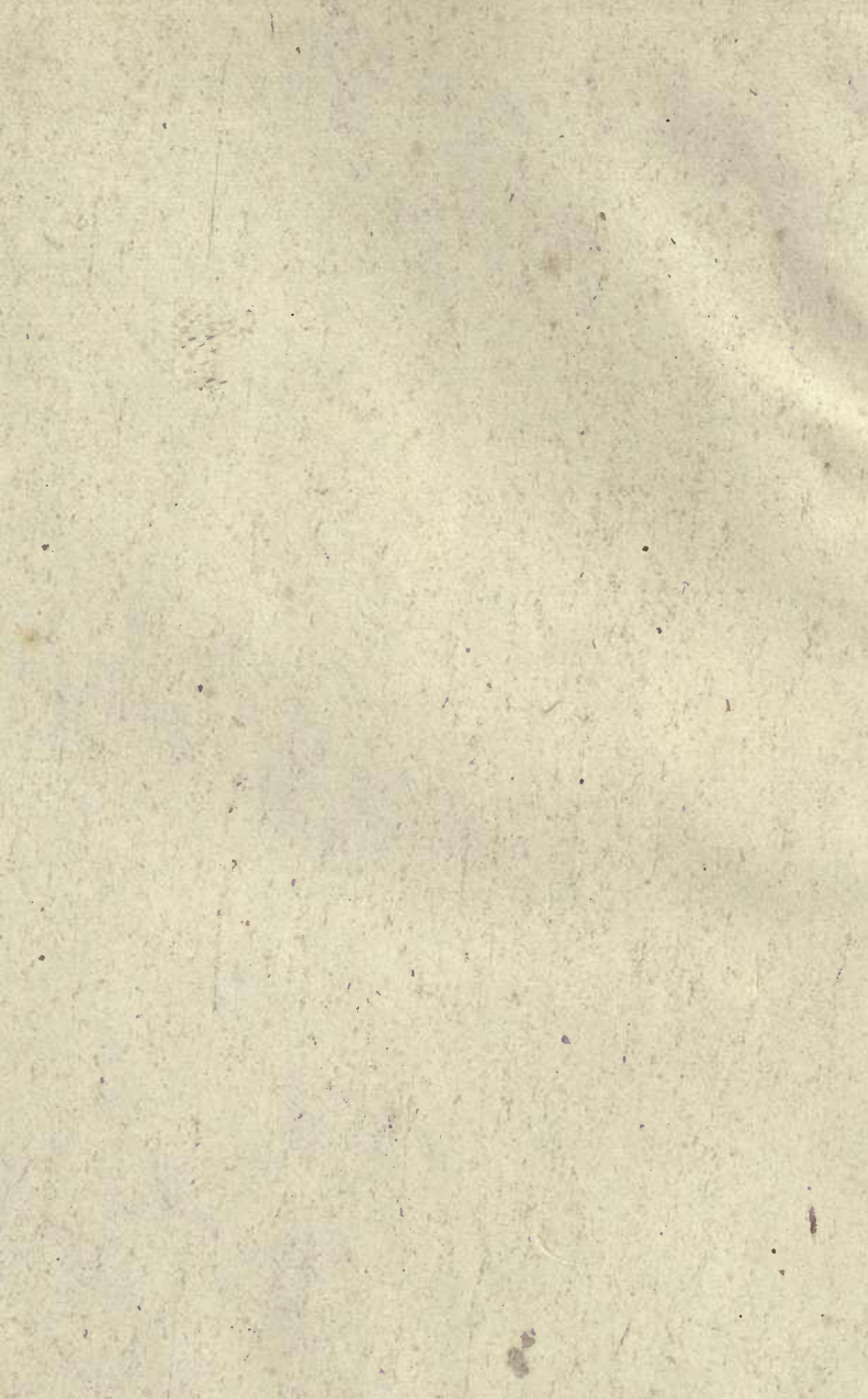


Prof. N.I a mes blank with the req ares of the Author 



\title{
OUTLINES
}

or

\section{COMPARATIVE ANATOMY}

\author{
- AND \\ M E D ICAL Z $00 \mathrm{~L} 0 \mathrm{GP}$. \\ BY
}

HARRISON ALLEN, M.D.,

PROFESSOR OF ZOOLOGY AND COMPARATIVE ANATOMY IN THE UNIVERSITY OF PENNSYLVANIA.

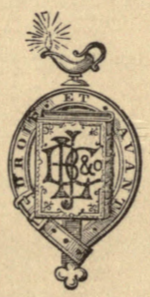

PHILADELPHIA :

J. B. LIPPINCOTT \& CO.

1869 .

01 TMET

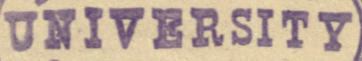

(3) 


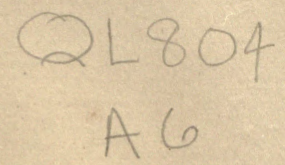

BIOLOGY
UIBRARY
$G$

\section{2}

Entered, according to the Act of Congress, in the year 1868, by

HARRIS ON ALLEN, M. D.,

In the Clerk's Office of the District Court of the United States in and for the Eastern District of Pennsylvania. 


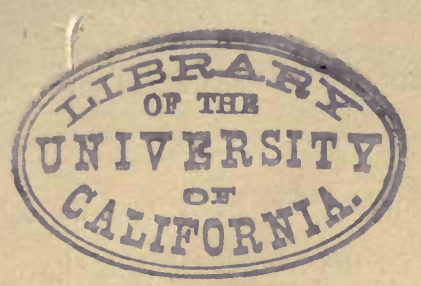

\section{PREFATORY NOTE.}

In the spring of 1866 , a desire was expressed by the Class to have the author's Lectures on Comparative Anatomy and Zoology published for distribution. Nothing definite, however, was determined upon until the following spring, when arrangements were entered into which have resulted in the appearance of this little volume. It is in many respects somewhat fuller than a synopsis, which, however, in general features, it resembles. Although prepared in answer to the expressed needs of a class composed chiefly of Medical Students, it is hoped that it may not be without value to the cultivators of rational anatomy elsewhere.

In the attempt, apparent in different portions of the book, to frame general definitions and give brief classifications of anatomical systems, the author is fully aware of the liability to error thus incurred. Any conclusions based upon the present state of a science so actively cultivated as Comparative Anatomy may eventually prove of but doubtful utility. It is easy to group about assumed standpoints the observations of others, but more difficult to preserve in such arrangements harmony between the old and new facts. In 
proposing such, the author has been actuated by a sincere desire to simplify a confessedly intricate subject.

In conclusion, he would desire to express his acknowledgments to Dr. George H. Horn for the contribution of the articles on Hemiptera and Cantharis; as well as to Professors Joseph Leidy, Edward D. Cope, and Horatio C. Wood, Jr., for assistance rendered while the work was passing through the press. 


\section{CONTENTS.}

\section{COMPARATIVE ANATOMY.}

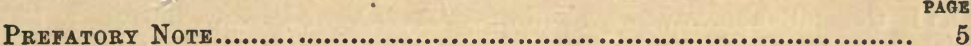

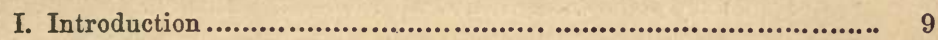

Elements of structure...................................................... 9

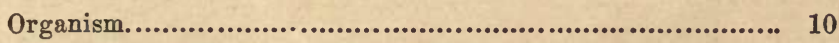

Distinctions between vegetables and animals........................ 11

Division of functional labor............................................ 12

II. Classification ................................................................ 13

Plan of star.............................................................. 15

( Sac .................................................................. 17

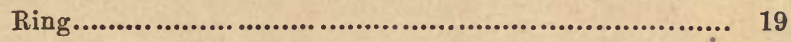

Vertebra.............................................................. 20

III. Skeleton............................................................................ 28

Nature of limbs in Vertebrata .......................................... 31

Table of elements of cranial vertebræ................................. 34

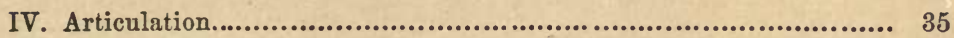

V. Apparatus of motion......................................................... 36

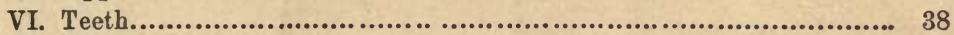

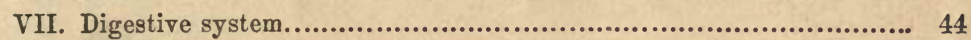

VIII. Circulatory and respiratory systems...................................... 52

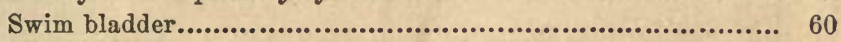

Relation of branchial arches to stylo-hyoid ligament................ 61

Spleen........................................................................... 63

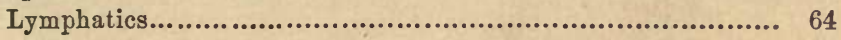

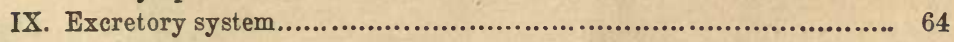

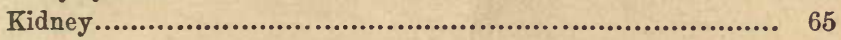

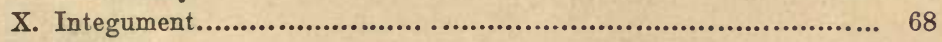

XI. Nervous system............................................................. 72

XII. Animal electricity and phosphorescence................................... 82

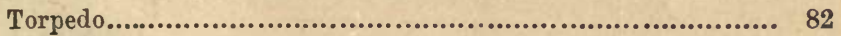

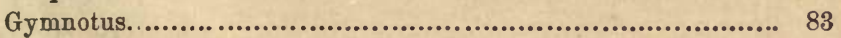

Malapterurus ......................................................... 84

Animal phosphore 


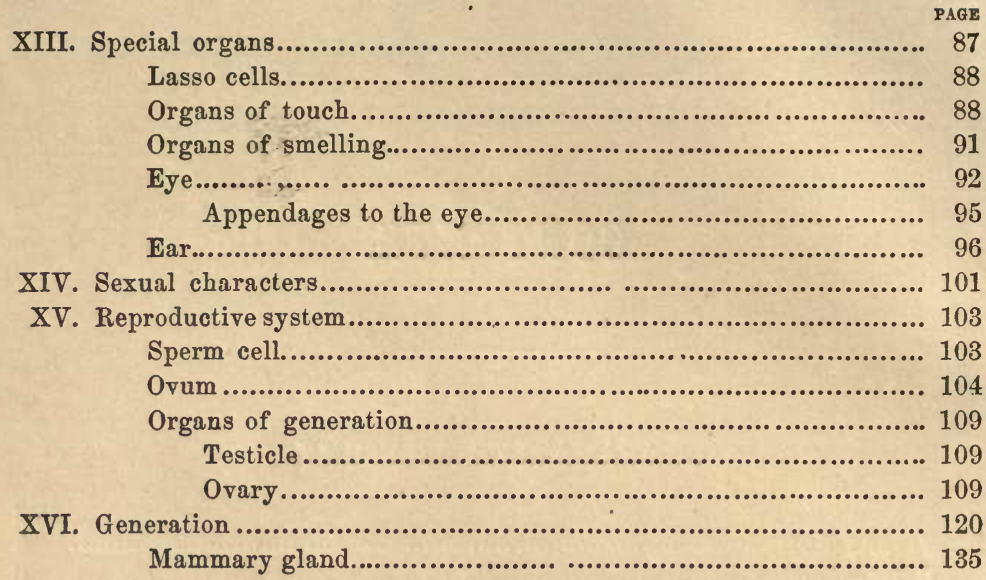

\section{MEDICAL ZOOLOGY.}

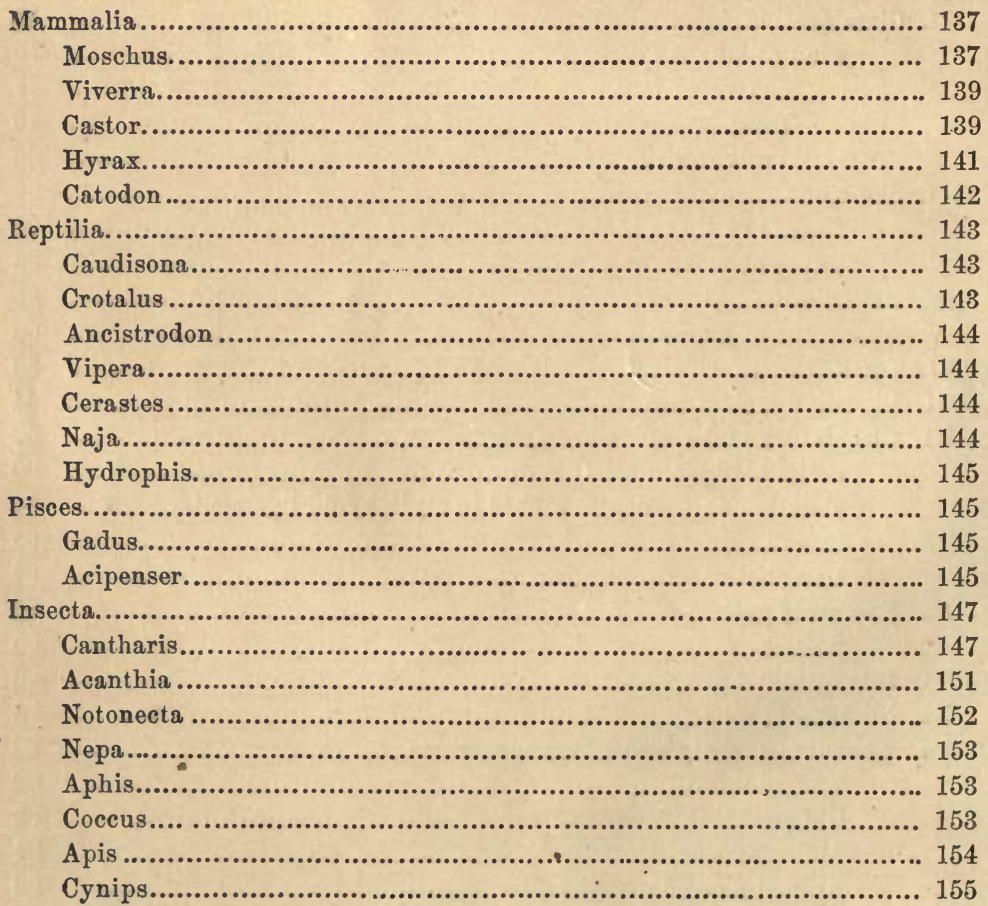


Pulex

Pediculus.......................................................................... 156

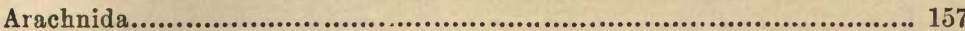

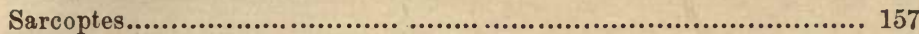

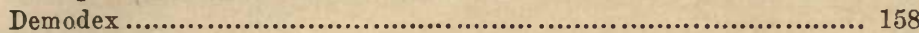

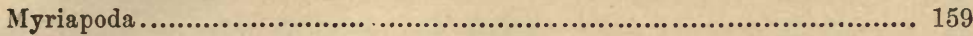

Scolopendra............................................................. 159

Annelida ...................................................................... 159

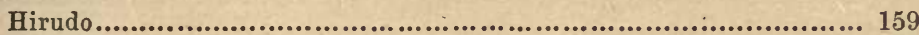

Entozoa ............................................................................. 161

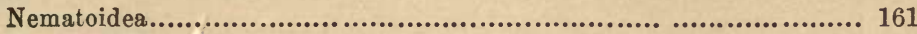

Trichina.............................................................. 161

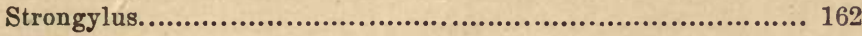

Trichocephalus...................................................... 162

Ascaris................................................................. 163

Oxyuris ............................................................... 164

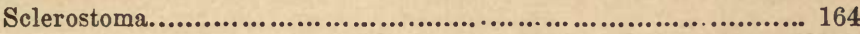

Dracunculus.......................................................... 164

Eustrongylus........................................................... 165

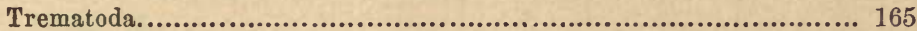

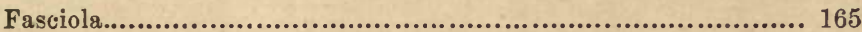

Distoma.................................................................... 166

Bilharzia.............................................................. 167

Tetrastoma ................................................................. 168

Hexathyridium........................................................... 168

Development of trematoda............................................ 168

Cestoda....................................................................... 169

Tænia.................................................................. 169

Bothriocephalus..................................................... 171

Development of Cestoda............................................... 172

Mollusea ...................................................................... 174

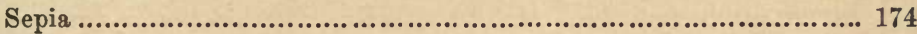

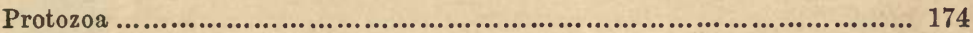

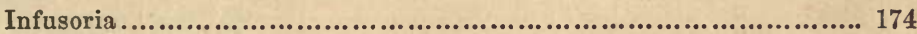

Virgulina.......................................................... 174

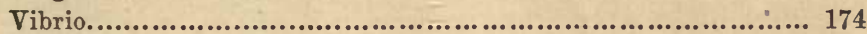

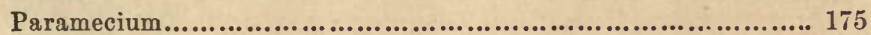

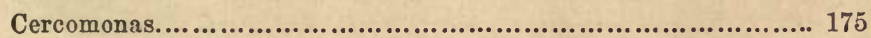

Trichomonas............................................................. 175

Psorospermiæ............................................................... 175

Gregarinidæ.......................................................... 176

Spongia................................................................... 177

Additions................................................................... 178

Table of Classification..................................................... 179

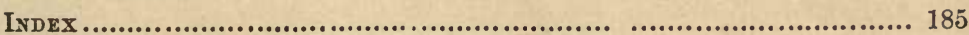




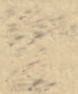




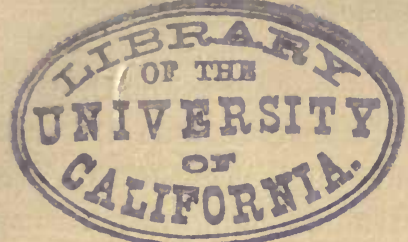 \\ COMPARATIVE ANATOMY.}

I.

INTRODUOTION.

ELEMENTS OF STRUCTURE.

THE composition of all bodies is either inorganic or organic.

An inorganic (mineral) body is homogeneous in structure, and is either crystalline or without definite form. Its increase results from external accumulation of particles. An organic body is a product of organization. An organized body (organism) is heterogeneous in structure, and has a definite form. Its increase results from nutritive processes carried on within.

Every organized body is composed of ultimate and proximate physical elements.

The Ultimate Physical Elements are (1) homogeneous liquid,-as in the germinative area of the egg immediately after impregnation; (2) homogeneous granules, -as in Monas crepusculum; (3) homogeneous filaments,-as in cilia, spermatic filaments, and Vibrio; (4) homogeneous membrane,as in basement membrane. (Leidy.)

The Proximate Physical Elements result through union of the ultimate elements. They are very constantly pronounced in varieties of the organic cell, of which it is convenient to speak, as an early, though not a primordial, expression of form.

As usually described, the organic cell is a minute form, composed of homogeneous membrane with intervening 
spaces occupied with homogeneous liquid. Three concentric spheres can commonly be detected: the first (nucleolus) placed within the second (nucleus); the third (cell wall) en. closing the other two. Homogeneous granules appear within the liquid, and filaments (cilia) may be appended to the cell wall.

Forms of Cells are round, oblong, elongate, cylindrical, compressed, polygonal, and stellate. Surrounding conditions and position determine shape.

Properties of Cells. - In addition to the nutritive processes common to all organisms, may be mentioned fissuration and motility.

Relations of cells to histogenesis lead to consideration of origin and significance of cells.

1st Theory.-Cells originate spontaneously in a homogeneous fluid, in the form of granules (nucleoli). Around these granules are subsequently developed others assuming the form of the remaining constituents of the cell, to be recognized as the nucleus and cell wall. (Schleiden and Schwann.)

$2 d$ Theory.-Omni cellula e cellula. (Virchow.)

3d Theory (generally known as the germinal theory).-The terminology of the cell is discarded, and the phrases "germinal matter" and "formed matter" substituted. The former is a structureless plastic substance everywhere pervading organized bodies, to which the formed matter stands in the relation of an evolved substance. (Beale.)

\section{ORGANISM.}

All organisms are sexual beings, and are, for the most part, composed of cells.

Many inferior organisms assume the form of cells, as Amoba* and Bodo. The ovum, apparently a cell, is in reality an undeveloped organism. The difference between a

* Amoeba, one of the lowest of Rhizopoda,-composed of sarcode, with an outer structureless diaphanous integument, and containing an interior circular contractile vesicle. Measurement, from $\frac{1}{70}$ to $\frac{1}{2} \frac{1}{80} \overline{0}^{\prime \prime}$ long. Is found in stagnant water. 
cell and an organism can be determined only by tracing out the life-history in each.

\section{DISTINCTIONS BETWEEN VEGETABLES AND ANIMALS.}

Many attempts have been made to separate vegetables from animals. The cell being common to both groups, attempts have been made to separate them by its means. A sphere of homogeneous membrane intervening between nucleus and wall of the vegetable cell, not peculiar to it; an analogous membrane is seen in cartilage cell.

There is no difficulty in separating high plant from high animal, as, for example, a horse from a tree; but acknowledged difficulty in distinguishing low forms, as a sponge from a Protococcus, an Amceba from an CEthalium. But, as a rule, confusion obtains not so much among the very lowest forms of animal and vegetable life, as, for example, between Rhizopoda and Protophytæ, as it does between others higher in the scale, as between certain Infusoria and Fungi, as the Myxomycetes.

Linnæus' definition: "Stones grow; plants grow and live; animals grow, live and feel."

Objections.-Stones do not grow, but increase in size by accretion. Feeling may be said to exist in the lower classes of both plants and animals, provided that contractility be accepted as a property of sensitive tissue. If it be surmised that pain is a result of feeling (i.e. sensation), it may be attributed to CEthalium with equal propriety as to Amoeba. Were every act of fissuration, evisceration or amputation accompanied with pain, it becomes difficult to understand why self-mutilation should be so frequently imposed for the preservation of both individual life and that of the species (see p.120). It is probable that at such times an organism feels no more pain than is experienced by the contractile contents of an ovum undergoing segmentation.

Among the attempts which have been made to separate plants from animals, may be mentioned the followingplaced, for convenience, in the form of propositions and objections: 
Prop. 1st. That while plants inspire carbonic acid they expire oxygen-the process being reversed in animals. Obj. Plants, in absence of sunlight, or in times of flowering, exhale carbonic acid.

Prop. 2d. That plants do not possess cilia-animals do. Obj. Many zoospores of plants are ciliated. Entire groups of animals, as higher articulates and osseous fishes, are without them.

Prop. 3d. That plants are without stomachs-all animals possess stomachs. Obj. The amœboid stage of development of Cthalium has a stomach in the same sense as Amoba; while Tonia (tapeworm) is without a stomach.

Prop. 4th. That plants have cellulose and starch as chemical constituents of tissue-animals have not. Obj. The mantle of the Tunicata contains cellulose; the ventricles of human brain contain starch granules.

Prop. 5th. That plants are stationary-while animals are contractile and motile. Obj. Many plants have active contractile zoospores, and Volvox globator and the Diatomaceæ are essentially motile.

We cannot, therefore, well express the difference between a plant and an animal; but can only ascertain the position of each disputed form by contrasting the sum of its life-phases with that of acknowledged types, as determined by development and sexual condition.

Contrasts between animals arise from the variety of methods by which the processes of life are performed. In the Amoba these processes are carried on in a common tissue (sarcode), so that at different times the same structure is subservient to different uses. But among the higher animals, which have many tissues, each organ has a limited functional power; the degree of such limitation bearing a fixed relation to the multiplicity of organs, so that in the highest animals each organ has but a single function to perform. Indeed, every animal, it is thought, has its tissues so specialized that the degree of its specialization is expressive of its position in the class to which it belongs. 
This leads to the following law:

The successive degrees of development attained by the animal kingdom depend upon the extent to which functional labor is divided.

\section{II.}

\section{CLASSIFICATION,}

Classification is the arrangement of objects into groups, the limitations of which are determined by some preconceived standard of comparison.

Classifications are artificial or natural, as the standard chosen is either false or true. Thus the classification of animals, according to Aristotle, is artificial, since the standard assumed, viz., the coloration of the blood, is false. An artificial classitication is the result of an imperfect knowledge of the things classified.

It is only by an intimate acquaintance with the anatomy, physiology, and development of each animal, that we can determine in what tissues, and at what time, the true standard for comparison exists. As a rule, the hard tissues, such as the shell, bone, teeth, scales, etc., furnish excellent secondary characters; yet in sub-groups of Vertebrata, soft tissues, as the blood and brain, afford reliable data. Sexual characters are occasionally of value, as the mammary gland, in Mammalia, and, in a less degree, the construction of the penis in the same class. The male, in Vertebrata, conveys the expression of potentiality of species; in lower types, it is subordinate.

Maturity very generally yields the true standard of comparison. Yet examples are not rare where it is best seen in the young. The articulated condition of Lepas (barnacle) is noticed only in the larval stage of the animal. The chorda dorsalis-the distinctive feature of the Vertebrata-disappears (ii comparatively few instances only is it persistent, viz., Cartilaginous fishes) before birth. 
The early condition of the embryo itself may determine the position of the animal. Thus in contrasting the early stage of the developing egg of an articulate with that of a vertebrate animal, it can be ascertained before the appearance of rings on one hand, or chorda dorsalis on the other, to which type the animal belongs. In the first, the embryo presents serrated borders, and is without a median groove; in the second, there is a median grove, but no lateral serrations.

Apart from the application of the general law (p. 13), the inferiority of an animal within its group can be determined either (1) by the repetition of parts, or (2) by the permanency of embryonic conditions. (1) The tentacles and partitions of Actinia are indefinitely repeated throughout life; they are reduced to a fixed number-eight-in Alcyonium: therefore Actinia is a lower form of polyp than Alcyonium. In like manner Gammurus (fresh-water shrimp), a crustacean articulate, from the repetition of its segments, is a type inferior to Lupa dicantha (crab), where they are consolidated toward the anterior extremity of the animal. (2) Upon observing among acaleph radiates that the genus Hydra corresponds in form to the first larval change of the Aurelia (see p. 126), Hydra is said to be a lower form than Aurelia. In perceiving that a canal of communication between an arterial and venous current (foramen of Botal) obtains in the systemic circulation of the reptile, while such a condition is peculiar to the fœtal circulation of the mammal, the reptilian type is said to be lower than the mammalian.

When the relations of closely allied animals are sought for, the characters are selected not so much from their physiological importance as from their constancy. Indeed, the most important vital organs with some groups of animals may furnish no characters for classification-as, for example, the heart in insects; while others having no apparent significance, such as minute differences in form and number of joints of antennæ, may be of the greatest value.

Systems of classification change with increase of knowledge, and, all things being equal, the latest is the best. But 
it appears probable that the present classification will never be materially altered. The main features are for the most part defined with clearness. As a result, a number of plans or types of structure are seen in the animal kingdom-each plan or type being taken as the standard of comparison for all animals included within its limits. To these ideal patterns the tissues more or less regularly conform. If they have the significance by many attributed to them, namely, in each being the expression of a divine idea, it follows that the great principles of classification are fixed.

These plans are four in number, and are arranged in accordance with the capacity possessed by each for development, as follows:
STAR.
SAC.
RrNG.
Vertebra.

In that large group, the Protozoa,* no plan or plans have yet with certainty been recognized.

Star (Radiata).

A radiate animal is one having its parts disposed around a common central axis, and diverging from it to the periphery. (Agassiz.)

Divided into groups of Cœlenterata and Echinodermata.

Cœlenterata subdivided into Polypi and Acalephæ.

* Protozoa. This term was proposed by Siebold to designate a group of animals, characterized by the various systems of organs not being distinctly separated. (Griffith in Micrograph. Dict.)

Divided into Rhizopoda, Spongida, and Infusoria.

Rhizopoda.-Essential characters are the gelatinous composition of the body, and the locomotive organs consisting of variable foot-like processes (pseudo-podia). (Griffith, ibid.)

Spongida._Fixed, aquatic, polymorphous animals; inhaling and imbibing the surrounding element through numerous contractile pores situated on the external surface; conveying it through internal canals or cavities, and ejecting it through appropriate orifices; having an internal flexible or inflexible skeleton. (Bowerbank.)

Interior mass occupied with numbers of chambers lined with flagellate cell-like bodies. (Carter.)

Infusoria.-Form variable, fixed or free, round, oval, etc., with integument furnished either with a ciliated spiral line, or a single flagellum. Iuterior mass slightly specialized; a gullet and contractile vesicles making their appearance. 
Polypi.-Composed of a sac divided into chambers by partitions arranged to the periphery (integument), as radii to a central point-the stomach. Such partitions may be more, though never less than six in number. "The upper margin of body is fringed by hollow tentacles, each of which opens into one of the chambers." They may be naked and present indefinite numbers of partitions and tentacles, as in Actinia (sea-anemone); or possess a definite yet large number of tentacles often accompanied with depositions of calcareous matter within walls between partitions, as in Madrepora (coral); or the tentacles may be restricted to six, with a tendency to formation of calcareous skeleton, as in Alcyonium.

Acalephæ.-This is a numerous and diversified group, composed for the most part of individuals, which, when mature, have a dome or umbrella-like form. The organs and systems of vessels are arranged in a stellate manner to a central point. Divided into Ctenophoræ, Discophoræ, and Hydroida.

Acalephs move by means of minute flappers arranged in vertical comb-like rows on outer side of the dome-like structure, as in Ctenophoræ; or through the movements of the edges or general contractile power of the Discophoræ and Hydroida.

In the last two groups, remarkable features are seen in the development of the young, the larval condition, as a rule, remaining fixed and dissimilar in form to the adult. (See p. 124.)

Echinodermata. - This is the highest group of radiates, composed of stellate globular or oblong forms, rarely fixed, and possessing, with the exception of one group, a system of foot-like processes (ambulacra), which may be inflated with water through ambulacral vessels, communicating by means of a peculiar canal (madreporic body)* with the exterior. The spaces between the ambulacral pores are the ambulacral spaces.

The majority of Echinodermata are more or less enclosed

* So called from the resemblance its sieve-like opening bears to a polyp chamber of Madrepora. 
by a complicated system of calcareous plates, giving a rigidity to the general form of the animal.

The plates constituting the dorsal system may be very numerous and complicated, so as to form a stem by which the animal is invertedly attached to the ground, while the ambulacral system may be limited to a comparatively small area, and the interambulacral system is wanting, as in Comatula (sea lily); the dorsal system, though large, may not form a stem, yet fold over on the under side of the animal so as to enclose entirely the ambulacral system, forming a kind of shield to the bases of the long snake-like arms, as in Ophiopholis; the system may occupy the back of the animal, but not to enclose the ambulacral suckers which find their way between the rows of small plates along the under side of the arms, as in Asteracanthion (star fish); the system may be contracted to a small area on the top of the animal, the rows of interambulacral plates which are separated and lie on either side of the ambulacra in the star fish may now be united, and both ambulacral and interambulacral systems bent upward, meeting in a small dorsal area above, as in Toxopneustes (sea urchin); or the ambulacral and interambulacral systems may take a great preponderance over the dorsal system, the latter being pushed out to the end of a cylinder, while the two former run along its whole length, as in Holothuria (sea cucumber).-(E. C. \& A. Agassiz.)

SAC (Mollusca).

A mollusc has the stomach and viscera enclosed by a fleshy sac. Principal nerve masses, consisting of ganglia, which are adjacent to, or surround the œsophagus. Intestine bending inward, or having an outward flexure. Heart on outer side of intestine. (Morse.)

Divided into Polyzoa, Brachiopoda, Tunicata, Lamellibranchiata, Gasteropoda, Pteropoda, and Cephalopoda.

Polyzoa.-Compound molluscs. Respiratory apparatus exsertile from sac in the form of ciliated tentacles around mouth. Intestinal canal definite, curved upon itself. Single ganglion situated at re-entering angle. Heart, none.

Brachiopoda.-Animals solitary. Mantle covered by bi- 
valved shell, arranged antero-posteriorly to body. Respiratory apparatus in the form of two long, ciliated tentacles. Alimentary canal curved upon itself, and either ends blindly in the middle line or else terminates in a distinct line between lobes of mantle. (Huxley.) Nervous ganglion placed within the re-entering angle of intestine. Vascular system imperfectly understood. An atrial circulation, or movement of water within system of communicating chambers, is well developed.

Tunicata.-Compound or single molluscs. Respiratory apparatus included within mantle. Gullet commences from the base of this branchial chamber. Endostyle* present. The intestine is curved upon itself and terminates at anal aperture, which is always situated within a chamber opening externally by a second aperture upon mantle. The nervous ganglion not placed within entering angle of intestinal fold. Heart of simple form always present. Atrial system present as in Brachiopoda.

Lamellibranchiata.-Solitary molluscs. Shell bivalved, arranged to right and left half of mantle. Respiratory apparatus in the form of lamellæ and are four in number, two on either side of visceral mass. Mouth often furnished with labial lobes. The intestine generally penetrates the heart, and terminates near anus between the mantle lobes at posterior extremity of body. Nervous ganglia generally of three pair, arranged as follows: one for the parts about the mouth, one for the foot, when present, and the remaining one for the posterior adductor muscle. The heart, often of two chambers, occasionally of one.

Gasteropoda.-Solitary molluses. Shell univalved or multivalved; whorls dextral, as a rule. Respiratory apparatus; comb-like gills in aquatic, lung-like structure in terres-

* The middle of the hæmal wall, viz., the side toward the heart, the pharynx, is pushed into a longitudinal fold, the bottom of which projects into a blood sinus, and has a much thickened epithelial lining. Viewed from one side the bottom of the fold consequently appears like a hollow rod, and has been termed the "endostyle." The functions of this structure are unknown. (Huxley.) 
trial types. Alimentary canal bent upon itself, the rectum very commonly opening into the mantle cavity above the cephalic portion of body. (Huxley.) Nervous system, same plan as Lamellibranchiata-tendency to aggregation of ganglia toward cephalic extremity. Foot constantly present.

Pteropoda.-Shell univalve, if any. Alimentary canal and nervous ganglia resembling in arrangement those of Gasteropoda. Cephalic extremity rudimentary.

Cephalopoda.-Shell univalved, either elaborate, rudimentary or absent. Respiratory apparatus by gills, either in one or two pairs. Alimentary canal and nervous ganglia as the last two groups. The margins of foot are produced into more or less numerous tentacular appendages, often provided with singularly constructed suckers or acetabula,-the mouth being situated at a central point.

Ring (Articulata).

The embryo of an articulate is evolved from the ventral aspect of the ovum, and presents serrated borders. In adult condition articulates present a series of rings joined together by intervening tissues. In the lower groups, as Rotifera, Entozoa, and Annelida, this arrangement is less evident than in the higher; hence these animals are by some separated from the Articulata and termed the Annulosa. A single ring of an articulate animal thus characterized contains a portion of the main blood-vessel, nervous system and alimentary canal, arranged in the following order: blood-vessel under dorsal surface, nervous system on the ventral, and the alimentary canal between. At the cephalic extremity of the animal, this arrangement is modified by the nerves at that point forming a collar or ring (œsophageal ring) around the gullet, which then terminates toward dorsal aspect of segments. The organs, as a rule, are arranged upon either side of a longitudinal axis. Divided into Rotifera, Entozoa, Annelida, Crustacea, Myriapoda, Arachnida, and Insecta.

Rotifera.-Aquatic, limbless articulates. Cephalic extremity furnished with a retractile (often lobed) disk, upon which are usually placed cilia. Water vascular system present. 
Entozoa.-Definition obscure. Water vascular system present. As name expresses, its forms are parasitic.

Annelida.-Worm-like articulates. Division into rings occasionally obscure or rarely absent. Limbs without articulations. Alimentary canal floating, with anus dorsal. Cilia present. Blood-ressel system complete.

Crustacea.-Aquatic articulates. Segments of head and thorax combined (cephalothorax); intestine straight; all pass through a series of metamorphoses in development-all undergo exuviation; all respire by branchiæ or by surface of body performing function of aeration. (Dana.)

Myriapoda.-Air-breathing articulates. Legs numerousfewer in young than adult.

Arachnida.-Air-breathing articulates. Segments of head and thorax combined (cephalothorax); legs, eight at maturity.

Insecta.-Air-breathing articulates. Head distinct from thorax; legs, six; body permeated with air: often winged.

Vertebra (Vertebrata).

The embryo of a vertebrate is evolved from the dorsal aspect of the ovum; a chorda dorsalis (notochord) is placed beneath a dorsal median groove; an internal skeleton is always present, composed of cartilaginous or osseous segments. These segments are thought to be modified portions of a number of typical vertebræ, each vertebra being composed of a centrum (body), neurapophysis (lamina), neural spine (spinous process), diapophysis (transverse process), zygopophysis (oblique process), pleurapophysis (rib), hæmapophysis (intercostal cartilage), hæmal spine (segment of sternum), epipophysis (spine above centrum), and hypopophysis (spine below centrum). The cavity defined above the centrum is the neural canal; that below the centrum, the hæmal canal. By this method the plan of the Vertebrata might be compared to a double ring - the upper designed for the reception of the neural axis; the lower for the blood-vessel and digestive systems, together with the sympathetic nerve.

Motion of jaw up and down. Complete vascular and lymphatic systems with portal circulation, spleen, and valvular heart present, except in Amphioxus (lancelet). The organs 
of a vertebrate animal possess a tendency to arrange themselves on either side of a longitudinal axis.

Pisces. - No amnion or allantois. Posterior or visceral clefts persistent, bearing branchiæ* (gills) throughout life. Limbs, properly so called, absent; fins median and rayed; nasal sacs, as a rule, do not communicate with a mucous surface; blood corpuscles nucleated and red, with exception of Amphioxus (lancelet), which are colorless; heart with one auricle and one ventricle, with the exception of Amphioxus; skull articulates with vertebral column through single surface, the basi-occipital bone; lower maxillary articulates with skull through a chain of bones (suspensorium), and presents a concave articular surface.

Batrachia. - No amnion or allantois. Posterior visceral clefts generally closing in adult, so that branchiæ are present in the majority of eases only in the young. Limbs pres-

* "It is at the beginning of the intestinal canal, where the ventral laminæ are converging, that the branchial arches are developed; the parietes of the body here become thinner; and in this, the cervical region, several clefts or fissures make their appearance, which sink downward, and penetrate through the mucous layer; there are three pairs, or, with the oval aperture, four pairs of such fissures, but the posterior pair are extremely small; they are called the branchial fissures-fissuræ branchiales; between them lie three segments, or divisions of the ventral laminæ, which are blunt and rounded anteriorly, beveled off toward the digestive cavity, and therefore sickle-shaped; these are named the branchial arches-arcus branchiales; the fourth branchial arch is placed hindmost, and is not yet distinct from the ventral lamina. On the fourth day the two most anterior branchial arches increase in thickness; a new fissure is formed posteriorly; on the fifth day the foremost fissure closes, and the foremost branchial arch unites with its fellow of the opposite side, and forms the lower jaw; the next in succession is transformed into the os hyoides. The two last branchial fissures close upon the fifth day; at the same time the first is lost entirely; but the second continues longer open. On the third and fourth days the part of the ventral lamina, which is situated in front of the lower jaw, thickens, and resolves itself into the lower jaw ; this part is more strongly marked on the fifth day. The two sides of the upper jaw do not meet in the first instance; they coalesce at a later period, through the medium of the frontal process which is developed betwixt the eye."-Extract from chapter on Embryology in Wright's trans. of Wagner. 
ent; blood corpuscles, red and always nucleated; nasal sacs communicate with a mucous surface (mouth); heart with two auricles and a single ventricle; skull articulates by double surfaces through ex-occipital bones; basi-occipital cartilaginous; suspensorium less complex than in Pisces; lower maxillary presents a concave articular surface.

Reptilia.-Amnion and allantois present. Posterior visceral arches always closed, consequently no branchiæ; skull articulates through single surface, composed of a basi-occipital and two ex-occipital elements; suspensorium consists of a single bone (os quadratum); lower maxillary presents a concave articular surface.

Aves.-Same as Reptilia, with the additional charactersunion of first row of tarsal bones with lower end of tibia, and second row with metatarsus; metatarsal elements anchylosed, excepting in Aptenodytes (penguin); aorta turns to right; bronchial tubes open into air sacs communicating generally with the interior of the bones; skin furnished with feathers.

Mammalia.-Amnion and allantois present. Posterior visceral arches always closed; red blood corpuscles nonnucleated; diaphragm complete; skull articulates by double surfaces, each of which is composed of elements from the basi-occipital and ex-occipital bones; cervical vertebræ seven -apparent exception in Bradypus (sloth); lower jaw articulates directly with skull by a convex condyle; mammary gland present; skin furnished with hair.

Each of the above plans is distinct. No member of one plan possesses a tendency to run into another. A few disputed forms have held doubtful positions, such as

Sipunculus. - Really articulate (through Echiurus) in arrangement of viscera with respect to a longitudinal axis, disposition of blood-vessel and muscular systems, and in dorsal position of anus. Apparently radiate (through Holothuria) in general appearance, habit, arrangement of oral tentacles, tortuous alimentary canal enclosed by folds of peritoneum, and structure of integument.

Dentalium.-Really molluscoid in presence of mantle, heart, 
protrusile foot, and in curvature of alimentary canal. Apparently annelidous in shape of shell, and red color of blood, as well as annulated form of embryo.

The following forms have, until recently, held doubtful positions among classes of Vertebrata:

Lepidosiren.-Really piscine in arrangement of gill arches, in construction of scapular arch, and fin rays, and in single auricle to heart. Apparently reptilian in external gill and position of nares.

Labyrinthodon.-Really batrachian in presence of double ' occipital condyle, parasphenoid and 'girdle' bones. Apparently saurian in length of ribs, and development of dermal plates.

Archoopteryx.-Really avine in union of tarsal and metatarsal elements, and presence of feathers. Apparently saurian in prolonged production of vertebræ in a caudal series, presence of teeth, and construction of pelvis.

Ornithorhynchus.-Really mammalian in presence of mammary gland, direct articulation of lower jaw to skull, complete diaphragm, and the fixity of inferior strait of pelvis. Apparently avine in presence of webbed foot, spur, and ducklike bill.

\section{III.}

\section{SKELETON.}

The Skeleton is the framework of the body. It protects the internal organs, while affording points of attachment to ligaments and muscles. It may be diffuse or compact.

The diffuse is composed of sclerous particles scattered throughout the tissues, having no fixed union with one another, and little or no power to retain the general form of animal after the removal of the soft parts. The compact is either composed of a solid mass encompassing the organism in a single piece, as in Helix (snail), or, being made up of ar- 
ticulated segments, is placed externally to the soft parts, as in Articulata, or arranged to them as a central longitudinal axis, as in Vertebrata.-The compact variety generally conforms to the type to which the animal belongs. Thus, in Radiata it is rayed, in Mollusca the mantle is calcified in one or more plates, and in the Articulata and Vertebrata the parts and accessories of the ring and vertebra are respectively maintained.

The skeleton may arise from animals whose tissues are not otherwise specialized, while in those highly organized it is often absent. Thus, Nanomia, a foraminiferous rhizopod, possesses an elaborate skeleton, while with Doris, a gasteropod mollusc, a few calcareous spicules are alone present. Within a natural group it may be absent (Amœba), diffuse (Thallasicolla, Sphorozoum), or compact (Foraminifera).

The skeletons of composite animals, as Polypi and Polyzoa, resemble one another more or less intimately.

The presence of the skeleton is determined by habit. Lowly organized animals, if floating (Aurelia, Physalia), often have no skeletons; but if fixed (coralline polyps) or moving upon a ground surface (Echinodermata), they are generally present.

Skeletons are of various composition, viz.: calcareous, corneous, chitinous, siliceous, cartilaginous, or osseous.*

ProtozoA. In Foraminifera the sareodous mass is contained within a chambered shell, having perforate walls and partitions, successive cells being added by a process of gemmation. The form of the shell is subject to great variety, the prevalent shapes being modifications of the disk or spiral. $\dagger$ In Eozoon, an extinct genus of Protozoa, allied to the Foraminifera, the skeleton is deposited between layers of sarcode

* A 'false skeleton' is an agglutination of extraneous matter fixed to the animal by cutaneous secretion, as in Terebella.

$\dagger$ So minute are these shells that it is estimated that 6000 can be counted in a grain, and $3,800,000$ in an ounce of foraminiferous sand. The pyramids of Egypt are built of what is known as nummulitic limestone, so called from the bulk of the stone being chiefly due to the presence of enormous numbers of a species of Foraminifera (Nummulus). 
(q. v.) as perforate masses of calcareous matter of no determinate figure. The remains of such skeletons form immense deposits in the earth's crust. In Thallasicolla (sea jelly), the large cells composing the mass are loosely connected by siliceous spicules. In Lithocampa, the skeleton is compact, domeshaped, with the cyst contained within the dome. The sarcodous mass is protruded at will through numerous fenestræ. In Infusoria, the skeleton is membranous, ciliated, has the precise form of the animal, and is often furnished with spine. In Ceratium, two horn-like processes are appended to a reticulated shell.

Radiata. Cœlenterata. Polyps naked. In Alcyonium, integument with granules of lime interspersed without order or forming calcareous masses-coral. These last are (1) fixed, rigid, as in Madrepora, or segmented, with corneous tissue, with or without spicules intervening, as in Isis and Gorgonia; (2) root loosely inserted in the bottom of the sea, of a leathery consistence, as in Pennatula (sea pen), or having, in addition, granules of lime interspersed, as in Renilla.-In Acalephæ, the hydroid stock of Hydroida is either coriaceous, branched, furnished with hydra cups and capsules, or naked. In Millepora alone is there a calcareous, coral-like skeleton. Porpita has a circular, radiate, calcareous disk; Velella, an upright triangular crest. The Discophoræ are naked.

Echinodermata.-Segmented in all; mobile, as in Pentacrinus, Comatula, Asterophyton, Asteracanthion; fixed as in Toxopneustes (sea urchin) and Spatangus; diffuse, as in Holothuria and Psolus squamatus; calcareous œesophageal ring present in latter group. In Synapta, curious anchor-shaped appendages to skin. Deciduous form of skeleton seen in larval form of Toxopneustes. (See p. 127.)

Mollusca. Polyzoa.-Skeleton compact for accommodation of many individuals; each cell perforate from within to accommodate protrusions of visceral sac.

Brachiopoda.-Skeleton bivalved (shell), placed to the body antero-posteriorly; opened by spiral valve.

Tunicata rarely with skeleton. Spicules of carbonate of lime, resembling raphides of plants, not unfrequent in mantle. 
In Chelyosoma, shell tesselated; Chevreulius, bivalved. Bol. tenia has calcareous granules at pedicle. Siliceous particles in integument of Salpa.

Lamellibranchiata.-Skeleton bivalved (shell), placed right and left to body; opened by elastic ligament at hinge. The line of hinge may be toothed or smooth.

Gasteropoda.-Skeleton generally univalved (shell). Operculum, a horny or calcareous disk attached to foot and employed in opening and closing mouth of shell. It is supposed by some to represent the second valve of the Lamellibranchiata. Shell generally whorled from right to left, rarely from left to right as in Physa; rudimentary in Limax (slug), multivalvular in Chiton.

Pteropoda.-Skeleton (shell) univalved; papery, as in Hyalea and Cleodora.

Cephalopoda.-Skeleton of two kinds, external and internal. External, representing the shell of other molluses, is univalved, and may be either an elaborate chambered shell (Nautilus), or rudimentary. When of the latter kind, it is developed from the dorsum of mantle, and is made up within a closed sac of a number of corneous pen-like bodies, as in Loligo (squid), or a single, light, calcareous piece, as in Sepia (cuttle-fish). Such skeletons are used as floats.-Internal form is cartilaginous. It is confined to four segments surrounding the brain, named as follows: brachial, cephalic, dorsal, and articular. This is the first appearance of an internal skeleton in the animal kingdom.

Structure of skeleton of molluses is chiefly that of columns of calcareous matter arranged transversely to the shell. Great variety exhibited in the detail of arrangement of these columns. Inner layer porcellaneous; outer layer epidermic; nacreous layer (mother-of-pearl), when present, in the inner aspect of porcellaneous layer. Pearls are formed by a deposition of the secretion of the nacreous layer upon some extraneous body lying between the mantle and the shell. This may be a grain of sand or the body of a parasite.

Tubular structure of nacreous table in Anomia and Arca; to the perforate type in Brachiopoda, few exceptions known. 
Shells mostly composed of carbonate of lime. Lingula an exception (phosphate of lime).

Shells grow in thickness and in length; the former is secured by secretion from the mantle everywhere excepting at the edge. Here growth in length takes place, as the shell extends. The shell may be variously colored by the secretion of pigment cells. Growth is periodic. Lines of growth, therefore, furnish an index to age. The muscles employed in closing valves of certain molluscs move their bases at each time of growth, so that the same relative position of the parts of the shell may be maintained.-Byssus is the hardened, cord-like secretion of a peculiar gland seen in certain bivalve molluscs. Fastened by one extremity to some submerged object, the other being in relation to the shell, the individual obtains through the byssus a secure anchorage.

Articulata. Skeleton external, composed of a number of rings joined by fibrous structures. May be chitinous or calcareous; diffuse or compact.

Annulations obscure in many Entozoa and Annelida.

Anus terminal in Crustacea, Myriapoda, Arachnida, Insecta; dorsal and generally terminal in Annelida; not constantly terminal in Rotifera or Entozoa.-Rudimentary forms of skeleton in Entozoa. Extraneous skeletons in Tubicola and in larva of Phrygana.

Structure epidermoid, as in Lytta; tubular in Scolopendra (centipede), Limulus (king-crab), and Balanus (acorn barnacle).

Certain articulates, as Crustacea and some larval forms of Insecta (Cicada), shed their skeletons periodically. This is called exigesis.

Limbs and wings are appendages to the segments. Limbs may be without joints (setæ), as in Annelida, or jointed (arthropod), as in Insecta. Wings are confined to Insecta.

Vertebrata. The vertebrate skeleton is a central segmented, longitudinal axis. Of two kinds, cartilaginous and osseous. In the cartilaginous form, confined to certain fishes, the chorda dorsalis is persistent. In the osseous form assemblages of bones are seen, developed for the most part from a cartilaginous basis. Those arising from another source are 
called membrane bones; and may form either in the perichondrium, or, as in the case of certain cranial bones, in the membranous roof continuous with the perichondrium. (Huxley.)-In conjunction with the osseous skeleton are often found portions of a cartilaginous framework more or less complete. This, for the most part, is confined to the cranium, and is best expressed in the heads of Batrachia and certain fishes, as in Rana (frog), and Esox (pike). With the higher Vertebrates it becomes less defined, until in man it is thought to be represented in the small cartilage occupying the median lacerated foramen at base of skull. This cartilage, together with a few others, such as the tracheal and auricular cartilages, never ossifies.

The study of the osseous vertebrate skeleton, with a view of instituting comparisons between it and that of man, should at all times be pursued in conjunction with the study of its development. In no other way can the construction of the skeleton be understood. As an approximation to truth it may be stated, that every centre of ossification stands for a bone, and therefore that there are as many bones in a skeleton as centres of ossification. The actual number in the adult skeleton of the majority of animals, however, is much smaller than its centres of development: a result obtained from the tendency of centres to group themselves into certain forms which are tixed and definite within recognized limits. Thus while any portion of a skeleton, resulting from the union of two or more centres, is for convenience called a bone, it is in reality an assemblage of bones. In the osseous fish there is no occipital bone; but its place is taken by a number of bones called basi-occipital, ex-occipital, and supraoccipital. Now in man the occipital bone is proved by development to be the union of the three portions seen in the skeleton of the fish, and is, therefore, not a bone, but an association of bones.

In like manner the sphenoid bone of man is divisible into basi-sphenoid, pre-sphenoid, ali-sphenoid, orbito-sphenoid, and internal pterygoid. The frontal, into right and left frontal; to which are added, anterior and posterior frontal 
elements. The temporal, into squamosal, tympanic, mastoid, epiotic, opisthotic, and pro-otic. The superior maxillary, into maxillary proper and intermaxillary. The lower maxillary, into angular, articular, opercular, and dentary bones.

As a rule, the tendency to union increases as we ascend the vertebrate scale. Exception in Batrachia, where the frontal and parietal bones of either side are united.

Pisces.-Skull articulates with vertebral column through body of occipital bone and first cervical vertebra. Bones of face greatly developed. First and second cervical vertebræ very large. Vomer of great size, often tooth-bearing; superior maxillaries of small size, rarely tooth-bearing; intermaxillary bones always distinct; para-sphenoid bone extending antero-posteriorly beneath eranial series. Inferior maxillary bone represented in five centres on either side, recognized as dentary, articular, angular, and opercular bones; the fifth is obscure. The articulation between bodies of vertebræ markedly biconcave. Bones generally flat, never hollow; sutures generally squamosal, rarely serrate.

Batrachia. - Skull articulates with vertebral column by two condyles on ex-occipital bones. Basi-occipital cartilaginous. 'Girdle bone,' placed in anterior part of cranial cavity of frog-like Batrachia, represents the ethmoidal and orbito-sphenoidal elements of skulls of higher vertebrates. Para-sphenoid present as in Pisces. Frontal and parietal elements on either side united into a single bone-the frontoparietal. Bodies of vertebræ may articulate by double concave surfaces, as in Spelerpes (salamander), by convex surface in front and concave behind, as in Rana (frog). Long bones very generally without epiphyses; exception in femur of Rana; tibia and fibula of same animal united in one shaft. Lower jaw commonly composed of three bones-dentary, angular, and articular.

Reptilia.-Skull articulates with vertebral column by a single condyle formed by portions of basi-occipital and ex-occipital bones. Para-sphenoid absent. Basi-sphenoid remarkably compressed antero-posteriorly in Crocodilia. The peculiar 'transverse' bone extends from the internal pterygoid 
to the point of junction between the zygomatic, the maxillary, and the post-frontal bones. Chevron bones are lateral appendages to cervical vertebræ, and represent the transverse processes of the corresponding bones in Mammalia.-Bodies of vertebra articulate by double concave, or ball-and-socket joint. Bones without epiphyses, generally solid; hollow in Dinosauria. Carapax and plastron portions of skeleton of Chelonia are modified vertebral segments. Inferior maxillary bone possesses five distinct centres-dental, angular, opercular, articular, and two smaller pieces seen upon the inner surface. Bones of skull commonly united by permanent suture, excepting in Ophidia and majority of Chelonia, where they are early consolidated.

Aves.-Articulation of skull as in Reptilia. Articulations of cervical vertebræ allowing free motion; but those of dorsal and lumbar vertebræ are immovable. Ribs also fixed; conspicuous posterior processes. Sternum of a variety of shapes, generally conspicuously keeled for origin of great muscles of flight (pectorales). Size of coccyx determined by that of tail feathers; long reptilian extension in Archoeopteryx -bones generally hollow; air is admitted, during respiration, into all skeletons as a rule, excepting terminal portions of extremities. In Hirundo (swallow), and Trochilus (humming-bird), the bones are solid. Bones of skull unite by early obliteration of sutures, excepting Struthio (ostrich).

Mammalia. - Articulation with spine, by two condyles made up on either side by union between single basi-occipital and the two ex-occipital bones. Intermaxillary bones unite with superior maxillary in man, but remain separate in lower mammals. Spheno-parietal suture tolerably constant in carnivorous, as temporo-frontal suture is in other types; number of cervical vertebræ seven,- - apparent exception in Bradypus (sloth); anterior tubercles of the transverse process of cervical vertebræ, and the transverse processes of the lumbar vertebræ, rudimentary ribs (pleurapophyses). Exo-skeleton (?) in Edentata. Inferior maxillary bone probably composed of the number of centres seen in lower animals. Often composed of two halves connected by cartilage at symphysis 
throughout life; or are permanently remote as in Macropus (kangaroo).

Methods of articulation of inferior maxillary to skull vary in Vertebrata. In Pisces, it is effected by means of a 'suspensorium,' which is composed of hyomandibular, symplectic, pretympanic, and hypotympanic (quadrate) bones, with opercular appendages (gill covers), in turn composed of operculum, pre-operculum, sub-operculum, and inter-operculum. Suspensorium of Batrachia, Reptilia, and Aves, hypotympanic bone only, the others having disappeared. In Batrachia a peculiar hammer-shaped membrane bone, situated on side of face, may represent the pre-operculum of fishes. (Huxley.) No suspensorium in Mammalia; the articular head of lower jaw convex in this class,-in all others concave.

\section{NATURE OF LIMBS IN VERTEBRATA.}

A vertebrate limb may be defined as an articulated appendage, placed internally to soft parts.

Pisces.-In osseous fishes, anterior extremity united to skull. Exception, Anguilla (eel). Elements of anterior extremity, supra-scapular, scapular, and coracoid bones; humerus, radius, and ulna. Distal extremity without phalanges, but furnished with rays of exo-skeleton, thus presenting a fin-like in place of a hand- or foot-like structure. Clavicle and posterior extremity absent.

Batrachia and Reptilia.-No supra-scapular bones; coracoid bones large, often meeting at median line; phalanges present. Posterior extremity, with ilium, ischium, and pubis as separate bones. Some extinct Reptilia, tarsal and metatarsal elements combine. Phalanges present.

Aves.-Anterior extremity, with coracoid bone large, distinct from scapula; clavicle (pull bone, furcula) not joining sternum, but anchylosed with fellow of opposite side; phalanges anchylosed to form an acuminate apex. Posterior extremity, with ilium, ischium, pubis, and sacrum anchylosed; tarsus and metatarsus united to form an elongate shaft, excepting Aptenodytes (penguin). 
Mammalia.-Scapula and coracoid bones united, excepting Monotremata; clavicle absent in ungulate quadrupeds, as in Bos (bull), present in unguiculates, as in Sciurus (squirrel). In ungulates the ulna and fibula are often rudimentary and anchylosed to shaft of radius or tibia. Toes, never more than five to each extremity, enormously developed in length in anterior extremity of Cheiroptera (bat); joined with tarsus and metatarsus in presenting an opposing surface for progression, in which case all five toes are present (plantigrade unguiculate), as in Ursus (bear); tarsus and metatarsus elevated, and an opposing surface obtained on tips of phalanges, in which case a number less than five is present, the first toe commonly rudimental or absent (digitigrade unguiculate), as in Canis (dog). Ungulates are properly digitigrade, and, excepting Elephas (elephant), have less than five toes, as follows, no mention being made of the absent digits: Sus (hog) has third and fourth toes, with hoofed rudiments of second and fifth; Rhinoceros, second, third, and fifth; Bos (bull), third and fourth, with concealed rudiments of second and tifth metatarsal; and Equus (horse), third, with concealed rudiments of second and fourth metatarsal (splint bones).* The elephant is thus seen to have five toes to each foot, the rhinoceros three, the hog and bull two, and the horse but one.

In this descent from five to a smaller number, the toes, whether of a plantigrade or digitigrade foot, are always removed from the sides, and are followed by loss of corresponding metatarsal and tarsal elements. But whatever their number and degree of development, the relations presented between the parts of a foot are constant; so that in the event of absence of all the toes excepting the third, the relations of this single toe to the bones above it are the same as though all five toes were present. $\dagger$

* The phalanges of the foot of the horse are called, from above downward, the pastern, coronary, and coffin bones.

+ A vertebrate foot may be defined to be that assemblage of bones placed toward the distal portion of the posterior extremity beyond the tibia. In 
In examining the structure of the foot of man (Fig. 1), it is observed upon the inner portion (I.) that the bones of the first, second, and third toes $(1,2,3)$ articulate with their metatarsal elements $\left(\mathrm{m}^{1}, \mathrm{~m}^{2}, \mathrm{~m}^{3}\right)$ and each of these with their

Fig. 1.

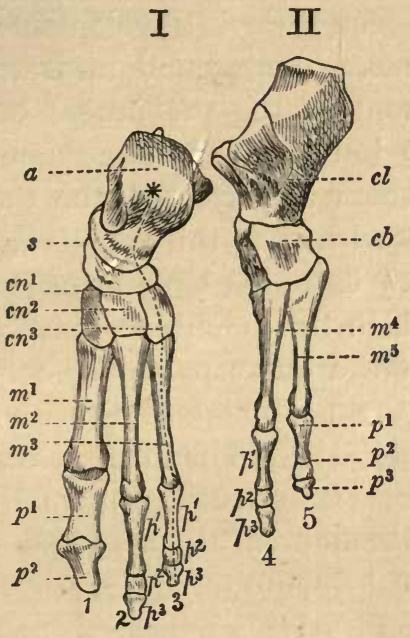

Fig. 2.

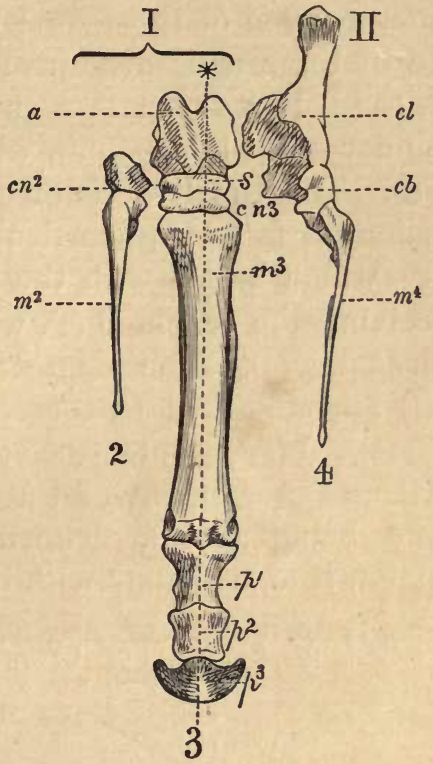

Plan of Construction of Foot of HoRse. - I. $p^{1}, p^{2}, p^{3}$, phalanges of series marked 3 . $\mathrm{m}^{2}$, second metatarsal $; \mathrm{m}^{3}$, third metatarsal. $\mathrm{cn}^{2}$, second cuneiform; $\mathrm{cn}^{3}$, third cuneiform bone. s. scaphoid bone. a, astragalus. II. $\mathrm{m}^{4}$, fourth metatarsal bone. cb, cuboid. cl, calcaneum. of each series marked 4,5 , phalanges. fourth metatarsal; $\mathrm{m}^{5}$, fifth metatarsal bone. cb, cuboid bone. cl, calcaneum.

The line * in each cut indicates an axis of bones constantly present in the foot of every mammal.

speaking of a foot of a mammal, therefore, reference is made to the posterior extremity only. The plan of construction of the hand-the analogous group of bones in the anterior extremity-is, however, essentially the same. 
corresponding cuneiform $\left(\mathrm{cn}^{1}, \mathrm{cn}^{2}, \mathrm{cn}^{3}\right)$. The three cuneiforms now articulate with the single scaphoid (s), and it in turn with the astragalus (a). Upon the outer division (II.) the elements of the fourth and fifth toes unite with the cuboid (cb), and it with the calcaneum (cl).-On comparing this arrangement with that seen in the foot of the horse (Fig. 2), the inner portion of the foot (I.) is seen to lack the elements of the first toe and metatarsal bone. The second metatarsal series (2) is reduced to a rudiment of the metatarsal bone -inner splint bone- $\left(\mathrm{m}^{2}\right)$, which joins the second cuneiform $\left(\mathrm{cn}^{2}\right)$. The third series of elements is perfected, the three phalanges $\left(p^{1}, p^{2}, p^{3}\right)$ articulate with the third metatarsal $\left(\mathrm{m}^{3}\right)$, which unites with the large flattened cunciform $\left(\mathrm{cn}^{3}\right)$, receiving the scaphoid (s), which in turn combines with the astragalus (a). The elements of the outer part of the foot (II.) are restricted to those of the rudiment of the fourth metatarsal $\left(\mathrm{m}^{4}\right)$-outer splint bone,-its phalangeal series, as well as the segment of the entire fifth toe and metatarsal bone, being absent. The fourth metatarsal $\left(\mathrm{m}^{4}\right)$ joius the cuboid, it to articulate with the calcaneum (cl).

Table of Elements of Cranial Vertebrce of Man. (Owen.)

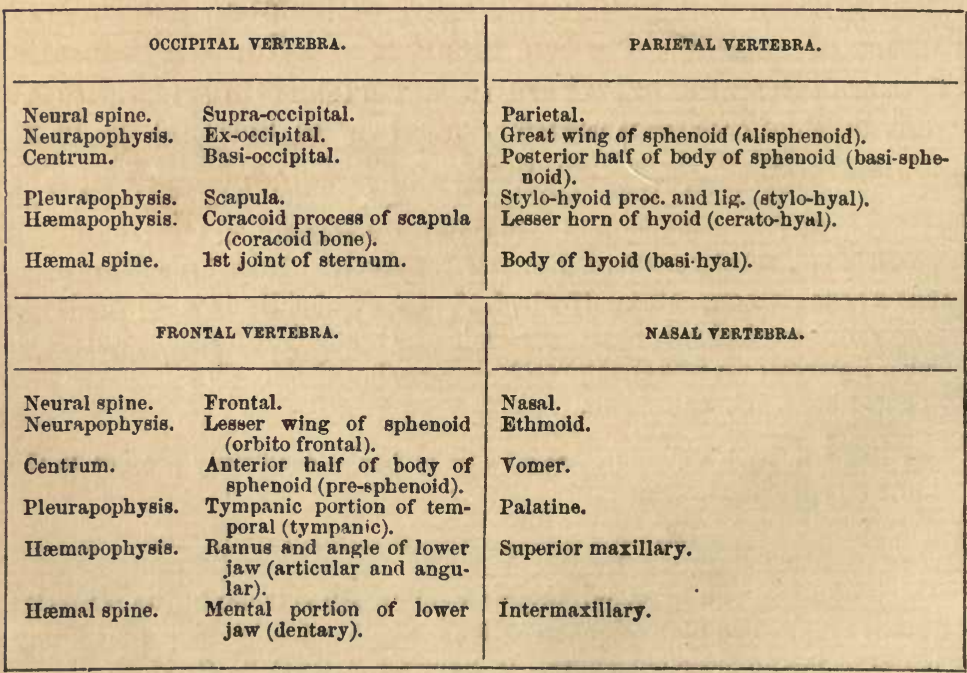


IV.

\section{ARTIOULATION.}

Av articulation is a union of any two sclerous segments of an organism through the intervention of a substance differing from both.

Synarthrosis (stiff joints).

Sutura-example, between bones of vertebrate skull, and exo-skeleton of Dasypus (Armadillo).

Gomphosis-example, insertion of alveolar teeth.

Schindylesis-example, rostrum of sphenoid with vomer.

Amphiarthrosis (joints mixed)-example, Isis, Gorgonia, Pentacrinus, articulation of bodies of vertebræ in Mammalia.

Diarthrosis (synovial joints).

Arthrodia (sliding joint)-example, symphysis pubis of human pelvis.

Enarthrosis (ball-and-socket joint)-example, vertebræ of Ophidia; occipito-atloid, articulation of Lepidosteus (garpike); spines of Echinodermata.

Ginglimus (hinge joint)-example, articulates generally. Here the movement between member of a limb is lateral, excepting Acöetes lupina, where it is vertical: hinge joint of bivalve shells, tempora-maxillary joint of mammalia.

P'eculiar apparatuses. Spiral valve of Brachiopoda, pediculi and ambulatory apparatus of Toxopneustes (sea urchin); pectoral fin of Pimelodus (catfish); structure of joints in extremities of birds; hock joint of horse; hip joint of Phoca (seal); and tibio-astragaloid articulation of certain Dinosaurian reptiles. 
$\mathrm{V}$.

\section{APPARATUS OF MOTION.}

THE movements of animals are effected by sarcodous or ciliary action.

Sarcodous Action. Due either to presence of sarcode or muscular tissue.

Sarcode.-This is a gelatinous, diaphanous, contractile substance, occurring abundantly in larvæ of insects, embryos of vertebrates, worms and radiates. (Griffith, Micrograph. Dict.)

It constitutes nearly the entire body in the Rhizopoda; and with them carries on all the nutritive processes. With such its contractility enables it to modify, from time to time, the form of the animal. Thus in the Amoba, from the alternating contraction and dilatation of portions of the sarcode, the shape of the animal is constantly varying.

Progression is effected by the protrusion of portions of the sarcodous mass from the sides of the organism, forming foot-like processes (pseudo-podia). These may be made to adhere to some adjacent object, and the body slowly drawn toward the point of attachment. Under certain circumstances $A$ moeba protrudes its pseudo-podia at one extremity of the animal immediately in advance of the contractile vesicle.

The motion of an embryonic mass within its egg capsule before any differentiation of tissue is seen, is perhaps comparable to that of sarcode.

Muscular Tissue.-This is a peculiar contractile substance resembling sarcode, arranged within tubular sheaths. A single sheath with contents constitutes a fibrilla, a collection of fibrillæ, a fibre, and a bundle of fibres, a muscle.

The primary elements of muscular tissue in a state of decomposition possess independent motion. (Clark.)

Every muscle being in relation to one or more movable 
points, motion of such points results when the muscular axis is shortened.

Muscles are divided into the striated (when the tubular contents of each sheath are transversely divided into disks) and the non-striated (when such division is absent). The muscles are striated in Salpa and certain Polyzoa;-Crustacea, Arachnida, Insecta (with whom it is seen in both voluntary and involuntary muscles); and Vertebrata, with whom it is confined to the voluntary muscles and heart. They are non-striated in Radiata, Entozoa, and Annelida; Lamellibranchiata generally, Gasteropoda, Cephalopoda, and in the majority of the involuntary muscles of Vertebrata.

Muscles are white in Invertebrata,* Pisces, Batrachia, and Reptilia. Exception, Salmo (salmon), Acipenser (sturgeon), Squalus (shark), where they are red. Constantly red in Aves and Mammalia, excepting pectoral muscles of certain granivorous birds, as Perdix (partridge), Phasianus (pheasant), Gallus (common fowl). This change of color is asserted to be a result of fatty degeneration of muscular fibre, from want of use,-a view, in a measure, confirmed by the leg muscles of Struthio (ostrich), which, ordinarily red, become white when the animal is for some time confined. (Quekett.)

Descriptions of special muscles.-Adductor muscles of bivalve molluscs, pectoral muscle of birds. Diaphragm of mammals, abdominal muscles of reptiles and mammals; cremaster muscle; panniculus carnosus (platysma myoides); muscles of external ear. Muscles peculiarly developed in man are glutei and sterno-cleido-mastoideus.

Ciliary Action. Due to the presence of cilia or spermatic filament.

Cilia.-These are minute processes (homogeneous filaments), placed in connection with a basement membrane, and endowed with a constant vibratile motion.

In Vertebrata, cilia are attached to epithelial membrane; but in other animals, and in certain embryos, they clothe the peripheral surface of organism. They are seen in all ani- 
mals excepting Cephalopoda, Crustacea, terrestrial arthropod Articulata, and Pisces, excepting Amphioxus.

Spermatic filament.-(See page 103.)

Among accessories to motion are erectile and elastic tissue. Erectile Tissue.-A periodic turgescence and collapse of certain tissues (erectile) by alternate excess and comparative absence of blood, may be considered a source of motion, as witnessed in the power of accommodation of parts of eye in fishes, through choroid body; and probably in the dilatation and contraction of the pupil of the eye of Mammalia, and in the erection of the penis of animals of the same class.

Elastic Tissue.-This restores parts to their original position from which they have been moved by muscular action, as by nuchal ligament of vertebrates; or maintains patulency of vessels, as in arteries; or aids to sustain the weight of varying bulks of tissues, as in the abdominal muscles of animals with large paunches, as in Elephas (elephant), and Rhinoceros.

The pedicle of Vorticella, and lassocells of Hydra also probably possess the property of elasticity.

\section{VI.}

\section{TEETH.}

TEETH are those sclerous appendages to the pre-assimilative portion of the alimentary canal subservient to the prehension or trituration of food.

They may be calcareous, siliceous, corneous, chitinous, or dentinal. In Invertebrata, the basis of tooth structure is commonly same as basis of skeleton, and is either developed in the same manner, as in the majority of Articulata, or in a special sac, as in tooth-bearing Mollusea and Nemertes. In Vertebrata, the dentinal sac is constantly present, is not seen in the skeleton, and arises from a formative bulb.

False Teeth.- 'Hinge teeth' of bivalve molluses, as Unio 
(mussel); 'teeth' around margin of certain univalve molluscs, as in Nerita peloronta (bleeding-tooth shell).

ProtozoA. For the most part without teeth; when alimentary canal is not defined, form of jaw simple, as in Dysteria.

Radiata. Cœlenterata without teeth. With some Echinodermata, as Toxopneustes (sea-urchin), the dental apparatus (Aristotle's lantern) is very complex. Five prismatic segments or jaws are arranged to one another around the mouth (which presents inferiorly), like the segments of an orange. A slender tooth extends through the longitudinal axis of each jaw, its basal or formative portion being above, and its free and trenchant portion exposed at mouth. The jaws are moved upon one another by abductor, adductor, and constrictor muscles.

Mollusca. No teeth below Gasteropoda.-Here teeth having a siliceous and chitinous basis are placed in numerous rows transversely to a narrow cartilage-like band (lingual ribbon), running along the floor of gullet. Each row is composed of denticles having narrow bases, but free, scalloped edges. The apparatus is moved to and fro by muscular action upon a simple curved plate (upper jaw) in the roof of gullet.

Scissor-like teeth in Tritonia. Calcareous plates upon walls of stomach (gastric teeth), in Bulla and Aplysia.

Many Pteropoda possess two horny, dentigerous jaws, opposing laterally; and a tongue armed with hooklets directed backwards. Simpler form in Hyalea.

Cephalopoda. - Dibranchiata have two horny beak-like processes at mouth.

Articulata. Teeth with few exceptions move laterally. Entozoa.-Commonly none. Gizzard-like teeth in Oxyuris (thread-worm).

Rotifera.-Chitinous œsophageal apparatus; composed of a central piece with lateral jaws; constantly motile, and protrusile.

Annelida.-With many the pharynx has a horny masticatory apparatus, sometimes of a very complicated structure, and which, when the pharynx is protruded, often extends 
beyond it, and serves as a prehensile organ. They are usually curved like hooks, and denticulated upon their concave sides. They vary in number from two to nine pair; when numerous they are of dissimilar forms with the same individual. (Siebold.) They move laterally upon each other, except in Acoëtes. (Stimpson.) Single siliceous tooth of Borlasia, placed in median line of head, with remote formative sacs. For Hirudo (leech), see page 159.

The parts entering into the construction of the mouth in arthropod articulates, excepting, perhaps, certain Crustacea, are as follows, named from above downwards: labrum (upper lip), mandibles (first pair of jaws), maxillæ (second pair of jaws), labium (lower lip), with ligula (tongue). The palpi are always appendages to either the maxillæ or labium.

Arachnida. - The mandibles (cheliceres) move horizontally in Scorpionidæ (scorpions), vertically in Araneidæ (spiders); maxillæ and maxillary palpi more or less pronounced, latter in male spiders employed as feelers, and in generative act (see p. 116). Ligula present in Scorpionidæ, absent in Araneidæ. Labium generally wanting; in Scorpionidæ deeply cleft; labial palp large, commonly progressive, used as feet, but in Thelyphonus and Phrynus as antennæ. (Wood.)

Myriapoda.-Organs arranged upon three types according as animals are (1) carnivorous, (2) herbivorous, or (3) suctorial.

(1) In Syngnatha (centipedes proper), labrum commonly large; maxillæ robust; maxillary palpi well defined with ligula placed between their bases. Labium rudimentary, but labial palpi large. Scutum of sub-cephalic segment or ring transformed into a broad false labium, or gular plate, with the feet transformed into powerful, prehensile organs, and provided with poison glands.

(2) In Chilognatha manucentia, as in Julidæ (millipedes), between a massive labrum and a broad opposing gular plate, robust maxillæ are inserted; other organs wanting. (3) In Chilognatha sugentia as in Octoglena, organs fused to form a suctorial tube. (Wood.)

Insecta.-Organs arranged upon two great types-(1) Manducatory, and (2) Suctorial. 
(1) Labrum pronounced; mandibles two hard, generally robust organs each composed of a single piece and commonly denticulate upon opposing surfaces. Maxillæ two softer opposing organs, furnished with palpi, each composed of one to six articles. Labium, a single inferior piece, furnished with labial palpi, each composed of from one to four articles. Ligula placed at the base of the labium. Includes Coleoptera (beetle), Neuroptera (dragon-fly), Orthoptera (grasshopper).-(2) The suctorial form of mouth may be due to the labium being prolonged into a grooved proboscis, with the other parts of the mouth appearing as setæ toward its base, as in Diptera (fly); or, to the labium preserving the function of a sheath to the setiform mandibles and maxillæ, the labrum becoming rudimentary, as in Hemiptera (bug); or, the labium may be absent, with the mandibles rudimental, while the maxillæ are enormously developed into a symmetrical suctorial canal, furnished at base with small maxillary palpi, the whole coiled and protected in rest by palpi arising from labium, as in Lepidoptera (butterfly).

Apparently intermediate between these two types appear the organs of Hymenoptera (bee), in which the maxillæ are mostly elongate, and form with labium a kind of sucking proboscis; at the same time the mandibles are well developed, but are used more for cutting and gnawing during search for food than in its preparation.

Crustacea.-Jaws when present are modified feet. In Limulus (king-crab), the feet perform function of jaws. In Decapoda (lobsters, crabs, etc.), an upper lip, an upper pair of jaws, furnished with palpi, two pairs of lower jaws, each with a palpus, are present.

Vertebrata. The tooth of a vertebrate animal consists of a cellular and tubular basis of animal matter, containing earthy particles, a fluid, and a vascular pulp. (Owen.)

The basis is dentinal in typical tooth; corneous in certain modified struetures, as in teeth of marsipobranchiate fishes, in Baloena (whale-bone whale), and Ornithorhynchus (duck-bill).

A typical tooth possesses a central dentinal mass, capped with enamel, and surrounded by cementum. Cementum 
and enamel may be, and often are, absent, but dentine never.

Developed within grooves upon surface of mucous membrane, the primitive papillæ may remain exposed, as in Selachia (sharks), or each become encapsuled within mucous membrane, as in many osseous fishes. When erupted, the teeth are seen to be either attached to mucous membrane alone, as in Pisces, or inserted in bony grooves (alveoli), which may be continuous, as in Reptilia, or divided transversely into sockets, as in Mammalia.

Teeth vary greatly in numbers and position. As a rule, it may be stated that animals developing large numbers of teeth on surfaces remote from the region of lips, are inferior to those erupting smaller numbers and restricting their site to the anterior portion and sides of mouth.

Teeth wanting in Aves, except in Archooopteryx. Rarely absent in other vertebrates, as in Amphioxus (lancelet), Acipenser (sturgeon), Chelonia, Myrmecophaga (ant-eater), and Manis (pangolin).

Pisces.-In cartilaginous fishes, teeth numerous, pointed, tesselated. Teeth confined to jaws proper, as in Selachia (sharks).-In Osseous fishes teeth variable in number and form. They may be conical, setiform, villiform, lobed, curved, etc. Placed chiefly upon vomer, palatine, intermaxillary, hyoid, pterygoid, inferior maxillary bones, and branchial arches, they occasionally appear upon superior maxillary, basi-occipital and nasal bones. Attachment in fishes generally ligamentous, as in Selachia. Dentinal varieties, vitrio-dentine, vaso-dentine, and osteo-dentine. Scarus (parrot fish) has apparently enamel and cementum in addition to dentine.

Batrachia. - Teeth generally simple, as in Rana (frog). Placed commonly on vomer, intermaxillary, and portions of inferior maxillary bones. Remarkable form of, in Labyrinthodon. In tadpole, horny beaks are present.

Reptilia.-Ophidia, conical, placed on pterygoids, palatine, maxillary bones. Teeth-like process on cervical vertebræ in Deirodon. Peculiarity of construction of poison fang; the 
tooth is curved backwards, forming a canal along posterior surface of tooth, which comrnunicates with duct from poison gland. In Lacertilia, Iguanodon partially, and in Alligator entirely inserted within alveolar groove. Peculiarity of Dicynodon, in which there is but a single large tooth on either side of superior maxillary bone.

Mammalia.-Teeth confined to intermaxillary, superior, and inferior maxillary bones; each is enclosed within a bony socket, and placed in a single series immediately behind the lips; and are the only teeth in Vertebrata which may possess more than a single fang. They are of a definite number, and appear in sets (when they are divided into two series, the deciduous or milk teeth, and the permanent teeth), as in the majority of mammals, or are of one set only, as in Cetacea. The deciduous teeth are always fewer in number than the permanent; and in Marsupialia are confined to a single tooth (posterior molar) on either side in each jaw. (Flower.) The deciduous teeth are sometimes lost prior to maturity (in utero in some Rodentia), or oftener at a comparatively early period after birth.

Teeth are divided into cutting teeth (incisors), tearing teeth (canines), and grinding teeth (molars), and always hold fixed relations to the character of food. Thus the preponderance of a conical form indicates a carnivorous habit. With it, the canines are greatly developed, the incisors, pointed; the molars are acutely cusped, and present surfaces adapted, in opposition, to divide the food by a scissorlike motion. In extreme carnivorous forms, the molars are rudimentary, as in Felis (cat), or are absent, as in Machairodus (sabre-toothed tiger).-The preponderance of a grinding form indicates an herbivorous habit. With it, the molars, always present, are large, flat, and yield either a tuberculated surface, as in Ursus (bear), or a flattened, uneven one, marked by ridges of enamel, as in Equus (horse). Every molar is constructed upon a common plan. The dentinal centre is capped superiorly by enamel, and the whole structure then surrounded by a cemental membrane. Both enamel and cemental membrane follow the curvings of the surface of the 
dentine. The newly erupted tooth, therefore, presents a cemental surface for mastication. This may be a simple membrane (membrane of Nasmyth) as in man, when it will soon disappear, and the enamel at once become the opposing surface; or it may contain cementum in abundance. In the latter case its gradual disappearance from the convexities of the grinding surface leaves exposed the enamel cusps. These, after a longer time, will in like manner be worn through, and expose circumscribed areas of dentine. So that in the molar tooth of an adult herbivore, as in Castor (beaver), or Equus (horse), the islands of dentine are encircled by enamel, while cementum fills up the depressions. In the herbivorous type, the canines are often absent. The incisors are absent as in upper jaw of Ruminantia, or very largely developed, as in Rodentia. - In the latter order they are peculiar in having no closed fang, but in remaining open and continuous with the pulp. The tooth is therefore always growing; a definite length being secured by the constant loss of substance by attrition at the crown. A rodentic incisor is covered with a thick layer of enamel anteriorly, a thin layer posteriorly; the latter wearing away more rapidly than the former, a scalpriform surface is always presented.

\section{VII. \\ DIGESTIVE SYSTEM.}

The solids and fluids taken into the body as food are subjected to a process called digestion, by which the solid portions are reduced to a fluid state, the nutritive particles separated from the excrementitious, and the whole prepared to become blood, skeleton, muscle, etc. (Agassiz and Gould.)

The digestive apparatus is composed of an alimentary canal and appendages.

ProtozoA. With the simplest forms of life, as in the Rhizo- 
poda, there is no alimentary canal. The substances received as food, by the extensions of the sarcodous mass, may be retained at any portion of the organism during the digestion of its nutritive elements; the excreta to be subsequently thrown off at a convenient point.-With certain ciliated Infusoria, the digestive system is wanting, as in Trichomonas. In Paramecium the food enters an oral opening, and is passed along a short gullet to the interior of the body, where, in the form of globular masses, it is digested. The ejecta escape by the mouth.

Radiata. Cœlenterata. - Digestion takes place within a central cavity.

Polypi.-Cavity simple, as in Hydra, or divided into chambers by longitudinal plications of the outer wall, as in Actinia. The wall of the cavity may be separated from integument by an intervening space (perigastric), which is commonly traversed from within outward by partitions defining a number of cells. These communicate with stomach by apertures closed during digestion, but which subsequently open to allow the escape of the chyle into the perigastric space. In the coralline polyps this space being common to many individuals, chyle may be conveyed to a distance from the cavity elaborating it.

Acalephæ.-Cavity large, as in Beroë, or small, as in Pleurobranchia. It is commonly furnished with thickened partitions, which transform the chambers into tube-like canals. The oral openings are often prolonged into pendant tentacles, which in Physalia (Portuguese man-of-war) are long and numerous.

Echinodermata.-The digestive apparatus is separated as a tube or sac, having a distinct oral and commonly an anal opening. When tubular, it is simple, enclosed in a peritoneal covering, and longer than body, as in Toxopneustes (seaurchin), or as long as body, as in Synapta. When sac-like, it is simple, with numerous short cæca not entering rays, as in Ophiura, or with cæca extending along entire length of rays, as in Asteracanthion (star-fish). The stomach is separated into two chambers by a circular projecting fold. The first of these is the true stomach, and the second sends off 
the radial cæca (Siebold). The anus, in Echinodermata, is placed alongside of mouth in Pentacrinus (sea-lily); upon dorsum, either directly opposite mouth in Toxopneustes, or to one side, as in Spatangus; at posterior extremity, as in Holothuria (sea-cucumber); or it may be absent, as in Astropecten.

Hepatic secretion formed from gastric follicles.

Mollusca. Polyzoa.-The mouth is surrounded by prominent ciliated, protrusile tentacles. The canal, after leaving a muscular stomach (gizzard), turns once upon itself to open by an anus near the mouth.

Hepatic secretion formed from gastric cells.

Brachiopoda. - The two respiratory arms (q. v.) are placed one on either side of the mouth. The canal may be simple, as in Lingula, or with stomach, as in Terebratula. Anus lateral, hidden between lobes of mantle; absent in Waldheimia.

Tunicata.-The oral opening at base of respiratory chamber (q.v.). From this point the canal, after commonly expanding into a stomach, curves at first downward, then upward, to terminate within the cavity of the mantle,-an excretory chamber, common to both alimentary and genital apparatus, conducting thence the ejecta.

Lamellibranchiata.-Mouth placed near anterior adductor muscle, with tentacular flap on either side. Stomach large, and lined with papillæ. Intestine often convoluted and intimately associated with other viscera. The rectum commonly traverses the heart (Ostrea, oyster, an exception); anus upon dorsum near hinge line, and behind position of posterior adductor muscle. Liver a large diffuse organ made up of distinct acini.

Gasteropoda.-Mouth simple, protrusile, and tooth-bearing. Gullet muscular. Stomach present, simple, as in Helix (snail); gizzard-like, as in Limnous; compound, as in Aplysia (seahare); occasionally armed with teeth (q. v.). Intestine convoluted, terminating upon right side, near respiratory orifice. Salivary glands present, placed either around œsophagus or stomach. Hepatic secretion always present; rarely secreted from intestinal cells or follicles, but as a rule from welldeveloped, lobulated liver, emptying by excretory ducts into 
stomach, as in Helix (snail), intestine, as in Lymnoeus, rarely in œsophagus, or partially externally, as in Doris.

Pteropoda.-Mouth furnished with sucker-bearing tentacles. In other respects the canal closely resembles that of Gasteropoda. Hepatic secretion from gastric follicles, as in Clio. Salivary glands pour secretion into mouth.

Cephalopoda.-Mouth surrounded by prehensile suckerbearing tentacles, and a circular fold of skin which is serrated at free edge. The parrot-like jaws encompass the opening leading into a muscular pharynx, which is furnished with a tongue upon its floor. Gullet, well defined, and extends thence to a stomach, which is generally simple, and lined with a mucous membrane thrown into longitudinal folds, covered with horny epithelium. In Nautilus a crop precedes the muscular stomach or gizzard. The intestine is narrow and convoluted, and terminates in an anus within the mantle upon the right side of body. Appended to the pyloric extremity of the stomach, in many Cephalopoda, is a globular or spiral viscus, which secretes a fluid held to be analogous to the pancreatic fluid of the Vertebrata. Salivary glands well developed, generally two pairs, opening into gullet near base of tongue by long excretory ducts. Hepatic secretion from well-developed liver, which commonly surrounds the œsophagus, the bile-duct opening into intestine at region of pyloric appendage.

Articulata. As a rule, the alimentary canal begins upon the dorsal aspect of the cranial segments and terminates upon the ventral aspect of the terminal caudal segment.

Rotifera.-The mouth is simple and placed between the ciliated disks. The armature of teeth (q. $\nabla$.) succeeds to a protrusile gullet emptying into a thick, simple stomach. From this passes a narrow intestine, either curved upon itself, as in Melicerta, to terminate upon the side, or, more straight, to open at caudal extremity, as in Rotifer.

Two cæcal appendages to stomach secrete a colorless fluid, perhaps analogous to a pancreatic product. A hepatic secretion is derived from gastric cells.

Annelida.-The mouth is usually surrounded with thick 
lips, with tactile appendages, as in Serpula. The canal is placed in the axis of the body, having no convolutions, as in Lumbricus (earth-worm), or possessing them, as in Sipunculus. It may be comparatively a simple tube, as in Lumbricus, though frequently sacculated, as in Hirudo, leech (q. v.). Anus dorsal. Walls of canal are very muscular, a free peristaltic motion commonly present.

Glandular appendages in the form of follicles surrounding the commencement of the intestine, as in Sangrisuga, or a defined gland emptying into the pharynx, as in Lumbricus, a secretion analogous to saliva. A hepatic secretion, constantly present, is elaborated from simple cells aggregated upon the walls of the intestinal tube.

Crustacea. - Mouth with numerous appendages. (See Teeth.) Stomach is a simple dilation, possessing a crushing apparatus which is either simple, as in Limulus (king-crab), or complicated and composed of three denticulated chitinous pieces, which are moved upon one another by the muscular coat of the stomach, to crush any intervening substances, as in Homarus (lobster). Intestine extends along the axis of the body without convolutions, and narrows as it terminates at the anus.

Salivary secretion rarely present, as in Lepas (barnacle). Hepatic secretion is poured into the canal from simple follicles at varying points, as in Daphnia. With the higher forms a liver is observed, having a distinct duct, as in Homarus.

Myriapoda.-Stomach rather long and intestine simple. Salivary glands generally in two pairs on either side of the œsophagus and stomach, opening into mouth.

Arachnida.-Intestine may be simple, extending without any divarication to anus, as in Buthus (scorpion), or with diverging cæca, as in Epeira. These may extend into the feet (phlebenterism), as in Galeodes; the terminal portions of the cæca communicating with the circulatory system, direct transmission of chyle into the circulatory fluid is secured. Termination of canal at end of œsophagus, allowing the fluid food to pass from this point directly into the soft parts of the 
body, as in Gamasus. Anus generally terminal, rarely in middle of ventral surface of abdomen, as in Acarus.

Salivary secretion universally present. Hepatic secretion from follicles either simple, as in Trombidium, or multiramose, as in Epeira.

Insecta.-Intestine can be divided into gullet, crop, gizzard, small intestine, large intestine, and rectum. Anus terminal. Great variation among different orders of insects with respect to the form and length of the canal. Coleoptera have crop, followed often by an ovoid gizzard. The small intestine is often longer and more convoluted in the carnivorous than in the herbivorous families. Orthoptera have gizzard armed with rows of horny denticulated plates. Hymenoptera, with simple, thin, and dilated sucking stomach. Hemiptera, with compound stomach, consisting of two or three chambers. Diptera, with sucking stomach, commonly pedunculated.

Salivary secretion elaborated in eæcal tubes, sometimes of great length, which open into the oral cavity. Hepatic secretion from gastric cells, or long simple cæca. A fluid, analogous to the pancreatic secretion, flows from follicles appended to the small intestine. - The connection we find existing between the alimentary canal and food of Vertebrata-the former being simple when the food is simple, complicated when much preparation is required of the food-does not subsist to the same degree among insects. Thus the Tenebrionidæ, which subsist on wood, have a comparatively simple canal, while Lepidopterous insects, living on honey, have a much more complicated one.

Vertebrata. Pisces.-Gullet short, wide, and ends in stomach by a slight constriction; regurgitation readily effected. Long fleshy processes from the mucous membrane project backward as in Selachia (sharks). Stomach generally simple. Gizzard-like structure in Salmo furio (Gillaroo trout). Intestine short, with few exceptions. Convoluted in a few Cyprinoids, rarely coiled around the air bladder (Campostoma). Anus commonly directly in advance of anal fin. Except Gymnotus (electric eel), and Aphredoderus, where 
it is placed more anteriorly. Intestine spiral as in Mustela (dogfish), convoluted, as in Zygcena (hammer-headed shark); terminates in anus without colon or cæcum. Liver large, oily, soft, lobular; gall-bladder present; duct terminates in duodenum near pylorus.

Pyloric eæca to stomach, as in Gadus (cod), furnish a pancreatic secretion.

Batrachia.-Tongue broad, flat, and attached anteriorly to margin of lower jaw, with free part lying behind; yullet short; stomach simple and intestine but little convoluted; rectum terminating in cloaca. In tadpole the intestine is longer and more convoluted than in frog. Liver with gallbladder; salivary glands often wanting; pancreas present.

Reptilia.-Tongue of various forms. In Chelonia covered. with papillæ; long, slender, and protrusile in Chameleo (chameleon). Gullet long, without crop. In Chelonia, furnished with papillæ or horny processes. In Ophidia, sometimes more capacious than stomach. Stomach simple. In Crocodilia, gizzard-like. In Ophidia the stomach is small, merging insensibly into gullet. Generally possesses thick, muscular walls with marked pyloric constriction. Intestine divisible into large and small; frequently with plicated mucous membrane as in Ophidia, thrown into zigzag folds as in Crocodilia; cæcum rarely present except in Sauria. It always terminates in a cloaca. Liver divided into two or more lobes; gall-bladder present, either embedded in organ (Amphisbona) or remote from it (Ophidia); salivary and pancreatic glands generally present.

Aves._Oral pouches in Pelicanus (pelican); œsophageal in Otis (bustard). Crop (ingluvies) usually on right side of neck in front of clavicles (furcula); in Columba (pigeon), one on either side, and is often furnished with numerous and varied glands. Power of regurgitation of the contents of crop possessed by some birds, as Columba. Crop absent in Anser (goose), and Cygnus (swan). Stomach divided into two parts. First, cardiac or glandular (proventriculus). This furnishes the true gastric secretion; its glands are of a variety of shapes. Second, pyloric, muscular (gigerium, gizzard). The walls are 
much thicker than in the other chamber-moderately so in rapacious-markedly so in granivorous birds. In the latter the epithelium forms two thick plates for the trituration or food. Hairy concretions found in gizzard of Cuculus (cuckoo). Intestine small and large,-small, folded several times upon itself; large, straight, with commonly two cæca, one on either side; terminates in a cloaca.

Salivary glands present: pancreas generally with more than a single duct. Liver almost always divided into two lobes; gall bladder wanting in few birds.

Mammalia.-Gullet narrow, with thick walls. Stomach either simple, constricted, sacculated, or compound. Simple in Carnivora and man, when it is pyriform, the base being at cardiac, and apex at pyloric end; constricted in Equus (horse), defining cardiac from pyloric extremity; sacculated in Phocona (porpoise), and Rodentia, where the constriction is carried so far as nearly to divide the stomach into distinct chambers. Such division is actually attained in Pteropus (frugivorous bat), in which two, and in Macropus (kangaroo), and Semnopithecus (douc monkey), with whom three divisions are seen, each of which in their turn may possess a tendency to sacculation,- - the last constriction recalling the form of large intestine. In Ruminantia the stomach is compound and divided into four peculiar chambers. First, paunch (rumen), much larger than the others, with thin walls, and furnished upon its inner surface with horny papillæ; second, honeycomb (reticulum, 'hood'), smaller, lies on the right of preceding and is lined with deep four-, five-, or six-sided cells; third, many-plies (psalterium, omasum, 'book'), the smallest, is of a sub-globular form, and furnished with a number of deep, longitudinal lamellæ of mucous membrane, which are closely approximated f fourth, the true stomach (abomasum, 'reed'), which resembles in form the human stomach; the mucous membrane is sparsely plicated longitudinally. With the Camelidæ, the many-plies is wanting, and the paunch is without papillæ, while a reticulated structure resembling that of the honeycomb is seen at its fundus.

Peculiar gastric gland met with in Phascolomys (wombat) and Rodentia. 
Small intestine long, of greater extent in herbivorous than carnivorous animals; villi present; numerous filiform, villibearing process in Rhinoceros. No valvulæ conniventes in Carnivora. Cæcum small and simple in carnivorous, large or compound in herbivorous mammals, as in Ruminantia and Rodentia. Furnished with two simple cæca as in Myrmecophaga (ant-eater), or with single bifurcated spiral appendage, as in Hyrax (cony). Vermiform appendix is the rudiment of cæcum; seen only in Phascolomys (wombat), anthropoid apes and man.

Salivary glands not present in Cetacea. Pancreas always present, commonly divided into two lobes. Liver divided into many lobes in the Carnivora. It is small and but little divided in those having a compound stomach. The liver of Quadrumana closely resembles that of man. Gall-bladder generally present; absent in Equus (horse), Elephas (elephant), and carnivorous Cetacea; double in Giraffa (giraffe). Bile may flow directly into the gall-bladder, as in the ox; but commonly the hepatic duct is joined by the cystic duct forming the ductus communis, as in man.-Adventitious intestinal products occasionally met with, such are tappen, from bear, during hybernation; ambergris from whale; bezoars from goat and deer; phosphatic and calcareous calculi from horse; felt-balls from paunch, and occasionally 'honeycomb' of ox, etc.

\section{VIII.}

\section{OIROULATORY AND RESPIRATORY SYSTEMS.}

Circulation is the movement of nutritive fluids of animals in fixed directions, and, for the most part, within a peculiar apparatus.

The object of a circulation is twofold-

(1) To convey from an assimilative surface nutritive elements, and distribute them through the tissues. 
(2) To bring blood in contact with aerating and excretory organs.

(1) No circulation is found in the simplest organisms; for at different times every portion of the common tissue comes in contact with fresh ingesta. But where parts are developed at points remote from a more or less defined alimentary canal, means for the transmission of a nutritive fluid (blood) from central to peripheral areas become necessary. This fluid may enter the system directly or indirectly: directly, through openings in the sides of the stomach into an irregular perigastric space, as in most Polypi, or by mouths of gastric cæca (phebenterism), as in certain Arachnida; indirectly, by absorption through veins, as in higher Invertebrata, or through both veins and lacteals, as in Vertebrata.

Blood, thus viewed in its broadest sense, is composed of a liquid (liquor sanguinis, serum) and corpuscles.-The liquor sanguinis very commonly is exclusively the product of the walls of the blood-vessel system; but, in lowly organized animals, it may receive accessions from without, as in Entozoa (q. v.).-The blood corpuscles are minute bodies, floating in the liquor sanguinis. They are generally rounded, or oval; possessing with the Invertebrata an uneven or obscurely tuberculated surface, and faintly granular, and, at times, nucleated contents. The shape and size of the corpuscles are tolerably constant in the blood of the individual, but may markedly vary in that of different species. With Vertebrata, two kinds of corpuscles recognized: the white, which corresponds to the above, and the red, which is the smaller and more numerous. The red corpuscle, subject to more variation than the white, may be round, disciform solid bodies, as in marsipobranchiate fishes, and man; oblong and nucleated, as in Rana (frog); oval and of great relative size, as in Proteus (salamander). Their numbers hold a relation to the natural heat of the animal; being more numerous in Aves than in Marnmalia, and in the latter than in Pisces.

Blood is of different colors. In Vertcbrata it is red, with exception of Amphioxus, where it is colorless. Commonly colorless with Invertebrata, it may be greenish, reddish, or 
brownish, as in Acalephæ; yellowish, greenish, or red, as in Annelida; or blue, as in Crustacea. The hue is generally resident within the corpuscles; but occasionally, as in certain Annelida, is contained within the serum.

Vascular currents are maintained by ciliary or muscular action. The latter may be secured everywhere in the contractile walls of the vessels, as in Annelida, or located in specialized portions (pulsatile vesicles, or 'hearts'), as in the majority of the higher forms.

Systems of blood-vessels may be complete when the arteries and veins unite through an intermediate network of small vessels (capillaries), as in most Annelida and Vertebrata; or incomplete, when, in place of the capillary vessels, spaces (lacunæ), irregularly limited by muscles and viscera intervene, as in Mollusca.

(2) Where no circulation is present, the interchange of gases takes place in all parts of the animal (aeration). But where one exists, a separate apparatus is devoted to the renovating function, which is then called respiration. Aeration, however, may occur in conjunction with respiration, as in intestine of Cobitis (loach), and dorsal integument of Rana (frog).*

The respiratory apparatus is subject to great variation in form and position. The plans of construction are dependent upon the type to which the animal conforms, and the nature of the medium in which it lives. This last may be (1) Nutritive Juices: examples include embryos of viviparous animals, as in Paludina (fresh-water snail), Anableps, Blennius, Selachia, and Mammalia. (2) Water containing air: examples include Pisces, young Batrachia, and all oviparous Invertebrata, excluding pulmonate Gasteropoda, and certain Articulata, as pulmonate Arachnida, and some larval forms of Insecta. (3) Air: examples include eggs of Reptilia and Aves, adult Batrachia, Reptilia, Aves and Mammalia, and those excepted in the preceding enumeration.

The aerating medium may be taken to the blood, entering

* For excretory function, see p. 64. 
and traversing the body for this purpose, either through a water-vascular system (q.v.), or through a system of tracheal tubes, as in Myriapoda, Insecta, and certain Arachnida. Or the blood may be brought to the medium, either through agency of (1) vascular processes (branchiæ), or (2) lungs.-(1) When the former, they may be suspended in the water, as in Pisees, the aquatic Mollusea, most Annelida, Crustacea, all larval and a few adult forms of Batrachia; or be inverted, forming a branching tube, as in Holothuria (sea cucumber). (2) When the latter, special air sacs are developed, which may be simple pneumonic chambers, as in terrestrial Gasteropoda, and pulmonate Arachnida, or lobulated, generally symmetrical sacs, opening by tubes (bronchi) into a single passage (trachea), as in all air-breathing Vertebrata.

Many aquatic invertebrates have, in addition to a true circulatory system, or, with some, apparently taking its place, means of introducing and retaining within their tissues, quantities of water. The fluid, which may be considered as analogous to the serum of the blood, passes in and out of the body, through appropriate openings which lead within to more or less defined expressions of communicating vessels, or lacunæ. While within the body it may become admixed with corpuscles, and is doubtless subservient to nutritive and excretory processes. Such is the fluid of the aquiferous system of Acalephæ; the perigastric space and pediculi of Echinodermata; the 'atrial' system of Brachiopoda and Tunicata; the aquiferous system in certain Lamellibranchiata and Gasteropoda; the water-vascular system (q. v.), etc.

ProtozoA. Infusoria.-The 'contractile vesicle' appears to represent a rudimentary circulatory system. In Paramecium two vesicles are present, which alternately contract and dilate. The site of each resicle is found upon contraction to be associated with a number of canals arranged in a radiate manner to a central point.*

* Both vesicles lie close to the wall of the body on the side nearly opposite to that on which the mouth opens. When expanded each vesicle is 
Radiata. Cœlenterata.-With some Polypi closed bloodvessels exist upon both sides of the body and stomach: they have proper walls, and circulate a fluid containing a great number of white globules. (Siebold.) Acalephæ.-Without proper sanguineous system. The so-called vessels would appear to be ramified and anastomosing gastric tubules. An 'aquiferous system' is announced in the form of ciliated canals traversing the body and receiving water through stomach, or directly from without, to be ejected through openings upon the extremity of the body and on the margin of the disk (Ibid.). - The Cœlenterata are without a distinctive respiratory apparatus.

Echinodermata.-Blood-vessel system complete. Its general expression is a circular vessel surrounding the mouth and anus, communicating with rudimentary hearts and possessed of diverging arterial and venous branches. Heart absent in Holothuria. In Asteracanthion (star-fish) and Ophiura, water passes freely through openings in the skeleton, the currents among the viscera being determined by cilia. This, the aquiferous system, performs in part the function of respiration. With others, internal branchiæ extend upward among viscera to assurne an arborescent form (respiratory tree), as in Holothuria (sea-cucumber): a smaller and more tentacular form is seen in Echiurus.

Mollusca. Blood-vessel system incomplete; heart, with the exception of Cephalopoda, systemic, i.e. one that receives the aerated blood from gills to distribute it through the body. Currents of water over branchial surfaces induced by ciliary action, except in Cephalopoda.

Polyzoa.-Respiration effected through tentacles surrounding mouth.

about half as broad as body. Upon contraction occurring, the radiated canals appear as fine streaks, which gradually broaden as the main portion lessens, until the former is emptied, and nearly invisible. As the main vesicle begins to expand, the canals, in nearly regular sequence, suddenly open and their contents pour into the central chamber. They then gradually disappear while the vesicle again contracts. (Clark.) 
Brachiopoda.-Hearts two, one on either side the alimentary canal. Respiration by two long spiral branchiæ.

Tunicata.-In Salpa, two vascular trunks are placed on either side of mantle, upon the inner side of which extend the branchix. With Ascidians, a heart of a single cavity is placed at lower part of body. The circulation of blood is to and fro. Branchial chamber at the same time a pharynx.

Lamellibranchiata.-Heart is simple with some, but may contain both auricle and ventricle. Occasionally, as in Arca, a distinct beart is placed upon either side of the body. It is generally pierced by rectum, Ostrea (oyster) an exception. There are two pair of branchiæ, which as four lamellæ, embrace either side of the abdomen and foot. Each lamella is formed by a widely-projecting cutaneous fold, the two leaves of which are connected by numerous transverse septa, to which correspond externally as many furrows, passing from the base of each branchia to its borders.

Gasteropoda.-Heart composed of two chambers, almost always in close relation with the respiratory apparatus, and often pierced by recturn. Respiration mostly by branchix, occasionally by lung-like structure. The branchial apparatus varies in its form, and may be situated upon different portions of the body. Thus, the gills may be exposed in tufts upon the back, as in Doris; or arranged on either side of the body, in a furrow between the mantle and the foot, transversely, in a single row, as in Phyllidia; or composed of divided lamellæ resembling divided leaves, as in Aplysia (seahare); or foliaceous, or pyramidal, arranged in rows ou either side under the margin of mantle, as in Chiton; or composed of numerous leavelets, arranged parallel, like the teeth of a comb, as in Paludina (fresh-water snail). The pneumonic apparatus is situated upon the right side of body, opening externally by an aperture through mantle, and furnished with a network of vessels running on its walls. The shell is a special protector to the respiratory apparatus, and is placed upon it even when rudimentary.

Cephalopoda.-Heart central, of two cavities, and surrounded by pericardium. Those forms having two pairs 
of branchiæ (Tetrabranchiata), as in Nautilus, receive two branchial veins; those having but a single pair (Dibranchiata), as in Sepia (cuttlefish), receive but one. At the base of each branchia is a muscular chamber, termed branchial heart, which transmits venous blood to the branchiæ. The return blood passes through a systemic auricle before entering the ventricle, thence to be distributed through the body. Currents of water over gill surfaces induced by muscular action in mantle.

Articulata. Rotifera and Entozoa. (See water-vascular system, p. 65.)

Annelida.-Blood-vessel system complete. Vessels numerous. Many arrangements obtain with different genera, the general plan conforming to that seen in all the higher articulates, in the presence of longitudinal vessels extending the whole length of body. As a rule, a dorsal and ventral canal are seen, occasionally combined with lateral vessels, which may in some instances communicate with a vertical set joining the other two.-The position of the respiratory apparatus determines the detail of the blood-vessel system. In Lumbricus (earthworm) there is apparently no apparatus exclusively devoted to respiration. Respiratory organs, however, generally present. These may be arranged in depressions upon cephalic segments, as in Nemertes; within the abdominal cavity, as in Hirudo (leech), q.v.; in a brilliantlycolored, spiral tuft to head, as in Serpula; or symmetrically appended to the dorsal surface of each segment, as in Eunice.

Crustacea.-Blood-vessel system incomplete. Heart of a single cavity beneath shell at anterior part of the body. Venous currents empty into a dorsal sinus which encloses the heart. Respiration by branchiæ, excepting in low forms, as in Cyclops and Lernoea, where aeration takes place from the cutaneous surface. Branchiæ may be free, as in Lepas (barnacle); or enclosed, as in Homarus (lobster), and commonly placed at the base of the anterior true or false feet. Constantly, without cilia, currents are secured by muscular action of false feet and appendages.

Arachnida.-Blood-vessel system incomplete. Heart com- 
monly a simple dorsal vessel. Respiration by tracheæ, as in Acarus (mite), or by lungs, as in Epeira (true spider). Aeration seen in Emydium (water-bear).

Insecta and Myriapoda.-Blood-vessel system incomplete. Dorsal vessel, or heart, articulated. Venous canals communicate in a dorsal sinus. Respiration tracheal. False tracheæ in aquatic, larval, and pupal forms, as in Ephemera (May-fly); but true tracheæ in all adult forms of Insecta.

Vertebrata. Blood-vessel system complete; hepatic portal circulation constant,- - blood contributed to it from tail in Pisces, and from tail and posterior extremities and kidneys in certain Batrachia and Ophidia. Heart, with exception of Amphioxus (lancelet), of more than a single cavity. Coloration of blood due to presence of red blood corpuscles.

Pisces.-The venous blood is conveyed to a large sinus near pectoral region. Heart composed of two chambers,-a single auricle and ventricle,-and is placed at the junction of head and trunk above the position of coracoid bones. It contains venous blood which is sent through branchiæ to be returned arterialized to the aorta, and is thence distributed over the body: it is thus seen to be a branchial heart as opposed to the systemic heart of lamellibranchiate and gasteropod molluscs. The commencement of the aorta is furnished with a special dilatation (bulbus arteriosus) which is rarely absent, as in marsipobranchiates, and Amphioxus. In osseous fishes it exhibits a single row of valves; but in the cartilaginous, excluding the types already mentioned, several rows are present. The blood-vessel system of Amphioxus differs from that of other vertebrates in the absence of a valvular heart, propulsion of the blood-current being induced through the agency of a number of contractile chambers developed at different points upon the arteries and veins. There are from twenty-five to fifty of these bulbs on either side.

Branchiæ are arranged in all fishes, in connection with the convex surfaces of osseous or cartilaginous arches placed on either side of the throat, in double rows. In Amphioxus, these rows, from seventy to eighty in number, are contained within a chamber opening anteriorly by the mouth and pos- 
teriorly by the alimentary canal. It is thus at once a branchial chamber and a pharynx; hence the name of the class, including the Amphioxus-Pharyngobranchiata. The process of respiration would appear to be aided by a number of very vascular processes of mucous membrane produced from the parietes of the chamber at its anterior portion.-In marsipobranchiates the branchiæ are enclosed within pouches (hence the name given to the class) upon the side of the body, each of which has a distinct internal and external orifice.*-In Selachia and osseous fishes, the arches vary from three to six in number; the branchial interspaces opening externally by a number of distinct apertures, as in the former, or terminating in common, and protected by portions of skeleton (operculum), as in the latter. In Selachia each branchia assumes somewhat a ribbon-like form (hence the name Elasmobranchiata).-In osseous fishes it may assume the form of a lobe or crest, as in Hippocampus (sea-horse), or that of a comb, as in all others.

False gills are vascular appendages to gill covers of certain Selachia.

Swim bladder. This is a simple or sacculated hollow viscus, present in many fishes; absent in Scomber (mackerel). It is oblong, and ordinarily furnished anteriorly with two cæca. Possessed of a smooth fibrous covering, it is lined with a glistening membrane, exceedingly rich in gelatine (ichthyocolla, q. v.), and at one portion of the surface is remarkably vascular, constituting the rete mirabile. The swim bladder, as a rule, is situated directly beneath the vertebral column, rarely within a vertical fold of intestine, and thus separated from contact with the abdominal walls, as in Campostoma.

* To understand the relation between these and the gills of ordinary fishes, we must suppose each compressed sac to be split through its plane, and each half to be glued by its outer smooth side to an intermediate septum, which would then support the opposite halves of two distinct sacs; if then these vascular surfaces be prolonged in gill-like structure, and an intermediate basis of support be given, we have the branchial arch of a Selachian, which is the homologue, not of a single gill sac, but of the contiguous halves of two distinct gill sacs. (Carpenter.) 
It is commonly isolated, yet may communicate with œsophagus, as in Lepidosteus (gar), or be obscurely cellular (pulmonic), and at times employed in respiration, as in Lepidosiren (mudfish). Hence the swim bladder appears in some fishes to represent a rudimentary lung.

Relations of branchial arches to stylo-hyoid ligament of man. The elements in the hyoid bone of osseous fishes are as follows: basi-hyal, glosso-hyal, uro-hyal, epi-hyal, cerato-hyal, stylo-hyal; branchiostegal, basi-branchial, hypo-branchial, thyro-branchial, cerato-branchial, epi-branchial, and pharyngo-branchial bones. Operculum, or gill cover is composed of opercular, pre-opercular, inter-opercular, and subopercular bones. The mechanism of respiration:-muscles producing adduction and abduction of operculum.

Batrachia.-Heart composed of two auricles and a single ventricle. The venous blood, collected by the ascending and descending cavæ, is thrown from the right auricle into the single ventricle, thence through the pulmonary artery to the lungs, to be returned by the pulmonary veins to the ventricle to be sent through the aorta to the body. Thus the blood of a batrachian is mixed in the pulmonic and greater portion of the systemic circulation. The larval form of some batrachians, as Rana (frog), breathe by gills, and in certain forms, as Axolotl, and Proteus (salamander), these are retained throughout life. The lung, when present, is a double, coarsely cellulated sac. The mechanism of respiration:-muscles of deglutition.

Reptilia.-Heart generally of two auricles and a single ventricle. A rudimentary septum is seen partially dividing the ventricle into two parts in Ophidia. The septum is perfect in the Crocodilia, making four cavities to the heart.The general plan of the circulation as in Batrachia, excepting Crocodilia. In these animals the venous blood contained in the right ventricle is sent not only to the lungs through the pulmonary artery, but also, through a second large trunk which becomes the left or descending aorta, to supply the abdomen and lower extremities. That portion of the blood arterialized and returned from the lungs is received in the left 
auricle, thence is conveyed to the left ventricle, to be sent to the head and upper extremities by the right or ascending aorta. But the lower portion of left aorta does not contain pure venous blood, since it receives blood from the right aorta through a communicating branch (ductus Botalli). Nor does the right aorta at all times contain pure arterial blood, for it may receive venous blood from the right ventricle through an opening in the inter-aortic septum.-Lung is coarsely cellulated; sometimes single.-Mechanism of respiration in Chelonia by the muscles of flank spaces (inspiratory) and muscles within breast box (expiratory); in Ophidia by movement of the ribs. Red blood corpuscles large, generally oval, nucleated. Portal circulation receives blood from kidneys, posterior extremities, and tail.

Aves.-Heart of four cavities. Circulation as in man, excepting that the aorta turns to the right. Lungs fixed, double; bronchi communicate with cavities of bones extensively in Rhamphastos (toucan); slightly in Gallus (fowl); but not at all in Hirundo (swallow).-Mechanism of respiration resident in abdominal muscles-since ribs and sternum remain fixed. Rudiment of a diaphragm in Psittacus (parrot). Respiration of egg of reptile and bird through allantois.

Mammalia.-Heart of four cavities; plan of circulation as in man. In Halicore (dugong) there is a double apex to heart-one for each ventricle. Bone exists in ventricular septum in ox. Foramen ovale at times persistent, as in Phoca (seal). Several methods of origin of the great arterial trunks from aorta. With the ruminants a single trunk from the arch divides into the subclavian and carotids; with the carnivores, the innominate artery gives both carotids as well as right subclavian. Anomalous arrangements of these vessels in man are reproductions of the normal ones of the lower mammals. Curious anastomoses of vessels (wonder nets) seen in Bradypus (sloth) and Cetacea.

The general plan of the circulation in Vertebrata can be detected in the development of the blood-vessel system in man. Thus in the human fœtus, the five cervical arches represent the five branchial arches of the fish. In the former, 
they are transient, and are represented in the infant as anastomoses between the arteries of the neck. But in the latter, they are persistent, and sustain the branchiæ throughout life. In the reptilian heart, the transmission of venous blood from the right to the left side through a septal foramen recalls the arrangement seen in the human fœtus at term.

SPLEEN.

The spleen is an appendage to the blood-vessel system. Commonly oval, it is seldom narrow, and elongate, as in Perca (perch). Usually single, it is occasionally double, as in Squatina, or multiple, as in Lamna (shark). (Van der Hoeven). It is situated in the cavity of the abdomen in proximity with the stomach, and consists of a red parenchyma, supported by fibrous bands (trabeculæ) extending inward from a capsule. The spleen is peculiar in the arrangement of its blood-vessels. The splenic artery abruptly terminates in large spaces (lacunæ), from the opposite sides of which the splenic veins as abruptly begin. Small branches of the artery, prior to entrance into the lacunæ, are distributed upon their walls, and have appended to their smaller twigs a number of minute white bodies-the splenic corpuscles.

Were no provision made for the reception of large volumes of blood which, from various causes, are poured into the vessels of the abdominal viscera from other parts, stagnation of vascular currents supplying organs essential to nutrition might at any time occur. It is thought to be the function of the spleen to avert this by receiving and retaining the excess of blood until an equalization of currents is again assured. This view would seem to receive confirmation from the organ appearing only in animals having a complete system of vessels, as in the Vertebrata.* With others, as in the Mollusca, the distensible lacunæ (which resemble in plan of construction that of the splenic lacunæ) are placed at all por-

* Other animals having closed vessels, but withuut spleen, as Annelida, Amphioxus, and marsipobranchiate fishes, have a compensatory feature in the extreme dilatability of their numerous vascular trunks. 
tions of the body, and preclude the possibility of untoward pressure upon any one point.

\section{LYMPHATICS.}

The lymphatics are accessory to the sanguiferous system. From the various tissues and organs they collect a fluid (lymph) which is apparently a transuded portion of the liquor sanguinis unappropriated by the tissues. In addition, they derive nutritive material through the villi (lacteals) from the food in the intestines. The liquids thus obtained are conveyed from smaller to larger vessels, until finally they empty by one or more great trunks into the venous circulation. (Leidy.)

The lymphatics are confined to Vertebrata, and are constant among its tissues; exceptions; spleen of Chelonia,- -and ganglia of nervous system. They are abundant without valves or glands, as in Pisces; abundant with valves, but without glands, as in Reptilia; less abundant, but possessing both valves and glands, as in Aves and Mammalia.-Pulsatile vesicles are in some Vertebrata associated with the lymphatics, as in Anguilla (eel), and Rana (frog).

\section{IX.}

\section{EXORETORY SYSTEM.}

THE function of removing from the organism the results of waste of tissue is called excretion. No organ is specially devoted to it among the Protozoa, Radiata, Mollusca below Lamellibranchiata, and Articulata below Arachnida and Insecta. Various bodies, apparently glandular, have had a depurative office attributed to them, but oftener from exclusion than possession of any certain knowledge of their nature. With various Articulata, as in Insecta, many of the appendages to the alimentary canal-particularly the conglobate forms emptying their products near the oral or anal extremity-are in part subservient to this purpose. The labor of 
removing excretory elements is not confined, even in the highest animals, to a single organ. Thus the respiratory apparatus may receive some of the inorganic elements, such as carbonic acid and water; other excreta, as in certain airbreathing animals, may exude either through the skin (exhalation), or its appendages, viz., the perspiratory and anal glands; whilst others may find their way into the intestines, to be voided with the ejecta.

Of necessity closely associated with channels of nutrition, excretory organs, wherever seen, are unusually vascular. It is partly from the recognition of this feature that systems of contractile vessels, having corpusculated contents, like blood, yet opening upon the exterior, like excretory tubes, have recently been assigned a position midway between the circulatory system and the emunctories. (See p. 55.)

Conspicuous among these is the Water-vascular System. This is an arrangement of vessels seen in certain aquatic and entozoic articulates, which contains a corpusculated fluid communicating with the external medium by a simple opening. The main trunk of the system arises from this point, and divides into branches which are distributed through the tissues. The walls of the vessels are well defined; and by their pulsation, a to-and-fro motion is given to the contents,permitting water to enter the body and excrementitious matters freely to escape.

The water-vascular system is best developed in the Entozoa, q. v.

Rotifera - The external aperture is situated at the posterior end of the body, and communicates with a large sac which rhythmically contracts. From this, ciliated trunks arise, which usually give off short lateral branches, to terminate in the trochal disk of the animal.

\section{KIDNEY.}

The kidney is that organ which, being specially devoted to excretion, elaborates a crystalline product. This is constantly uric acid or guanin, either free or combined. With many 
highly developed animals there are also present various organic bodies, such as urea, creatin, and creatinin,--as well as inorganic compounds, as phosphates of ammonia and magnesia.- Secretion commonly elaborated from venous blood, but in Mammalia partly from arterial also.

No true kidney below Mollusca.

Moldusca. Organ absent in Polyzoa, Brachiopoda,* and Tunicata.

Lamellibranchiata.-The kidneys (organ of Bojanus) always double. Each is an oblong gland of a brown or brownish-yellow color, placed upon dorsal region of body, near the hinge line, beneath pericardium and inferior adductor muscle. The usually very thin walls of these two sacs have numerous folds or plicæ, which form compartments or areolæ, all of which are covered with ciliated epithelium. (Siebold.) The short excretory duct opens into mantle upon side of base of foot, and is generally isolated from genital pore, or is in cammon with it. Secretion solid.

Gasteropoda.-Organ lamellose without cilia, and placed near branchial vein; in Doris at region of membrane about heart; in pulmonic types at posterior and upper part of respiratory chamber between the heart and rectum. It is provided with excretory canal opening by the side of the pneumatic orifice, as in Limax, or within the respiratory chamber, as in Helix. Secretion solid.

Cephalopoda.-The kidneys (spongy bodies) are appendages to main venous canal. The renal cells are placed upon the sides of everted follicles, the bases of which are formed by the walls of the vein itself. Each cell is granulated, and possesses well-defined nucleolar elements-and commonly a crystalline product. The urine passes along an imperfectly defined duct into the cavity of the mantle, thence to escape from the body through the syphon.

Articulata. Kidneys absent below Myriapoda;-function with some supplied through water-vascular system.

* Hancock looks upon the 'great perivisceral chamber with its extensive ramifications' of Brachiopoda as having a renal significance. 
When present, organ follicular, and empties in intestine. Secretion solid.

Myriapoda.-Kidney composed of long, convoluted tubes generally opening into intestine at anterior part.

Arachnida.-Several cæca empty into intestinal canal, near its termination, a solid urine.

Insecta.-See p. 64.

Vertebrata. Kidneys are two in number, and generally situated immediately beneath the vertebral columns. Composed of numerous vascular tufts (Malpighian bodies), each is placed in relation with the termination of a slender tubule lined with mucous membrane, which afterward unites with its fellows to form a single excretory tube (ureter). The Malpighian bodies are always placed toward the periphery of the organ: when the layer thus occupied is well defined, it is called the cortical portion. The uriniferous tubules extend from the region of the Malpighian bodies toward the centre: when this layer is well defined, it is called the medullary portion.-The urine is excreted in part only from the Malpighian tufts, some of its ingredients being elaborated from a network of small veins surrounding the uriniferous tubules. This network results either from division of the return blood of the renal artery, or is received into the kidney from another source. From the analogy such an arrangement bears to the portal circulation in the liver, it is known as the renal portal circulation.

Two types recognized. (1) Organ not separated into cortical and medullary portions; tubules may be ciliated, and urine solid; portal vein received from posterior part of body and lower limbs, when present: includes Pisces, Batrachia, Reptilia, and Aves. (2) Organ separated into cortical and medullary portions; tubules never ciliated, and urine always fluid; portal vein received from renal capillaries: includes Mammalia.

Pisces.-Kidneys absent in Amphioxus. With others, long and narrow, without pelves, and placed upon either side of median line, immediately beneath bodies of vertebræ. Ureters may unite and form one tube or empty separately into rectum from above. 
Batrachia and Reptilia.-Kidneys compact, deeply situated, often tirmly connected to iliac bones, when present, by peritoneum, as in Chelonia and Sauria. Bladder present with many Lacertilia (lizards) and Batrachia. Kidneys of Ophidia not placed on same level, the right situated more anteriorly than the left; the structure is more lobulated and less compact than in Chelonia.

Aves.-Kidneys deeply situated, and extend from lungs downward as far as rectum. The posterior surface is moulded into the cavities formed by the bones on which it rests. There is no pelvic cavity, and the ureters empty into cloaca. (Johnson.)

Mammalia.-Form often lobulated, as in Rhinoceros, and Phocana (dolphin). The urine escapes from uriniferous tubules into pelvis, to empty into bladder through ureter, thence to be voided by urethra.

\section{x.}

\section{INTEGUMENT.}

The layer of tissue investing an animal is called the integument. In the embryonic condition of many of the lower forms the investment is continuous over the surface of the body, without any proper processes or irregularities.

Protozoa. See Skeleton and Spongia.

Radiata. Cœlenterata.-Integument composed of a simple cellular commonly translucent, thick gelatinous layer without appendages. In Auretia (jelly-fish) it forms a loosemass, somewhat resembling connective tissue, interspersed with occasional elastic filaments and muscular fibre. The hydroid polyp stalk possesses two dermal layers-one, inner, is cellular; the other, outer, is structureless, and forms a sclerous covering to the animal.

Echinodermata.-Integument more or less calcified. (See Skeleton.) 
Mollusca. Polyzoa.-Integument, represented by a structureless membrane, containing calcareous or siliceous particles, is received by pullulation into skeleton, q. v.

Brachiopoda.- Integument contractile, cleft, forming halves to a mantle* placed in relation to shell, q. v.; bud-like processes, as in Polyzoa.

Tunicata.-Within the integument (test) of Ascidia numerous cartilage-like cells are in relation with a membranous matrix. The matrix presents great diversities of structure, representing, in fact, almost every known tissue. Thus in one genus we have a test resembling cartilage; in another, bone; in a third, connective tissue. In Ascidia the integument separates into two layers, but in Boltenia the tendency is less evident. An epithelium results from the imperfect metamorphosis of the integumental layer. A structureless, homogeneous epidermis, is naked and wrinkled in Salpa, furnished with spines, or tesselated in some species of Boltenia. The integument of Tunicata possesses the remarkable property of elaborating cellulose.

Lamellibranchiata.-The integument generally with two openings, as in Tunicata-one for the admission of water, the other for its ejection. These often take the form of tubes (siphons), more or less lengthened and projected at will. The receiving siphon communicates with the cavity included between the branchiæ, the discharging one with another cavity behind the leaves. In some species, however, the discharging siphon is alone present. In Ostrea (oyster) there are no siphons, the mantle being entirely open. (Gosse.) -Edges of mantle furnished with retractile papillæ, rich in glands and pigment cells. (For shell, see p. 26.)

Gasteropoda and Pteropoda.-Integument a dense contractile derm of a cellular structure, often containing pigment matter free or in cells. It is covered with a ciliated epithelium, which partially or entirely covers the body. Its

* 'Mantle' will be restricted to that fold or other portion of the integument designed to elaborate the shell. Where both shell and fold are absent, 'test' will be employed. 
surface is striated or tuberculated, and recalls the appearance of a mucous membrane. With many species the skin forms around the neck or back a fold, the posterior part of which (mantle) is dilated into a hernial sac containing a portion of the viscera. (Siebold.)-(For shell, see p. 26.)

Cephalopoda. - Integument composed of a contractile fibrous tissue, and a delicate non-ciliated lamellose epidermis. Within the meshes of the skin a number of contractile cells (cromatophori) are lodged, eash surrounded by a delicate elastic membrane. The pigment granules, which they enclose, are always of the same color in each cell, and produce the blue or violet or yellowish-brown spots, whose extent and shade vary according as the cells are contracted or dilated. (Siebold.)

Articulata. The spines, hairs, and scales of Crustacea, Arachnida, and Insecta are portions of the true skeleton, q.v. Glandular appendages seen in Annelida.

Vertebrata. Integument composed of two well-defined layers-the inner, fibrous (derm, true skin); the outer, cellular (epidermis, cuticle).

Pisces.-The appendages to the skin form the exo-skeleton. This is composed of tins, and scales or plates; and may be calcareous, osseous, or corneous. Fins are vertical folds of integument, either entirely dermal, as in Anguilla (eel), or supported by bony rays, as in the majority of osseous fishes. Fins are named from their locality-the dorsal, caudal, anal, ventral, and pectoral fins. The latter is not a true fin, but in part a representative of the anterior extremity of higher vertebrates. The caudal fin is homocercal when rays diverge both above and below the position of vertebræ, as in the majority of recent fishes; or heterocercal when they diverge from the under surface of the terminal vertebræ, as in Acipenser (sturgeon). Scales are organs analogous to horns and nails of mammals. They may be inserted into skin each by a species of socket or matrix, which is formed either in the true skin or within its folds, and arranged in lamellæ, as in majority of osseous fishes, without order, as in Anguilla (eel), or in plates, as in Acipenser (sturgeon). Those with a rounded 
free edge are known as the cycloid, and those with a comb-like edge the ctenoid scales. When the scales are of a small size and irregular form, they are called placoid, but when large and tesselated, ganoid. The minute anatomy of the two last varieties may more or less closely resemble that of tooth or bone. All fishes have an abundant mucoid product thrown off from the cellular sub-epidermic layer. It is especially abundant about the gill covers and along the 'lateral line,' and is everywhere exceedingly copious in Anguilla (eel), with which the scales are rudimentary.

Batrachia.-Integument loosely attached to muscle, and is without scales,-rarely with plates, as in extinct Labyrinthodon. In Rana (frog) the whole surface of the epidermis is beset with minute trifid apertures leading to spherical sacs. (Huxley.)

Reptilia.-Integument never scaled; often tuberculate, or epidermis assuming form of tesselated plates, as in Chelonia. In Ophidia and Sauria the epidermic plates are more or less laminated. During process of shedding skin, which occurs periodically with Ophidia, the epithelial layer is thrown off entire. No glandular appendages.

Aves.-Integument loosely connected to muscle, and covered with feathers, q.v. Horny beak, spur, and tesselated plates to tarsi, are examples of cuticular development. While papillæ of derm may be pronounced, glandular appendages are absent.

Mammalia.-Derm well developed; papillæ generally small, large on the pads of feet, or on muzzle. Epidermis rarely forming a cônnected layer, as on tail of Castor (beaver), in bone-like plates, as in Dasypus (armadillo), or in laminated processes, as in Manis (pangolin).

Nails are flattened, horny plates developed from the upper surface of the phalangeal integument only, as in many monkeys and man. Claws are nails which embrace a larger portion of the phalanx, being developed not merely from its upper surface, but also from its extremity, and extending far round on its sides, as in carnivores. In the dog and cat a bony plate extends from last phalanx into the posterior fold 
of nail.-Hoofs are claws with the terminal portions blunted and rounded, and adapted to the support of the limb. (Huxley.) Hollow horns, as in Ruminantia, are analogous to claws, but solid horns, as in Rhinoceros, are without bony support, and probably are the result of coalescence of hairs.

Two kinds of glands, sebaceous and sudoriferous. The former, almost always in connection with hair bulbs, produce a fatty secretion. The latter lie within the subcutaneous connective tissue as simple tubes, the ducts from which pursue a more or less wavy course to open on the skin. In most mammals the tube is coiled at its commencement, but in ox and dog it is straight. In the latter the glands upon the body are rudimentary cæca, but upon the ball of the foot they are large. (Huxley.)

\section{$\mathrm{XI}$.}

\section{NERVOUS SYSTEM.}

Nerve tissue is that peculiar product of organization which, while the source of sensation, controls excito-motory and nutritive acts.

Two kinds recognized, cellular and commissural.*

The nerve cell is globular or oval, and, possessed of at least one spherical nucleus, is generally unipolar or bipolar, rarely multipolar. A collection of nerve cells constitutes a ganglion. A commissure may be either a prolongation of the cell wall, or a distinct structure, characterized in the higher animals as a white thread-like band, having an axis fibre, enclosed by a medullary sheath, and the whole supported by basement membrane (neurilemma). A 'nerve' is a bundle of commissures. Ganglia are supposed to generate nerve power; commissures to convey it from ganglion to ganglion, or to and fro from adjacent structures. The nerves, however,

* By 'commissure' is assumed a band which not only unites ganglion with ganglion, or perceptive area with ganglion, but also associates ganglion with motor area. 
are not entirely passive agents, but are endowed with a peculiar property (neurility).

The simplest expression of a nervous system is a ganglion placed in relation with a pair of nerves. One of these, extending from the tissues (perceptive areas) to the ganglion, is designed to convey an impression to the centre generating power, and hence is called afferent, or sensory. The other, extending from the ganglion to the tissues (excito-motor areas) is supposed to transmit the power excited to activity by the reception of sensation, and hence is called efferent, or motor. To the transfer of an impression either way the continuity of the conductor is essential.

The complexity of a nervous system is determined by the number, arrangement, and degrees of development of its ganglia and commissures.

\section{Protozoa. No nervous system apparent.*}

Radiata. Cœlenterata.-Form of nervous system not determined.

Echinodermata.-The plan is that of a number of ganglia arranged in the form of the circle or pentagon, connected by commissures and sending branches to the surrounding tissues. In Asteracanthion (star-fish) the ganglia are situated at points between the rays.

Mollusca. A number of ganglia generally surround the gullet, and constitute the 'œsophageal ring.' Other ganglia are seen at various points of the body connected with the above, and with one another by commissural threads, their position and size being determined by the relations and importance of the regions concerned. Processes of the cell wall often extend far into the nerves, while the distinct neurilemma contains orange or reddish pigment cells.

Polyzoa.-No nervous, system has with certainty been recognized.

Brachiopoda.-An œesophageal ring, composed of two im-

* Animals having no nervous system are by some included in a group named the Acrita. 
perfectly defined ganglia, supplies branches to mantle, arms, and viscera.

Tunicata.-A single, often yellowish ganglion, confined to mantle, is placed between the oral and atrial openings.

Lamellibranehiata. - The ganglia are symmetrically arranged in three pairs. The members of the first, or labial pair, are placed one on either side of the gullet, and are united by a slight transverse band superiorly. It supplies the parts about the mouth and anterior portions of the viscera. The second, or branchial pair, is usually placed upon anterior surface of posterior adductor muscle; it communicates by long nerves with the labial pair, and gives branches to the adjacent muscle, branchiæ, and mantle. The two ganglia are blended when the branchiæ are united behind, as in Unio (fresh-water mussel). The third, or pedal, is confined to the foot. When this is absent, as in Ostrea (oyster), the ganglia are wanting; but when it is largely developed, as in Mytilus (sea-mussel), they often unite, forming a single bilobed ganglion.

Two diffuse œsophageal rings are thus formed,-one occupying the greater part of the visceral mass and defined in front by the labial and branchial ganglia, the other by the labial and pedal ganglia, and both on the sides by their communicating branches respectively.

Gasteropoda.-Ganglia with commissures forming œosophageal ring. The upper part may be recognized as the brain, from which branches are distributed to the eyes, tentacles, and adjacent parts of mantle. The sub-œsophageal ganglia always connect with branchial and pedal ganglia by conspicuous commissures.-A distinct set of ganglia intimately associated with the mouth, gullet, and stomach, have been observed in some naked-gilled forms, as Doris and Eolis. It is probably analogous to a sympathetic system.

Pteropoda.-The nervous system resembles that of Gasteropoda, with the exception that the supra-œsophageal ganglia are absent.

Cephalopoda.-The ganglia are of large size, and are more or less perfectly enclosed in a cartilaginous brain case. (See p. 
26.) The supra- and infra-œsophageal ganglia are connected by commissures, as in Gasteropoda. In Nautilus, the latter are two in number and placed one in front of the other. The optic nerve arises from the superior ganglia; the olfactory nerve, and branches for the tentacles and body, arise from the inferior. In Argonauta, the ganglia are in a single mass in the median line, the optic nerve arising from the lateral portions. Brachial nerves enter the axis of the tentacles, and are furnished with ganglia, which control the action of the suckers.

Articulata. The ganglia are arranged in the axial line of body and joined by a double chain of commissures, excepting Rotifera and Entozoa. The 'neural cord,' thus constituted, lies upon the ventral aspect of the segments. Its anterior portion commonly surrounds the œsophagus, forming an œsophageal ring. As a rule, each segment retains a pair of ganglia with its afferent and efferent nerves.

Rotifera.-The nervous system has been imperfectly made out. It is probably not strictly conformable to that of the articulate type.

Entozoa.-See p. 161.

Annelida.-The neural cord not fixed to ventral region, but floats freely in viscera. Supra-œsophageal ganglion bilobed; sub-œsophageal, conspicuous. Nemertes differs remarkably from the other Annelida, in the nervous system being without apparent enlargements, and composed of two separate cords, one on each side of the body, which send off lateral branches along their course. (Siebold.)

Crustacea.-The nervous cord is usually connected to cerebral ganglia by an œsophageal ring. As a rule, the ganglia are distinct; but in certain forms, where segments of the skeleton are fused together, those portions of the cord corresponding to such segments form one mass, within which are represented the elements of as many ganglia. In the higher Crustacea, as in Homarus (lobster), the cord forms two separate centres of ganglionic union, one for the head and thorax, and one for the abdomen.

Arachnida.-The cord forms, as a rule, two enlargements, one for the cephalo-thorax, and one for the abdomen. 
Myriapoda and Insecta.-The cord presents many varieties of form, but the general arrangement is similar to that in other articulates.

The nervous system of an insect developing by true metamorphosis presents a distinct form for each condition, as follows: The larval, a simple duplex gangliated cord; the pupal, in addition, a degree of coalescence of the ganglia; and the imagal or sexual, the highest degree of such coalescence.

Vertebrata. Nervous system composed of a cerebrospinal axis with branches, and a sympathetic system.

The cerebro-spinal axis is placed above the alimentary tract, within a cartilaginous or osseous chamber (neural canal), and consists of numbers of ganglia arranged for the most part in pairs, with a tendency in separating to form median cavities (ventricles). It is divided into a brain (encephalon) and spinal cord (medulla spinals, myelon). In the spinal cord the gray matter is arranged in ganglia of an indefinite number, and placed within the white commissural mass. With comparatively few exceptions, it fills the neural canal, and contains throughout its whole extent a narrow ventricle, which expands at the commencement of brain into the fourth ventricle.-Within the brain the gray matter is placed upon the outer side of the commissural mass. The ganglia are of a fixed number. With the exception of Amphioxus, this number is four, each ganglion receiving a distinct name, as follows: cerebellum, optic lobe, cerebrum, and olfactory lobe. Of these the cerebellum is a single mass; the others are in pairs, excepting olfactory lobes of Rana (frog), cerebrum of Squalus (shark), and the optic lobes of Lepidosiren (mudfish), which present no tendency to divide. Pituitary and pineal bodies constantly present; the latter are without calcareous matter below man.

Cranial nerves never of more than twelve or less than three pairs. In Amphioxus these are (1) trigeminal, (2) pneumogastric, glossopharyngeal, and spinal accessory represented in one, and (3) hypoglossal. The olfactory and optic nerves always arise from their respective ganglia. The olfactory nerves are, properly speaking, those branches arising from 
the olfactory bulbs or ganglia. Their roots or peduncles, originating from beneath cerebrum, are of the nature of commissures. Decussation (chiasm) of the majority of fibres of optic nerves rarely absent, as in Amphioxus.

The medulla oblongata is intermediate in character to the brain and spinal cord. It is composed of several ganglia,the gray matter being placed internally. With it all the cranial nerves excepting the olfactory and optic have connection.*

Sympathetic system. The differences obtaining between the representatives of this system are not sufficiently defined to require comment.

Pisces.-In Amphioxus the spinal cord terminates at either end without enlargement. The position of the brain can only be recognized by the points of origin of nerves of special sense. The spinal cord generally is thickest at the middle third. It gives off fifty-five to sixty pairs of nerves, each nerve arising from a single root.

With all fishes, except Amphioxus, the brain is well defined. -The medulla oblongata is slender, not distinctly divisible into pyramids. It is often open from above, exposing cavity of fourth ventricle, and possesses on either side a number of small projections known as the lateral lobes. These are peculiar to fishes, and in Trigla (gunard) and Torpedo (electrical torpedo) are specially marked._-Olivary body wanting.-CereDellum relatively of large size, generally roundish and smooth, but in active predatory fishes, as Selachia, hollow, presenting trausverse folds, and commonly communicates with cavity of fourth ventricle. With the exception of Scomber (mackerel), where they are small, it is entirely devoid of lobes.-Optic lobes are of large size, and constitute the most conspicuous and bulky mass of the brain. They are hollow, occasionally communicate, and each contains, in osseous fishes, a rounded nodule. The optic nerves commonly form a chiasm.-Cerebral hemispheres smaller than the preceding, solid, separated

* It will be included in description under head of 'brain.' 
from one another by a cavity traversed by a single commissural band. Immediately in advance, the olfactory lobes arise; they are particularly large in Selachia. Pituitary body well developed; infundibulum generally long, as in Gadus (haddock).-Pineal body a small globe of gray matter situated between optic lobes, very distinct in Anguilla (eel); less apparent in other species. In Salmo (salmon) it constitutes a plexus of slender vessels, anastomosing to form a club-shaped mass. In Squalus (shark) it is particularly distinct, being larger than in any other fish (Wyman).-The brain, as a whole, is small, and forms but about $\frac{1}{1500}$ part of the axis. It does not fill the brain case,-a quantity of loose adipose tissue being placed around it.

Batrachia.-Spinal cord extends the length of the vertebræ excepting in some tailless forms, as Rana (frog). Brain resembles in general features that of Pisces. The region of cerebellum less developed; the cerebellum is a small flattened transverse band continuous on either side with medulla oblongata, which is without lateral lobes.-Optic lobes large, conspicuous.-Cerebrum larger than in Pisces, and extends with but slight or no constriction into large olfactory lobes. Optic thalami and corpora striata present. Each portion of the brain hollow, and lined with ciliated epithelium, excepting optic thalani and cerebellum, which are solid.

Reptilia.-Spinal cord contains a canal which in Sauria and Ophidia extends as far as the first coccygeal vertebræ. In Chelonia it is shorter. Brain.-The cerebellum consists of a median portion only. The fourth ventricle is open from above, but is closed in Chelonia. Optic lobes of a rounded form, and contain a ventricle which communicates with the third ventricle.

The posterior portion of each lobe is constricted transversely in Python. Cerebral hemispheres more developed than in fishes, larger than optic lobes, smooth, hollow, and imperfectly subdivided into lobes. Each hemisphere enfolds a portion of pia mater and contains upon the base of its ventricle representatives of the corpora striata and optic thalami. The third ventricle is traversed by the anterior 
and posterior commissures, the middle being absent. Olfactory lobes large, hollow, possessing chambers which communicate with the ventricles of the cerebral hemispheres. The brain relatively larger than that of the fish. In the frog it forms $\frac{1}{712}$ part of the whole tract. But in the tortoise is much less, viz., $\frac{1}{568}$ part. It does not fill brain case, and, as in fishes, is on the same plane with spinal cord.

Aves.-Spinal cord smaller in mass than brain. It completely fills spinal canal. A narrow ventricle runs through its middle. Couspicuous swellings are noticed at the points of origin of brachial and sacral plexuses. At the latter position a distinct ventricle (sinus rhomboidalis) is seen, lined with ependyma and containing a fold of pia mater.

Medulla oblongata without pyramids or olivary bodies. Cerebellum joining with cerebral hemispheres to conceal the ganglia beneath. It is without lateral lobes and folded. Transverse section displays the arbor vitæ.-Optic lobes hollow, united into a single rounded mass of small size and concealed by junction of the cerebellum and cerebral hemispheres.-Cerebral hemispheres relatively longer than in reptiles and fishes; heart-shaped with the apex directed forward; lobes not convoluted. Corpus callosum present as a rudiment; fornix small or wanting. Bodies, so called, corpora striata and optic thalami present; former not striated; latter not united by commissure, and joining with optic lobes in origin of optic nerves.-Olfactory lobes large, apparently appendages to anterior lobes of cerebral hemispheres. Olfactory nerve escapes from cranium through a single opening.

The brain is relatively larger than that of either fishes or reptiles, is placed at an obtuse angle to spinal cord, and entirely fills brain case. In Fringilla canaria (canary) it comprises $\frac{1}{25}$ of whole tract, in Anas (duck) $\frac{1}{3} \frac{1}{0}$.

Mammalia.-Spinal cord, with but few exceptions, furnished with ventricle. It is swollen at points of origin of brachial and sacral plexuses, and frequently shorter than its enclosing canal,-the intervening space being occupied by the obliquely-placed nerves (cauda equina).

Medulla oblongata is divided into pyramids and lateral 
tracts; a conspicuous ganglion (olivary body) is added.-The body (vermiform process) of the cerebellum is small and transversely folded. Its lateral appendages (hemispheres) have now a size exceeding that of the body. They are united inferiorly by a band of commissures (Pons Varolii) which traverse the course of fibres going to form the crura cerebri, and, with but few exceptions, by another smaller set (trapezium), which cross immediately in advance of the anterior pyramids.-The optic lobes (corpora quadrigemina) are small, concealed from above, and are bi-partite, or imperfectly quadri-partite.-The cerebral hemispheres, exceeding in size other portions of the brain, are divided into lobes, most generally convoluted, and, with few exceptions (Implacentalia), united by commissure (corpus callosum).-Corpora striata striated.-Optic thalami at times give partial origins to optic nerves.-Olfactory lobes rudimentary in man, but large and containing ventricle in Ovis (sheep).-As a rule, the relative size of the brain is greater than in that of any other class of Vertebrata, occupying in ox $\frac{1}{75}$, in Elephas (elephant) $\frac{1}{500}$, in Vulpes (fox) $\frac{1}{50}$, and in $\operatorname{man} \frac{1}{40}$ part of the whole tract.

Monotremata.-Spinal cord in Ornithorhynchus (duck bill) is long, slender, and fills the canal. In Echidna (porcupine ant-eater) it is thicker and shorter, and extends but half the length of the canal.-Medulla oblongata with pyramids and olivary bodies defined.-Cerebellum large, folded; median portion with small lobes. - Optic lobes quadri-partite (Echidna); median fissure faint, sometimes absent. - Cerebrum, with great commissure absent. Hemispheres smooth in Ornithorhynchus; slightly convoluted in Echidna, where three equidistant, transverse folds characterize the posterior portion of each hemisphere.-Olfactory lobes relatively very large. In Ornithorhynchus a portion of the nerve arises from the inferior surface of the posterior part of the cerebrum behind the quadrigeminal body. In Echidna the nerve is yet larger; it arises from the anterior part of the cerebral hemispheres, and contains a prolongation of the lateral ventricle. Cerebral hemispheres encroach very slightly upon cerebellum. 
Marsupialia.-Olfactory lobes large, for the most part rounded and constricted. Cerebrum not encroaching upon cerebellum, is irregularly lobed and smooth. In Macropus (kangaroo) and some other forms, small lateral appendages lie in fossa upon petrous portion of temporal bone. Corpus callosum rudimentary, and in some genera entirely absent. Optic lobes quadri-partite. Relative size of brain less than in other Mammalia. In Dasyurus (dasyure), it is 1 to 520, in Phascolomys (wombat), 1 to 614, and in Macropus, 1 to 800 .

Rodentia. - Brain - Cerebrum generally of a rounded shape, not impinging upon cerebellum, and without convolutions. Optic lobes quadripartite; nates larger than testes. Cerebellum of moderate proportions, with well-marked hemispheres.

Cetacea.-Brain large, that of the Balcena (whalebone whale) weighing three pounds four ounces. Cerebrum, nearly covers in the cerebellum, is broader than long; the convolutions are numerous and deep. Olfactory lobes rudimental, and were believed to be absent. The hemispheres of cerebellum divided into a number of lobes, six on either side, obtained for the most part by subdivision of the lobules mentioned in human anatomy. Trapezium absent.

Quadrumana. - The brains of all the old world monkeys below the Anthropoids possess the following characteristics when compared to that of man. The breadth of encephalic mass is proportionately greater than the length; the cerebral hemispheres do not cover the whole of the cerebellum; the convolutions are smaller and less deep; the sensory ganglia are of small size; the corpora albicantia are united into one mass; the cerebellum is smaller and Pons Varolii consequently less.*

* The above resumé gives, it is thought, the principal variations seen in the nervous system of Mammalia. 


\section{XII.}

\section{ANIMAL ELEOTRIOITY AND PHOSPHORESOENOE.}

ANIMAL ELECTRICITY.

THE following are electrical animals:

Fishes.-Torpedo oculata; Raia batis; Raia clavata; Gymnotus electricus; Malapterurus electricus; Tetraodon electricus; Trichiurus electricus.

\section{Articulates.-Scolopendra electrica.}

Torpedo oculata. The disk is somewhat broader than long, abruptly rounded in front; the tail is as long as the disk. The distance from the beginning of the ventral fin to its free end is, as a rule, considerably smaller than the distance from that to the end of the ventral fin. In the young individual the border of the spiracle is surrounded with five to nine teeth; these are lost in the more aged. The dorsal fins have rounded angles, and convex or straight posterior borders. The caudal fin is either longer than high or the length and height are equal.

The coloration is subject to variation. The prevailing tint of the dorsal region may be reddish brown with bluish spots around the eyes, varying in number between seven and one. If a few of these alone be present they are situated in the median line of back. Or the spots may be of a white color, scattered over the region of back. These have a palish border, with an intense central spot of a copper color. Or the points surrounding the spiracles may be absent, and in place of the bluish spots a uniform brown color be prevalent, with a few whitish spots scattered over the surface.

Measurements.-From the tip of nose to mouth, $1^{\prime \prime} 1^{\prime \prime \prime}$; from the inouth to anus, $5^{\prime \prime} 9^{\prime \prime \prime}$; from anus to end of caudal fin, $5^{\prime \prime} 6^{\prime \prime \prime}$; length of disk, $6^{\prime \prime}$ $3^{\prime \prime \prime}$; breadth of disk, $7^{\prime \prime}$. Habitat.-The Mediterranean Sea and Atlantic Ocean. (Miiller and Henle.)

Anatomy of Electrical Organs. - The electrical organs occupy a large part of the broad expansions of the body, which in the other allied fishes are formed only by the lateral fins. They form two separate masses, one on either side of the head and gills. Each is an irregular ellipsoid, convex on either side, its long diameter not quite parallel to the axis of the body, and extending outward to the cartilaginous margins of the great fins, and posteriorly to the cartilage which separates the thoracic from the abdominal cavity. Their form and the honeycomb embossments of their surfaces can be distinguished through the skin both of the dorsal and ventral aspects. The common integuments being removed, two strong fascial coverings are discovered 
investing the electrical organs. The outer one has longitudinal fibres, which are rather loosely adherent, and around the margin of the organs seem to inosculate with the skin. The inner fascia is of considerable density, forms the immediate tunic of the electric columns, and sends delicate processes, with an accompanying network of arteries, veins, and nerves, down between them to form their partitions. Throughout their whole extent the essential ${ }^{\circ}$ part of the electrical organs is formed by a whitish soft pulp, divided into numerous pentagonal prisms by the fascial processes above mentioned. These lie closely together, parallel with one another, and perpendicularly between the dorsal and ventral surfaces of the fish, so that their extremities are separated from these surfaces only by their fascia and the common integuments. When these are removed, the columns present something of the appearance of a honeycomb. The columns are longest next to the head and gills, and, being at these points about one inch in length, thence gradually diminish outwardly, until on the exterual margin they are only about onesixth of the length of the internal ones. Most of these columns are either irregular pentagons or irregular hexagons; a few are nearly tetragonal. They are united to one another by short but strong fibres, and by a reticular expansion of tendinous threads spread over them. Their number varies considerably according to the age of the fish, but averages about 470 to each organ. (Coldstream.)

The nerves distributed to the electrical organs are of great size. They consist of three principal trunks arising from the cerebro-spinal system. The two anterior are portions of the fifth pair; the third is a branch of the tenth. They appear to arise in part from an appendage to the cerebellum ('fourth encephalic lobe'), and terminate upon the sides of the columns by loops.

Rudimentary conditions of an electrical apparatus are met with in other rays, as for example Raia batis (skate) and Raia clavata. Each of these possess an electrical organ imbedded in the muscles of the tail. It commences on either side of the caudal region, at about one-third of its length from the base, and, extending toward the tip, gradually occupies much of its space. Its form is that of a tube surrounded by a nervous covering. It is supplied by spinal nerves, which resemble in their distribution those of other electrical organs. (Murray.) The electricity elicited from this apparatus is similar to though weaker than that from the Torpedo. (Robin.)

Gymnotus electricus (electrical eel).-Body long, eel-like, naked, without dorsal fin, covered with mucoid secretion. Head is short, somewhat flattened from above downward, and furnished with a number of mucous follicles. Mouth large, lips thick and mobile. Upper jaw a little longer than lower, and furnished with a number of small acute teeth. The tongue is large and furnished, together with the pharynx, with a number of small papillæ. The eyes, which are situated upon the superior aspect of head, are very small, and each possess a yellowish iris. 
The general hue of the animal is blackish, relieved by a number of lighter spots, some of them having a reddish tinge. Lateral line double, one passing near the median line of back,-in other in line with the anal fin. Pectoral fins small, anal fin long, caudal fin obtuse. (Blooch.)

Anatomy. The abdominal cavity is short; anus placed a short distance behind branchial cleft. The electrical organs occupy nearly one-third of its whole bulk. They are formed by two series of tendinous membranes, one of which consists of horizontal plates running from the abdominal cavity towards the tail, placed one above another, with short distances between them ; the other of perpendicular plates, forming, along with the other series, small quadrangular cells, which are filled with a semi-gelatinous transparent substance. This structure is divided longitudinally into two pairs of distinct organs, one considerably larger than the other. The greater pair lies above the other, and immediately beneath the long muscle of the tail. They are separated from one another by part of these muscles, by the air bladder, and by a central membranous partition. They occupy a large portion of the lower and lateral parts of the body, and are covered externally only by the common integuments. The smaller pair are covered also by the muscles of the caudal fin. Both pairs of organs are somewhat angular in their transverse section, truncated anteriorly, tapering towards the tail. In a Gymnotus of average length the larger organ of one side is about one inch and one-quarter in breadth at its thickest part, and in this space there are thirtyfour longitudinal septa. The smaller organ is about half an inch in breadth, and contains fourteen septa, which are slightly waved. These septa probably answer the same purpose as the columns in Torpedo.

The nerves of the electrical organs are derived from the spinal marrow alone. They are large, numerous, and divided into fine twigs on the cells of the organs. (Coldstream.)

Measurements. $-5^{\prime}$ to $5^{\prime} 3^{\prime \prime}$ long.

Habitat.-Amazon River, S. A.

Malapterurus electricus (raasch, thunder-fish). - This fish belongs to the Siluridæ (cat-fishes).

Malapterurus.-Only one dorsal fin, which is adipose, and situated before the caudal ; anal of moderate length, or short; caudal rounded; ventrals six-rayed, inserted somewhat behind the middle of the body; pectorals without pungent spine. Barbels six ; one to each maxillary, and two on each side of the mandible. Both jaws with bands of villiform teeth; palate edentulous. The entire head and body covered with soft skin. Eyes small. Gill opening very narrow, reduced to a slit before the pectoral. An electric organ extends over the whole body, and is situated between two aponeurotic membranes below the external integument.

M. electricus.-Description. Rays to anal fin 10-13. Eye rather small, the diameter being less than one-third its distance from the upper end of the gill opening. The length of the head is contained four times and a third in 
the total (without caudal). Jaws equal in front. The outer mandibulary barbels extend to the root of the pectoral Body with more or less numerous small roundish black spots, a part of which are sometimes confluent into larger irregular patches; anal and caudal fins with a white margin. Dorsal vertebræ 17 ; candal 22.

Habitat. - Nile, and rivers of the west coast of Africa.

The only organ that can be regarded as connected with the electrical function in this fish is a thick layer of dense connective tissue which completely surrounds the body immediately beneath the integument. So compact is it that, at first sight, it night be mistaken for a deposit of fatty matter; but, under the microscope, it appears to be composed of tendinous fibres, closely interwoven, the meshes of which are filled with a gelatinous substance. This organ is divided by a strong aponeurotic membrane into two circular layers, one outer, lying immediately beneath the derm, the other internal, placed above the muscles. Both organs are isolated from the surrounding parts by a dense fascia, excepting where the nerves and bloodvessels enter. The cells or meshes in the outer organ, formed by its reticulated fibres, are rhombic in shape, and very minute, so as to require a lens to see them well. The component tissue of the inner organ is somewhat flaky, and also cellular.

The nerves of the outer organ are branches of the fifth pair, which runs beneath the lateral line and above the aponeurotic covering of the organ. This aponeurosis is pierced by many holes for the transmission of the nerves, which are lost within the cellular tissue of the organ. The intercostals supply the inner organ; their electrical branches are numerous and remarkably fipe. (Coldstream.)

M. Beninsis, M. Affinis.-Species closely resembling above. Habitat.Old Calabar. (Günther.)

Of the electrical power of Tetraodon electricus and Trichiurus electricus, as well as Scolopendra electrica, little is known.

Animal electricity presenting so many features in common with that derived from inorganic sources, was at one time believed to be identical with it. The idea originated with Galvani, who discovered that by bringing a current induced by placing two metallic plates-one of copper and the other of zinc-in contact with the nerve of a leg of a dead frog, contraction of its muscles ensued. (Galvanism.) He inferred from this that he had re-supplied the force removed by death, and that the nervous power and the agent he had employed were convertible. His opinion received apparent confirmation from the fact that all electrical organs

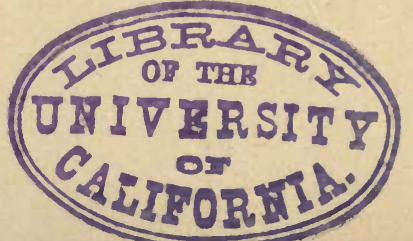


are largely supplied with nerves, as well as from the observation that portions of the brain (gray matter of cerebral hemispheres) and the terminal branches of certain nerves of sensation (Pacinian corpuscles, Wagnerian corpuscles, conjunctival corpuscles) resembled in construction electrical machines. But it was afterward found that nerve power could not take the place of an electrical current. A string tied round a nerve produces paralysis of motion beyond the obstructed point; but no ligature upon a metallic conductor can obstruct an electrical current. If the nerves going to a muscle be cut, the muscle is rendered incapable of contracting. If the nerves going to an electric organ be severed, the organ can no longer give out electric discharges. But if the dead organ be taken, electricity can be developed from it in the same manner as it can in an organic voltaic pile.

Animal electricity is essentially a life product.

ANIMAL PHOSPHORESCENCE.

Animal phosphorescence is confined to the Invertebrata.

The majority of phosphorescent animals are marine. Conspicuous among these forms is the Noctiluca miliaris. This is a small sub-rounded animal, about one-sixtieth of an inch in diameter, composed of a structureless and somewhat dense integument, and furnished with a long sub-cylindrical filiform tentacle. Mouth simple, situated upon under surface of body and behind tentacle; from its base a very delicate filament protrudes, which exhibits a rapid undulatory motion. In advance of mouth, and between it and tentacle, a horny-looking bifid ridge is present,- the so-called tooth. (Huxley.) Intestine and anus not determined. The 'nucleus' a strongly refracting oral body of about $\frac{1}{460}$ inch in length. By some considered a radiate, Noctiluca is more properly classified with the Protozoa.

Among other animals possessing this property are many cœlenterate radiates, and some echinoderms; Salpa and Pyrosoma among molluses; and various Infusoria, Annelida, and Crustacea. Among light-bearing terrestrial forms may be 
mentioned the Pyrophorus luminosus (cucujo), a large beetle of Cuba; Lampyris noctiluca (English glow-worm); Photinus scintillans (small firefly, lightning bug); Photuris pennsylvanica (large firefly); and Scolopendra electrica (electrical centipede).

\section{XIII.}

\section{SPECIAL ORGANS.}

A sPectal organ is one subservient to a function ordinarily not essential to the economy of the individual. It may be of a peculiar structure, or consist of modifications of a kind already existing. Of the first an example is found in ink-gland of Sepia (cuttlefish); of the second, in venomgland of Caudisona (rattlesnake).

A special organ may have a sexual significance (see p. 102), but more commonly is intended for purposes of offense and defense.

When a special organ is designed exclusively for reception of external impressions, it is called a SENSE CAPSULE. In its simplest expression a sense capsule is a chamber having connection on one side with a nervous filament. It follows that among the lowest animals no sense capsules are found. But at the earliest point where differentiation of function occurs and organ-making begins, they not infrequently attain to proportions and degrees of development far in advance of other apparatuses.--Such special organs stand in exacter relation to habit, and particularly to the medium in which the animal lives, than to its zoological position. Thus in the higher Cephalopoda the shelled Nautilus has an eye of much simpler construction than its naked congener, the Sepia. In Talpa (mole), living under ground, the eye is rudimentary or absent; but its near associates, living above ground, have it fully developed.-There is a power, however, apart from influence of surroundings, which controls the production of sense capsules, 
namely: the capacity for general development possessed by animals of a given type. In Radiata where this is small, the eye or ear are never seen to attain that degree of complexity secured by Articulata or Mollusca.

\section{LASSO CELLS.}

Affixed to tentacles of Physalia (Portuguese man-of-war), Cyanea, Eucoryne, Hydra, Astrangia, Actinia, etc. are peculiar cell-like structures, endowed with the property of exciting, on contact with a sentient surface, a prickling or stinging sensation.

The essential feature to a stinging apparatus is a filiferous capsule. This, within an oval or ovoidal cell, contains a spirally wound thread, or consists of smaller cells, each containing, in addition, a style extending from one pole to about the centre of the cell.*

\section{ORGANS OF TOUCH.}

ProtozoA. Parts specially designed for exercising the sense of touch do not exist, if the long lash-like appendages (flagella) to certain Infusoria be not excepted.

Radiata. Excluding the lasso cells, no organs of touch are met with in Cœlenterata. The tentacles are in part subservient to this purpose.

* Under circumstances not readily explained, the cells eject their contained threads with an astonishing degree of rapidity; in so doing the cells are absolutely turned inside out, and remain attached to the emptied cells as long extended tubes. From the smaller cells the style is also extruded, and then appears as a more expanded portion of the thread, with which it is continuous at one end and the capsule at the other. An attentive examination of the extruded thread exhibits a more complicated structure than would have been suspected, and its exact character is extremely difficult to ascertain. In the case of the larger capsules a spiral arrangement is readily distinguishable, extending the entire length of the extruded thread. This arrangement, in some instances, appeared to depend upon minute cilia which project at right angles from the thread and apparently pursue a spiral course; but in other instances it appears as if the thread, during its eversion of the capsule, assumed a spiral course within the portion preceding it, and that the thread externally was encircled at regular intervals with non-vibrating cilia. (Leidy.) 
Echinodermata.-In oral tentacles, ambulacra and pedicellariæ, the sense of touch partially resides.

Mollusca. The tentacles of Polyzoa and Brachiopoda, the papillæ on free edge of mantle of Lamellibranchiata, the conspicuous cephalic tentacles of Gasteropoda, Pteropoda, and Cephalopoda are doubtless of tactile significance.

Articulata. Organs of touch resident toward cephalic extremity. In Annelida processes of various forms and degrees of complexity are observed. They are generally inarticulated, though sometimes have distinct segments. In Crustacea, Myriapoda, and Insecta, in addition to palpi to certain parts of mouth, jointed processes to eephalic segments (antennæ) are present. (See p. 41.) In Arachnida antennæ are absent. Palpi rarely absent,-forficulate in certain scorpions, as Thelyphonus and Phrymus. Anterior feet in latter resemble antennæ both in construction and use.

Vertebrata. Pisces.-The tumid lips of many fishes and adjacent barbels are organs of touch. Special organs are in addition met with in the integument. Placed within a canal running beneath the 'lateral line' of osseous fishes, and extending thence to opercular and maxillary regions, are numbers of special sense organs. These consist of cellular structures appended to knob-like terminal filaments of the fifth or tenth pair of nerves.*

The Pacinian corpuscles are thought to be analogous to these tactile organs.

Batrachia and Reptilia.-Special organs of touch absent. Tongue generally protrusile and tactile.

Aves.-Sense of touch located in tongue and parts about the bill.

* Each knob is covered by a coat consisting of tiers of much elongated cylindrical cells. Its substance consists of more or less gelatinous connective tissue. In the osseous fishes this nerve usually perforates the peculiarly modified scale of the lateral line, which supports and encloses the canal at these points. In the cartilaginous fishes, the canals have sometimes special fibro-cartilaginous coats; or, if sacculi, a number of them may be contained in a common cartilaginous investment, as in the Chimera. Leydig insists, with great justice, on the identity of the structure of these organs with that of the semicircular canals of the ear. (Huxley.) 
Feathers are appendages to dermal papillæ. The feathersac or follicle is an involution of the integument, having at its base a modified tactile papilla. The derm constitutes the fibrous wall of the follicle, the elements of the epidermis comprising the root sheaths. These sheaths are two in number, an outer and inner. The former is placed in contact with the fibrous wall of follicle, the latter (first 'striated' membrane) with the developing feather. A second 'striated' membrane lines the shaft of the quill.-The bulb is a collection of cells surrounding the papilla, from which are developed the constituent parts of the feather.

Every feather is composed of an outer cortical and an inner medullary portion. It is divided into regions, as follows: vane (shaft, 'quill'), primary branches (barbs), which give off secondary branches (barbules)-these in turn originating tertiary branches (barbulinæ). In the majority of feathers the proximal part of the vane has its barbs and barbules long, loose, and floating, so as to form a compact downy mantle next the skin of the bird, to retain the high temperature of the body. In the rest of the vane the barbs are more firm, straight, regular, and united, to assist in flight, or to protect the body. (Grant.)

Mammalia.-Organs of touch highly developed. The tactile (Wagnerian) corpuscles upon terminal branches of nerves to the hand of man furnish marked examples.

Hairs are appendages to dermal papillæ. The hair sac or follicle closely resembles the feather follicle, but lacks the lining membrane to shaft; the latter possesses an additional covering - the cuticle. The cuticle on that portion of the hair which lies within the sac is composed of two layers. In man the outer layer ceases at the level of the sebaceous glands; and the edge of the plates of the inner layer lie very closely appressed to the shaft. In many of the lower animals, however, as in some bats, the plates are at a greater angle to the axis of the hair, and their projecting edges give rise to the most elegant sculpturing of its surface. (Huxley.) Although, wherever developed, hairs are considered as organs of special sense, it is particularly about the 
snout that they are employed in exercising the sense of touch, as in whiskers (vibrissæ) of many quadrupeds.

\section{ORGANS OF SMELLING.}

Many Invertebrata possess the sense of smell; but with them no organs have been definitely assigned the function.*

Vertebrata. Pisces. - The nasal capsules, two in number, are placed one upon either side, on periphery of body, commonly at a point midway between the eye and snout. Each consists of a depressed rounded chamber, lined with a very vascular plicated membrane, and in some cartilaginous forms covered with ciliated epithelium. Nose rarely communicates with palate. $\dagger$

Batrachia and Reptilia.-Nasal apparatus, in common with all Vertebrata above fishes, is contained within a diverticulum from respiratory canal. In Proteus the peripheral portion is plicated, as in fishes, but opens upon palate, behind upper lip. Region of turbinated bone cartilaginous. With others, olfactory nerves are distributed upon the mucous membrane lining the anterior portion of the 'girdle bone;' and are separated from one another by a median partition. In Crocodilia the anterior nares may be closed by muscular action. In Ophidia, turbinated bones rudinentary; nasal glands present.

Aves.-Anterior and posterior nares well defined; latter often unite to form a single opening, covered with protecting papillæ. The turbinated bones are larger than in reptiles, though the convoluted portion of the ethmoid is yet but partially ossified. Conspicuous nasal glands constantly present.

* To the antennæ of insects have been assigned the double function of smell and hearing. There can be very little doubt that the former sense is so situated, and, by the diversity of form of the small fossits seen, it is possible that those of a larger size and greater depth pertain to hearing. (Horn.)

$\dagger$ There is great reason to believe that, suited to their surrounding element, the nasal capsules of fishes are much more sensible of odorous bodies dissolved in water, and applied by its medium, than we should be if the application of the object was to be made to our organ of smell by the same medium. (Monro.) 
Mammalia.-Nasal cavities complicated by sinuses occupying superior maxilla, sphenoid and frontal bones; ethmoidal scrolls greatly developed. Turbinated bone long and comparatively simple in Ruminantia, but elaborately convoluted in many Carnivora. Exterior openings of nostrils valvular in diving animals, as in Castor (beaver). The space including the nostrils, when not prolonged beyond the lips, is called the muzzle; when moderately extended, the snout, as in Sus (hog); when conspicuously developed, the proboscis, as in Elephas (elephant).

EYE.

The eye is the organ of vision. To adapt itself to the function of receiving upon a nervous expansion a series of external images or diffused rays of light, the anterior portion of the capsule is transparent, convex, and very generally placed upon the periphery of the body. The wall of the capsule is the sclerotica; its anterior arc, the cornea; the liquid contents, the humors; the nervous expansion, the retina; and the nerve filament, the optic nerve. These characters are essential to an eye. Accessories both within and without the organ add to its complexity. Eyes may be single, agglomerate, or compound.

In the lowest animals the essential features of eye and ear resemble one another so intimately that it is with difficulty that the organs are distinguished. As a rule, the constantly vibratile action sustained by the otolithes may serve to identify an ear, since the analogous body in the eye (crystalline lens) is more fixed.

Protozoa. Eyes wanting.

Radiata. Many radiate animals possess capsules upon the edges of the body, as in Aurelia (jelly-tish), or near tentacles, as in Syncoryne. Immediately behind the corneal portion, and within the chamber, are occasionally lodged movable polygonal crystals of carbonate of lime (crystalline lens), which are generally of a red color.

Mollusca. Polyzoa and Brachiopoda.-Eyes wanting. 
Tunicata.-With Ascidians eight pigment- or eye-specks (ocelli) have been detected at the entrance of the respiratory tube; and six of a deep yellow color at the entrance of the anal tube. (Owen.)

Lamellibranchiata.-Eyes often numerous. Each possesses a highly refractive crystalline lens, and a pigment lining (choroid coat) forming an iris anteriorly. They may be situated along the margin of mantle, or, as in burrowing forms, around the orifices of the breathing tubes.

Gasteropoda.-Eyes, when present, two in number, situated at the extremities of tentacles in fresh-water and pulmonate forms, -at the outer side of base in marine. In the latter case they are fixed, but in the former can be protruded and protracted at will. A conspicuous optic nerve traverses each tentacle. The crystalline lens often lenticular, and vitreous humor viscid. Eye particularly conspicuous in Strombus, Natica, and Bulla. Janthina is without eyes. In Strombus a sclerotic coat, choroid, iris, crystalline lens, and cornea are present.

Cephalopoda.-The Tetrabranchiata, as in Nautilus, have small sub-hemispherical eyes placed upon pedicles, and are probably without crystalline lens. - In Dibranchiata, as in Sepia, the eye is singularly complex. Within an orbit formed in great part by the integument, the bottom of the cavity alone being cartilaginous, is placed the eyeball covered anteriorly by the skin. This is very thin and transparent where it extends in front of the eye, to assume the function of a cornea. The sclerotic coat is incomplete in front, and perforate behind through numerous openings for the passage of branches of the optic nerve. The second tunic, the retina, is thick, and extends forward in a remarkable manner to the anterior portion of the eye where it appears to hold the crystalline lens in position. The pigment layer (choroid coat) is apparently placed within the retinal layer. In this anomalous position it is difficult to understand how rays of light can pass through the pigment layer to be received upon the optic expansion. With some cuttlefishes a granular nerve-like layer has been recognized mithin the pigmental layer which has 
received the name of the 'pre-pigmental retina,' though no connection between it and the optic nerve has been demonstrated. The crystalline lens is unique in being divided transversely into two parts-an anterior and a posterior-between which a fold of choroid membrane is inserted. The posterior segment is much larger than the anterior, and projects backward into the interior of the eye.-At the posterior part of the orbit a closed cavity is limited in front by the eyeball, and behind by a layer of the sclerotica, which, extending backward, encloses the terminal portion of the optic nerve and a gangliform enlargement upon its trunk.-Between the globe of the eye and cornea is seen a chamber resembling a serous cavity, but which communicates with the external medium by a minute central opening. Its lining membrane is analogous to that of a conjunctival surface.

Articulata. Annelida.-Simple eyes not unfrequent in the dorsibranchiates. For eyes of Hirudo (leech), see p. 159. Remarkably large form in Torrea.

Crustacea.-Eyes agglomerate and extremely brilliant in Daphne. To a mass of ocelli, often chiefly composed of pyriform lenses, a single cornea is found. Compound aggregated eye, either sessile or pedunculated, seen in Decapoda, as Homarus (lobster). Fine illustrations of compound eye met with in extinct trilobites.

Cirripedia (barnacles) - Eyes multiple; remarkable for being concealed within abdomen-rays of light transmitted through the tissues.

Insecta.-Eyes single or compound, aggregated. When compound, each ocellus possesses a flattened cornea, a prismatic vitreous humor, and between the two a layer of variously-colored pigment matter. One optic nerve supplies all the ocelli of a mass, each ocellus being furnished with a distinct branch from the main trunk; the so-called 'retina' is an expansion of nerve-like substance between the secondary and terminal subdivisions of the nerve.

The ocelli in the majority of insects are arranged in two lateral masses, one on either side of the head, each mass being made up of large numbers of eyes. In Musca (house- 
fly), they are 400 in number; in Libellula, 12,000; in Mordellá, 25,088 .

Vertebrata. Pisces.-Eye compressed antero-posteriorly; sclerotica thick, sometimes bony, as in Cephaloptera (devilfish); crystalline lens globular; iris fixed; pupil in Anableps (star-gazer), double. Surrounding the entrance of the optic nerve into the eye of osseous fishes is seen a crescentic body, called the 'choroid gland.' It is not glandular, but erectile, being composed of congeries of blood-vessels. Its use is not certainly known. It may assist in accommodation, by pushing the retina forward during turgescence.-The eye of the fish is adapted to focusing through a dense medium under great pressure.

Reptilia.-General features of eye those of other air-breathing vertebrates. Certain extinct animals, as Ichthyosaurus, had a more complex sclerotica than any extant forms. It was composed of a number of distinct plates, by which the focusing distance could be regulated by muscular action. (See Aves.) Rudiments of this structure can be detected in the eyes of certain Chelonia and Sauria.-The Chameleon can 1) move eyes in opposite directions. Pupil, as a rule, fixed, slit-like.

Aves.-Most peculiar feature witnessed in rapacious bird, where the sclerotic coat is composed of a number of plates arranged in the long diameter of the organ, capable, by mutual compression, of elongating, or, by relaxation, of shortening the axis of the organ. By this means an object of prey can be distinguished at a great distance while it is equally visible at the moment it is seized. Within the choroid tunic a peculiar body, called from its appearance the pecten, is situated: it is a fold of the choroid, and is often attached to the capsule of the lens. Its function is unknown.

Mammalia.-Eye closely resembles that of man. Is slightly compressed antero-posteriorly (as in fishes) in certain aquatic animals, as in Phoca (seal). Eye rudimentary in Talpa (mole). Appendages to eye.-Conjunctiva well defined, excepting in fishes, where it is rudimental and yields no secretion.

In Reptilia lachrymal gland makes its appearance for the 
first time; eyelids without cilia. Third eyelid (nictitating membrane) present both in reptiles and birds. This structure is a transparent elastic membrane, which while at rest lies folded up at inner side of eyeball. It is moved across the front of the eye by appropriate muscles situated at the back of the organ. These muscles are two in number, and are named from their shapes the quadrate and pyramidal muscles. "The first of these arises from the sclerotica at the upper and back part of the globe of the eye, and its fibres slightly converge as they descend toward the optic nerve, above which they terminate in a semilunar tendinous sheath having no expressed or fixed insertion. The pyramidal muscle arises from the sclerotica, from the lower and nasal side of the eyeball; its fibres converge as they pass to the upper side of the optic nerve, and there terminate in a small round tendon, which glides through the pulley at the free margin of the quadratus, and winding round the optic nerve, passes along a cellular sheath at the lower part of the sclerotica, and is inserted into the lower part of the margin of the third eyelid, along which it is continued for some distance, and is gradually lost." (Owen.)

In birds an additional gland (gland of Harder) is placed upon inner surface of orbit, and furnishes a secretion resembling that from the Meibomian follicles of mammals. Mammals possess both lachrymal glands and Meibomian follicles.-Quadrupeds have two orbital muscles in addition to those seen in man, - a retractor and compressor.

EAR.

The ear is the organ of hearing. The auditory capsule (labyrinth) receives sonorous vibrations upon its anterior surface, and conveys them across the fluid contents to act upon the nervous expansion (acoustic nerve). The impression is intensified through the agency of one or more free motile sclerous particles (otolithes, otoconites, lapilli, ear-stones, eardust) almost constantly present.*

* These are wanting in Amphioxus and marsipobranchiate fishes. (Müller.) 
With the Invertebrata the peculiarities noticed in different animals are due to the position of the sac, as well as to the number and color of its otolithes. The motility of the latter is thought to be due to presence of cilia within the capsule. The organ is wanting below Radiata.

Radiata. In Medusa the ears are numerous, and are placed. at regular intervals along the margin of the disk, each containing one or more refractile otolithes. In Geryonia the capsules are thicker, and contain red granules.

MoLLusca. In Tunicata function of hearing is assigned to a capsule containing calcareous bodies lying beneath the nerve mass. - In Lamellibranchiata the ear is placed near foot, when present. The capsule is elastic, opaque, tenacious, and contains a circular commonly motile otolithe.-In Gasteropoda the ears (two in number) are often situated upon periphery of body at the sides and beneath the œesophageal ring, less frequently above it. The otolithes, as a rule, are numerous, motile, and composed of carbonate of lime.-In Cephalopoda the ear-chambers (two in number) are lodged in the lower middle portion of the cephalic cartilage, where they form two more or less large, rounded cavities, separated by a cartilaginous septum, and without any external communication. (Siebold.) Each chamber holds in relation to its walls, by delicate fibrous threads, an otic capsule containing a soft calcareous otolithe.

Articulata. Annelida, in Torrea, possess distinct auditory capsules.-In Crustacea and Insecta the organ, as a rule, is appended to the basal segment of one of the anterior extremities. The capsule may be completely enclosed within the calcareous walls of the segment, as in Lucifer; or the anterior portion of the capsule may be exposed, as in Crustacea and Insecta generally. In Homarus (lobster) the membrane is open, and permits siliceous particles to enter from without to assume the functions of otolithes. They rest upon a number of hair-like points fixed to the bottom of the sac. In Palcomon anterior membranous portion of sac is fissured; and the single ovoidal otolithe rests upon the extremities of hair-like processes projecting from basal surface of capsule. 
Vertebrata. Organ divided for convenience into internal, middle, and external ears.

The internal ear (labyrinth) is the true otic capsule, and corresponds to the ear of Invertebrata. It is constantly divided into vestibule (sacculus) and semicircular canals; and in all Vertebrata above cartilaginous fishes is enclosed in an osseous case composed of three bones, named pro-otic, epiotic, and opisthotic. It may be entirely closed, as in fishes and perennibranchiate batrachians, or present a single orifice anteriorly (fenestra oralis), which may be occupied by end of - columnella, or stapes. When the cochlea (which is recognized as a modified semicircular canal) is added, a second opening (fenestra rotundum) is seen, which is covered by membrane. Otolithic contents commonly present.-The middle ear (cavity of tympanum) is a chamber placed in advance of otic capsule, and defined within by its anterior portion, without by the tympanic membrane. It is lined with mucous membrane, communicates with pharynx through Eustachian tube, and is traversed by a single bone (Batrachia, Reptilia, and Aves), or a chain of bones (Mammalia).-The external ear is all that portion beyond the middle ear. It is divided into an external auditory canal (meatus) and an auricle (conch).

Pisces.-In Amphioxus and marsipobranchiate fishes, ear enclosed within cranial walls; semicircular canals two in number, not distinct; otolithes absent. In Myxine the capsule is a single circular canal. In Raidæ, auditory sac, embedded in walls of cranium, communicates with the exterior by several openings, and contains a quantity of gritty matter; otolithes less dense than in osseous fishes.-In osseous tishes the ear is enclosed in a bony envelope. The semicircular canals are always three in number. The main body of capsule (vestibule) contains a large otolithe nearly filling the chamber: no communication seen with either pharynx or integument. With some fishes the labyrinth is extended by a portion which unites with that of the opposite side, and afterward, on the outside of the occiput, to terminate in a chamber on the first vertebra. Here, by means of a small 
chain of bones, it is brought in connection with the swim bladder, so that by this arrangement the intensity of the vibrations of sound is augmented. In other osseous fishes, as in Cottus, the swim bladder extends, without such a chain of bones, to membranous spaces in cranium which are in connection with the auditory apparatus. (Van der Hoeven.)

Batrachia.-Internal ear based upon same plan as in Pisces; vestibule, however, is proportionately smaller. In Proteus (perennibranchiate) it is imperfectly, but in Rana (caducibranchiate) completely embedded in otic bones. Otolithes granular. Middle ear absent in aquatic types, as in Proteus; rudimentary in others. Generally remote, the mouths of Eustachian tubes sometimes unite in middle of palate. Tympanic ossicle (columnella) single. Tympanic membrane on side of head in Rana.

Reptilia.-Internal ear completely enclosed within otic bones. Cochlea present,-rudimentary, slightly curved, not divided by internal lamina (scala) except in Crocodilia. Otolithes in Ophidia dense,-in Chelonia and Sauria softer.Middle ear larger in Sauria than Ophidia; traversed by columnella, and covered externally by a thin, transparent, naked membranous continuation of the skin placed on a level with general surface of head, or slightly projected, as in Crocodilia. (Grant.) In Ophidia the tympanic membrane is covered by skin and muscles.

Aves.-Internal ear with narrow vestibule; cochlea curved, and, assuming the form of the spiral, is divided internally by lamina. Semicircular canals long and narrow in rapacious birds, large and wide in singing birds. Otolithes small.-Middle ear traversed by columnella and vidian nerve. Eustachian tubes commonly unite before they open into posterior nares. Walls of cavity pierced by several foramina which lead to large cells between two tables of skull.-External ear present in most birds in the form of a crescentic fold of skin extending upward from the superior margin of the external meatus. (Grant.)

Mammalia.-Internal ear with vestibule comparatively small. Cochlea, excepting in Ornithorhynchus (duck-bill), 
where it resembles that of the bird, is a large heliciform chamber abundantly supplied with filaments of the acoustic nerve, and divided longitudinally by a solid lamina. Otolithes granular.-Middle ear traversed by chain of bones called, from within outwards, stapes, incus, and maleus. The vidian nerve escapes through tympanum, as in Aves. Communication with diploe is seen in the openings between the middle of the ear and mastoid process.

The temporal bone of mammals is divided into three portions-squamous, mastoid, and petrous-and is usually described as arising from six centres of ossification: squamous, tympanic, zygomatic, styloid, mastoid, and petrous. But the petrous portion in reality arises from two distinct centres of ossification (opisthotic and pro-otic), the mastoid (epi-otic) in part only from one.

In the human skull the petrous portion of the bone, as thus formed, is a very complicated adjustment of bony elements, viz.: an inferior opisthotic bone containing the lower part of cochlea, and a superior, pro-otic, sheltering the greater part of the vestibule, the upper part of the cochlea, the anterior vertical semicircular canal, part of the posterior vertical canal, and the external semicircular canal. (Huxley.) The epi-otic is confined entirely to the mastoid process.*

Monotremata.-Cochlea smaller than in other mammals; semicircular canals relatively large. Tympanic ossicles anchylosed, resembling columnella of reptiles and birds. In Echidna (porcupine anteater) external auditory canal long and wavy.

Marsupialia.-The middle ear often extends into petrous portion of temporal and body of sphenoid bones.

Rodentia.-Bony portion of external auditory canal often extended, and directed backwards, as in Lepus (hare).

* Although in man the tympanic bone becomes early united with the squamous, it remains separate from it in many of the lower animals; in some of these, as in Cetacea, it is joined to the petrous and mastoid, and forms, with them and the styloid, a bone which continues distinct from the squamous. The mastoid portion remains quite separate in some animals, and occasionally, though very rarely, in the human skull. (Humphrey.) 
Cetacea. - Tympanic membrane plicated. External auditory canal long, narrow, flexible.

Carnivora, Insectivora, and Cheiroptera.-External auditory canal apt to be inflated at base, forming a conspicuous convexity beneath on base of skull. The remainder of canal is membranous.

Quadrumana.-The external auditory canal entirely membranous in New World monkeys.

Auricle or external ear is absent in Cetacea, rudimentary in Phoca (seal), and is rudimentary generally in aquatic animals, as Lutra (otter), or in certain burrowers, as Talpa (mole). With terrestrial mammals it attains its greatest development. Commonly employed in collecting ærial vibrations, it at times serves as an organ of touch, as in Corynorhinus.

\section{XIV.}

\section{SEXUAL OHARAOTERS.}

THE reproductive function profoundly modifies the nutritive processes of the organism. The results of such modifications furnish the basis for sexual characters. In the higher animals the sexes can be separated by organs of generation constantly present. The tout ensemble of sexual characters here pertain less to the organs than to the influence exerted by them upon the whole economy. But in many lower animals the power thus exerted by the organs over the general appearance of the animal is less evident, and with some it is entirely absent. With the cœlenterate radiates, for example, sex can be distinguished only by the increased growth of the organs during periods of procreation. Indeed, in Hydra the organs do not appear at any other time.

Sexual characters are general and special. (1) General characters are those maintained throughout life, and are best 
pronounced at maturity. (2) Special characters are those peculiar to times of procreation and rearing of young.

(1) Size. - With Invertebrata the female is the larger; with the Vertebrata the reverse is true as a rule. In species where the female carries large numbers of eggs within her tissues, either preparatory to ovi-position or throughout development, their accommodation and support necessitate extensive growth and active nutrition. Such females are always larger than the eorresponding males. Examples are found in many nematoid Entozoa, some rotifers, as in Asplanchna, in Argonauta (paper nautilus), and in many insects, as particularly seen in Termes (termite ant).*

Special organs.-Special organs may be divided into those (a) for the attraction of the opposite sex, such as luminous organs of Photinus scintillans (small firefly); vibratory, stridulous organs, as in Gryllus (cricket), where certain nervules of the anterior wings rasp against one another; or, as in Cicada (American locust), where a cavity placed upon either side of the last thoracic segment is covered in by a tympanic membrane which is rendered tense and vibratory by muscular action; (b) for retention of the female in coitus, such as the claspers in Squalus (shark), where they are placed one on either side of the position of the genital pores;-or in the sternal plates and finger-like appendages to front feet, as in a genus of Batrachia (Cystignathus); (c) other characters, as spur of Gallus (cock), and Ornithorhynchus (duck-bill).-Peculiarities of existing structures, as seen in growth of hair on pubes and face (man), - on neck (liou); - or in modifications of voice due to changes not fully appreciated.

(2) Increased functional activity:-as in pigment cells of ovaries of Toxopneustes (sea-urchin),-in color of fins in Cyprinoid fishes, $\hat{\delta},-$ in plumage and wattles of birds, $\delta$ $\$:-$ as in secretion of the cervical gland of Crocodile, $\hat{\delta},-$ sebaceous gland of penis of Anser (goose), $\hat{\delta},-$ labial gland of Camelus (camel), 5 ; - testicles and ovaries of Aves,-and in the 'moult-

* In some animals, as certain Cynipida (gallelies), and some entomostracan crustaceans, the male is unknown. 
ing' of feathers:-in increase of size of mammæ, $?:-$ in periodic discharge of ova, as in Vertebrata (egg-laying reptiles and birds),-or accompanied with turgescence of organs of generation (mammalia). - Structural changes:-as swollen shell for protection of eggs, Unio (mussel), ; ; -in development of sculptured capsule for eggs, Argonauta (paper nautilus) ; in webbed foot and dorsal fold of Salamander, 5; -iu the greater development of thumb of Rana (frog), $\delta$; in the growth of antlers, Cervus (deer) $\delta$;-changes in larynx in certain birds producing song, $\widehat{\jmath}$.

\section{XV.}

\section{REPRODUCTIVE SYSTEM.}

The reproductive system is composed of the organs of generation, and is devoted to the development and retention of the sexual elements. These are sperm cell and ovum.

\section{SPERM CELL.}

Enclosed within the sperm cell are very generally a number of other cells (daughter cells, vesicles of evolution), within which, in turn, spermatozoa (spermatic filaments) are developed. Each spermatozoon, as a rule, is formed in the same vesicle of evolution with many others, though occasionally singly, as in nematoid Entozoa. Very generally the result of an obscure transformation of the contents of the daughter cell, the spermatozoon may be a modified nucleus,_-or less frequently the transformed cell itself, as in decapod crustaceans.

The forms of spermatozoa are exceedingly various'. The principal ones are as follows: slender filament, with ovoidal expansion at one extremity; this expansion oval, acuminate, as in man; flat and obtuse in Sciurus (squirrel); sickleshape, as in Mus (rat); pyriform, as in Canis (dog); verm- 
iform, with fine hair-like tail, as in Aves and Reptilia; staff-shaped expansion, with short filament often coiled upon itself, as in Batrachia generally; globular, as in osseous fishes; vermiform, as in marsipobranchiate, elasmobranchiate fishes, and cephalopodous molluscs; - and acuminate-oval with long filament, as in Helix (snail), with short cylindrical or pyriform fibres, as in Unio (mussel). In Nepa the expansion is slight, and filament long,-cylindrical in Epeira (spider),-pyramidal, with concave sides in Julus, - or of a grotesque shape, with central body and radiatory filaments, as in Homarus (lobster), and other decapod crustaceans. In Oniscus (pillbug), the spermatic filaments are large enough to be seen by the naked eye.-The quantity is at all times greatly in excess of the number of eggs actually impregnated. It is estimated that in a drachm of human semen more spermatic filaments are contained than there are people in the world.

\section{OVUM.}

The ovum (egg) is the product of parental sexual generation from which the young of animals are produced. (Thomson.)

The simplest expression of the egg is a sphere with faintly granular contents, as in Stentor. It may present two concentric spheres, as in Laomedea; or in the higher animals, as most molluscs, articulates and vertebrates, three concentric spheres, called after their position from within outward, nucleolus,-germinal spot (nucleus, Wagnerian vesicle),-and germinal vesicle (germ cell, vesicle of Purkinje).

Every egg is composed of an albuminous and oleaginous substance. The first of these is on the side of the ovum with the germinal spot and vesicle, which is hence called the germinal area; the second is upon the opposite side, and is known as the yolk (vitellus). Ordinarily the yolk is formed with germinal vesicle in ovary, but in Holothuria (sea-cucumber) and in certain Entozoa (q.v.) distinct appendages (yolk glands) to the oviduct are reserved for this purpose.

The egg becomes impregnated by the entrance of one or 
more spermatozoa. These may be lost within investing membrane, or gain access to the germinative area through a special opening (micropyle).

The first evidences of impregnation are disappearance of the germinal vesicle and spot, when present,* and the segmentation of the vitellus, forming the mulberry mass. Segmentation may be partial, as in Aves, or complete, as in Annelides.

The unsegmented yolk is designed for the nourishment of the embryo during incubation, and bears fixed relations to the conditions surrounding the impregnated egg and to the time occupied in the evolution of the embryo. Where ova are retained in connection with, and are nourished through the tissues of the mother (gestation), as in Mammalia, or where they are early discharged from the mother, and development to a self-supporting stage proceeds rapidly, as in Protozoa, Radiata, Entozoa, and most Mollusca, little or no vitellus is required. Such examples compose the first group of eggs, characterized as follows: Eggs, for the most part of small size, often very minute; the yolk substance entirely composed of elementary granules or minute and simple spherules; the process of segmentation affecting the whole mass of the yolk, and the germinal layer, resulting from that segmentation, extending from the first over the whole surface of the ovum. The whole yolk is germinal, or converted into the parts of the future embryo.-In the second group, the great majority of which are oviparous, the ova are proportionately of the largest size. The yolk substance consists very obviously of two kinds of organized particles, viz., of small granules, nearly similar to those which form the whole yolk in the last group, and which alone undergo segmentation, large cells, usually non-nucleated, and fat vesicles, which constitute the greater part of the mass. The first of these enter into the germinative area, the second-the part making up the great bulk of the egg-is strictly nutri-

* Rarely the germinal spot and vesicle are not lost after conception, but the germinal vesicle itself undergoes segmentation, as in Ascaris mystax. (Nelson.) 
tive. Such eggrs are met with in Ares, Reptilia, cartilaginous fishes, and perhaps also in Cephalopoda and a few other invertebrates.-In the third group, the yolk is of medium size and composed of two kinds of granules. But the nutritive are but few in number and are subject to considerable variety; the greater part of the mass undergoing segmentation. Within this group are included the eggs of osseous fishes, Batrachia, the higher Crustacea, Arachnida and Insecta. (Thomson.)

The egg is generally spherical, though occasionally oval, as in Sepia. The shell is commonly smooth, as in Vertebrata, but may present many curious tubercular, fringed or spinous processes, as in Insecta. In Polyzoa the egg is often furnished with bifid hooks, as in Plumatella.

The investing membrane of egg is termed the chorion. It may be shaggy, as in Mammalia, or smooth, as in all others. In eggs of the second group the chorion (membrana putaminis) is divided into two layers, the outer one lining the shell, the inner one enclosing the albumen (white of egg). At the 'butt' of the egg the two layers are wide apart, constituting the 'air chamber.' Within the albumen a chalaziferous membrane is found-forming the 'chalaza'-upon either pole of the vitellus. Immediately surrounding the vitellus is a diaphanous vitelline membrane. The ' $\mathrm{egg}$ shell' may be composed of carbonate of lime, as in certain Entozoa, Helix, and oviparous vertebrates; or one of various kinds of coriaceous and chitinous structures.

The number of eggs varies greatly in different animals. As a rule, it bears a direct proportion to the risks attending development. Where the ova are well protected during gestation, as in the placental mammal, a few only escape at a time, and with many animals, as the human female, the number is restricted to one. With aquatic forms, on the other hand, the eggs may lie unprotected during gestation. Great numbers are, in consequence, consumed by carnivorous animals, become infected with parasites, or may otherwise fail to attain 
maturity by the frequent modifications occurring in the accompanying conditions of life. Were no provision made for these inevitable losses, species so propagating would be in danger of extinction; a result, however, ordinarily precluded by the enormous number of eggs deposited at each sexual period. It is estimated that at such times a single female cod will discharge from $4,000,000$ to $9,000,000$ eggs, Doris, 600,000 , and Gordius (hair-worm), 6,000,000. In Tonia (tapeworm), 200 eggs can be counted within each segment.

Eggs are disposed of in various ways. In F'ulgur (whelk) they are contained within disks,-composed of a hardened secretion from oviduct,-which are loosely connected longitudinally. In Sepia (cuttlefish), each of the clustered eggcapsules (marine grapes) contains from twenty to thirty ova. The capsules of Doris assume the form of long lace-like bands; those of Janthina that of a conoidal raft which remains attached to parent; those of elasmobranchiate fishes, quadrate, tray-like figures with long, prehensile tendrils pendent from angles. During development of eggs of oviparous forms, they are either set entirely free and remain unproteeted, as in most aquatic animals, or are covered by the female, as in the majority of birds. In the former case they may be agglutinated in an albuminous product of the oviduct, as in fresh-water Gasteropoda and Batrachia. In osseous fishes they are often cast into grooves in the sand (ridds). In Insecta they may be placed through ovipositors in localities where, during the larval condition, the most appropriate nourishment can be procured for the embryo, as in Apis (bee), or where the larva can best procure its own food, as in Cynips (gall-fly).

Eggs are often carried by parent, viz.: in the marginal pouches of discophorous Acalephæ (jelly-fishes),-between the gills of Unio (mussel), -within the peculiar shell of $A r$. gonauta (paper nautilus), - to the sides of entomostracan crustaceans, as Cyclops, - or beneath the tail segments of Homarus (lobster). They are at times secured to the skin of abdomen, each by a separate pedicle, as in Aspredo lociis 
(Surinam catfish), or Hylodes lineatus (Surinam frog). Entwined in a figure-of-eight coil around the hind legs, as in Alytes obstetricans, they may be contained within a large cutaneous dorsal fold opening posteriorly at coccyx, as in Osteocephalus. Among fishes they may be held in a pouch near anus, as in the male of Hippocampus (sea-horse), or in the mouth of the male of Bagrus.

The oviduct may retain the egg during a portion of the time required for development, as in Chelonia, implacental mammals, or during the whole of it, as in Paludina vivipara, Anableps, Ditrema argenteum, Blennius (blenny), the innocent serpents, and placental mammals. Such animals are called for convenience viviparous.

The placenta is a structure peculiar to placental mammals (see classification, and p. 134). Placenta-like structures seen in some nematoid Entozoa;-Salpa; Squalus (shark), and an osseous fish, Ditrema argenteun. In implacental mammals the embryo is discharged at an early stage of development to be attached to mammary gland within an inguinal pouch, as in Marsupialia, or, in absence of pouch, after a manner imperfectly understood, as in Monotremata.

The act of an egg at maturity escaping from the ovary is termed ovulation. The time of its occurrence varies in different animals. In a majority of species the act is repeated for a number of years consecutively, generally in the spring, in terrestrial animals, and frequently several times a year; most of the lower animals, however, lay eggs in the fall, or during winter. In others, on the contrary, it occurs but once during life, at the period of maturity, and the animal soon afterward dies. (Agassiz and Gould.) Ovulation is frequently accompanied with sexual excitement (see sexual characters, p. 102). In Mammalia it induces a determination of blood to the genital organs of the female, accompanied by sexual desire. This is termed 'rut' in the deer, boar, etc., and 'heat' with carnivores.* Phenomena of menstruation confined to Quadrumana and the human species.

\footnotetext{
* The heat belongs more properly to the female than to the male, as there are many species whose females receive the male only at particular seasons,
} 
ORGANS OF GENERATION.

Testicle.-A circumscribed collection of sperm cells is called a testicle. Its cells are free, as in Tethya, or arranged loosely to one another between folds of membrane-peritoneal or otherwise, as in most Radiata and marsipobranchiate fishes; or line either straight or convoluted follicles, as in most Mollusca, Articulata, and Vertebrata. In the first two groups the filaments are discharged adventitiously without duct, i.e. by bursting through capsule of organ. In the majority of the last they pass along a well-defined and commonly tortuous canal (vas deferens), which opens by an independent point (genital pore), as in cartilaginous fishes and most Invertebrata, or joins urethra near its termination, as in the majority of Vertebrata. The appendages to such a canal, when present, may be follicular (urethral), convoluted (vesiculæ seminales), racemose (prostate body and glands of Cowper).

Ovary.-A circumscribed collection of ova is called an ovary. It bears a marked external resemblance to testicle when cells are free, as in Tethya,-or loosely held together without oviduct between festoons of membrane, as in Radiata and marsipobranchiate fishes. The resemblance is less decided when the cells partially or entirely line the blind extremity of a tube, the contracted continuation of which forms the oviduct, as in majority of osseous fishes,- - or where the cells are supported by a distinct cellular or fibrous stroma distinct from oviduct, as in other Vertebrata. In Vertebrata each oviduct may unite with its fellow in median line, as in Mammalia, or continue to outlet separately, as in others.

When an organism possesses both sexual elements it is said to be hermaphroditic (bi-sexual, monœcious, androgynous), when one cell only unisexual (diœcious). Although

whilst the male is at all times fit for propagation. In others, constituting the majority of instances, the male organs are subject to the same periodical increase of activity as the female. The male in these animals is usually in heat at an earlier period thas the female. (Thomson.)

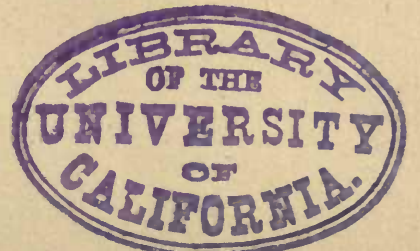


within every hermaphroditic animal two essential elements of generation are contained, few animals possess the power of self-impregnation. Such are Hydra, Holothuria, solitary Ascidians, and probably animals developing by encapsulation (q. v.).

The union of cell-products results in impregnation of ovum. This may occur outside the body, as in certain annelides, molluses, and fishes; or just within the mouth of the oviduct by adaptation of parts (coitus), as in the majority of animals. Coitus may be simply the contact of the mouths of the seminal and oviducts, or penetration of the latter by means of an intromittent organ (penis).

ProtozoA. Animals, so far as known, hermaphroditic. In Tethya spermatic filaments and ova lie side by side; no ducts. In Paramecium the 'nucleus' represents the ovary, the 'nucleolus' the testicle; no ducts. Reciprocal transmission of spermatic filaments takes place through the oral openings.

Radiata. The sexual organs resemble one another so closely that, excepting at times of procreation, they cannot be distinguished, and even then only by their minute structure. They may be developed in the indifferent tissue of body, as in Hydra, or appended to the inner edge of the body, as in Actinia. Their contents, as a rule, escape by the digestive cavity. Polypi may be hermaphroditic, as in Hydra, or unisexual, as in Actinia. In Acalephæ the genital organs are not developed, except at the time of procreation, and this period is very brief. The organs consist either of elongated pouches or ribbon-like bands, which are situated in different parts of the body. In the first, sperm and eggs escape through particular excretory canals; in the second, they escape directly outward from the ovaries or pass through large cavities which communicate. In Hydroida the organs are rarely found upon hydroid stock, as in Rhizogeton; more often they are arranged in the form of brilliantly-colored rays beneath umbrella-like expansion of medusa bud.

Echinodermata.-Generally unisexual. Holothuria and Synapta exceptions. In Toxopneustes (sea-urchin) the posi- 
tion of reproductive organs varies; each organ is composed of simple or branched tubes, with proper excretory ducts; these last are sometimes wanting, when the contents of the former escape by rupture, and, falling into the cavity of the body, pass out through the respiratory openings. (Siebold.) Copulatory organs absent. In Toxopneustes (seaurchin) the organs fill up the interspaces between rows of ambulacral vesicles. Holothuria is bi-sexual. The ovary is in the form of slender tubes floating freely in the cavity of the body, the efferent canal (oviduct) opens upon the back in the neighborhood of the mouth, below the osseous rings, between the tentacles. Peculiar appendages to oviduct seen in the form of so-called yelk glands. Male apparatus closely resembles the above. In Synapta the testes and ovaries are in one tube; the eggs become impregnated by being pressed against the sperm cells.

Moludsca. Polyzoa.-With the hermaphroditic Polyzoa a ribbon-like ovary and testicle are suspended from the extremity of the stomach. In these organs are developed only two to four eggs or fasciculi of spermatic particles from cells arranged like a string of pearls. (Siebold.) The sexual elements are probably voided through tentacles.

Brachiopoda.-In the unisexual Brachiopoda two pairs of ovaries and testicles are developed between mantle and the lining membrane of the venous sinus. The method of escape is unknown.

Tunicata-The Tunicata, excepting the solitary Ascidians and Salpa, are hermaphroditic. The former may be self-impregnating. The organs are situated between the branchial chamber and mantle.

Lamellibranchiata.-Rarely hermaphroditic, as in Cyclas. The male or female organ is placed in relation with the liver, and beneath the mantle. The oviduct empties in or about the renal sac. When the foot is largely developed, the testicle is commonly placed within the interior of the base, while the vas deferens, toward the base of foot when present, or near mouth, as in Ostrea (oyster). No copulatory organs.

Gasteropoda. - The Gasteropoda may be either herma- 
phroditic or unisexual. Of the former Helix (snail) is an example; of the latter, Paludina. A Fallopian tube passes from the ovary, commonly lodged in or near liver, to the uterine sac, at whose base lies an albumeniparous sac, while at the point where it is continuous with the vagina, a receptacle for semen is situated. The male genital organs consist of a testicle, a vas deferens and an ejaculatory duct, which may present a simple orifice, or open into a retractile penis often of great size. With the hermaphroditic species the two kinds of genital organs are more or less blended together,- the testicle with the ovum and the vas deferens with the Fallopian tube. Every folliculus is double, and within the external, which contains eggs, an internal is enclosed, the ova and sperm filaments thus lying in close juxtaposition. Very often, also, the vagina is united with the ejaculatory duct, forming a cloaca into which open several special secreting organs. Both male and female organs are usually lined with ciliated epithelium. (Siebold.) The genital pores may be upon the right or left side. Extraordinary appendages are seen to sexual organs in Helix (snail), consisting of a sac opening near the outlet, containing numbers of dart-like spiculæ which, under sexual excitement and immediately preceding coition, are successively ejected.

In Pteropoda the ovary and testicle are contained within the liver and appear to be a single organ. In Phyllirhoe, a genus of Heteropoda, the outer part of the single organ is the ovary, the inner the testicle. The ova and spermatic filaments mingle within, and impregnation occurs at the lower portion of the oviduct.-Penis of remarkable length in Clio.

Cephalopoda.-The ovary is enclosed in a loose capsule, into which from time to time the ova fall, to be conveyed thence through an oviduct emptying at base of funnel on left side of body near rectum. A glandular appendage furnishes accessories to the eggr. Placed upon ink-bag are two peculiar bodies (nudimental glanus) having a common outlet near the orifice of the oviduct. They yield an adhesive substance by which, after their expulsion, the eggs are fixed upon 
submerged objects.-The testicle resembles in general features the ovary. The gland is composed of numerous convergent cylinders; is enclosed in a loose membranous capsule from which emerges the slender tortuous vas deferens. The tube terminates in mantle near rectum, a small intromittent organ protruding. The canal at lower portion is of varying degrees of thickness. A single conspicuous glandular body (prostate) and a muscular chamber (Needham's pouch) being appended.-This latter cavity is occupied by whitish filaments (spermatophores), each having an average length of half an inch. Each filament contains a convoluted tube occupying the greater part of the cavity, which is filled with spermatic particles and connected anteriorly to a solid cylindrical body continuous behind with a spiral ligament. This latter is enclosed within a thin sheath which is attached to the end of the sac. The escape of the sperm from this apparatus is effected during coition by the rupture of the anterior extremity of the filament, when the contents are forcibly ejected by the action of the spiral ligament.

In Argonauta (paper nautilus) the male organs are upon the same type as those already described, but the manner by which their product effects union with the female is peculiar. The spermatophore is lodged in the base of one of the arms, which, upon the former becoming charged with filaments, is spontaneously severed from its connections. It now receives the name of the Hectocotylus, and floats off in search of the female.

Articulata. Entozoa.-See p. 161.

Rotifera.-Organs simple. Ovary opens by oviduct into cloaca. Male organs unknown.

Annelida.-Genital apparatus of various forms. In Lumbricus (earthworm), which is hermaphroditic, the male and female organs resemble one another very closely. Their orifices are situated in pairs upon the ventral surface at the anterior extremity of the body, surrounded by a thickened circular fold of integument.- The capitobranchiates and dorsibranchiates are of distinct sexes. The organs 'which project from the ventral surface into the cavity of the body 
between the fasciculi of the cutaneous muscle, communicate with the general visceral cavity, the genital products escaping thence through openings between the feet. (Siebold.)

Crustacea - Generally unisexual; hermaphroditic forms are seen with Cirripedia.-Male and female organs, as a rule, resemble one another. Great variety witnessed in the detail of their arrangement in different families. The sexual elements are placed within simple tubes arranged bi-laterally, and with comparatively few exceptions, open upon ventral surface of animal by distinct pores. At the female genital pore a special glandular canal is occasionally met with; a receptacle for semen (spermatotheca) is rarely seen.-The male pore is commonly furnished with copulatory organs, in the form of stylets or canaliculi, which serve to transfer the sperm to the female. To these may be added the 'claspers,' which are more remotely placed. In Homarus (lobster), the genital pore in male is upon basal articulation of last pair of ambulatory feet; in other decapods the orifice is upon abdominal surface of last thoracic ring. Copulation is common.

Insecta.-Always unisexual. The genital organs are composed in general of two symmetrical ovaries or testicles, often intimately resembling one another, situated in the abdominal cavity, and of two oviducts or deferent canals, which unite in a common excretory duct opening back of the anus or in it, forming a cloaca. This duct has several double or single appendages of which one, with the female, serves as a seminal receptacle, or as a copulatory organ, while the others, in both sexes, are true secretory organs.-In the female the vagina is often prolonged into an ovipositor. This may be composed of segments which can be drawn within one another, as in Diptera (fly); or protected by two valvular projections which appear to prolong the body posteriorly, as in Locustæ (grasshopper); or long, stout, and employed as borer (tenebra), as in Cynipidæ (gallfly), slender and acuminate, and employed as sting (aculeus), as in Apidæ (bee).The same segment modified in the male constitutes the penis. It commonly opens on ventrum at about the ninth ring.The seminal receptacle is a double or single capsule of vari- 
able form and surrounded by a muscular layer. It opens into the vagina below the point of junction of the two oviducts, by means of a canal of variable length. The seminal vesicle is empty, except after copulation, when it always contains a multitude of spermatozoa moving very actively: these movements are kept up for a long period. The secretory glands, situated at the lower end of the vagina, consist of two rather long glandular tubes on each side of the vagina, into which they open, either directly or through two small special excretory ducts. They often have on their course two vesiculiform reservoirs. -- The male organs recall the general plan of the female. The vas deferens, ordinarily simple, may have at its lower extremity a vesicular dilatation (vesicula seminalis); at their point of junction on the ejaculatory duct there are usually two longer or shorter simple mucous glands, which secrete a quickly coagulating granular mucus, which serves, during the copulatory act, partly to fill and distend the copulatory bursa and partly to surround portions of the sperm, and thereby form spermatophores. (Siebold.) A variety of copulatory organs are seen, most generally modifications in last segment of abdomen or chitinous deposition in terminal portion of vas deferens, and often protruded through agency of complicated muscular apparatus.-With Libellula (dragon-fly), the opening is simple, being covered by two very small oval valves. The seminal vesicle is placed in a depression at the base of the abdomen. Under sexual excitement the male fills the vesicle (which, owing to the flexibility of the abdomen, is readily accomplished) and secures the female about the neck by the anal claspers. He remains passive during coition, which is accomplished by the female placing her genital pore in connection with that of the vesicle.

Arachnida.-Sexes distinct, except in Tardigrada. Ovaries or testicles double, blended together on the median line; they have two excretory ducts which open by a single pore at the base of abdomen or under the thorax. Rarely is there an ovipositor or penis as in Phalangidæ. Accessory glandules to the oviduct or vas deferens do not differ essentially from 
those of insects. Coition always occurs. Copulatory organ of male frequently complicated.*

Vertebrata. Pisces.-Ovaries (roe) generally double. Single in many cartilaginous fishes, and in Perca (perch). In Amphioxus, Anguilla (eel), and Salmo (salmon), the ovaries are without oviducts. They are either 'adherent by one side to the walls of the abdominal cavity,' or engaged within loose festoons of the peritoneum. The eggs are discharged into abdominal cavity, in all probability, to escape by minute pores placed one on either side of the median line immediately behind the anus. In marsipobranchiate fishes and Acipenser (sturgeon) the eggs, after escape, are received into short incomplete oviduct. In Selachia the ovaries are placed at the anterior portion of abdomen, and are distinct from oviduct. The latter is dilated at its inferior portion into a longitudinally plicated chamber, which is analogous to a uterus. A somewhat similar dilatation is met with in Blennius vivaparus and Anableps.-In osseous fishes the ovaries, which are relatively of great size, are more defined, and enclosed within a capsule. They communicate directly with the oviducts, so that the eggs may be said to be discharged internally, thereby differing from all other vertebrates. The oviducts may unite, as in Clupea (herring), or proceed separately to terminate at a common genital pore.

Between the external form of the testicle (milt) and ovaries of most fishes no prominent distinctions exist. The sperm cells are arranged within a cellular matrix and without seminal ducts, as in Amphioxus, marsipobranchiates, and Pleuronectes (flounder). The cells line terminal ends of coiled tubes, which often join the excretory duct, as in majority of

* "Spiders use their hollow, spoon-shaped palpi in copulation. These are filled with sperm and applied to the entrance of the vulva. For this purpose, the last article of the palpi, which is always hollow and much enlarged, contains a soft spiral body terminated by a curved, gutter-like, horny process. Besides this, there is an arched, horny filament, and several hooks, and other appendages of the most varied forms. These are protractile, and serve, some to seize the female, and others as conductors of the spern." (Siebold.) 
osseous fishes,-or they are arranged within chamber communicating by convergent seminal canal with a single tortuous duct, which pursues a zigzag course, to widen at its lower portion. It here receives the duct of its fellow, to finally terminate at a point just within the cloaca.-Penis small. Two conspicuous organs, composed of several segments of cartilage, are placed upon opposite sides of genital pores. They are termed claspers, and are employed in coition.

Batrachia.-The ovaries possess free opening into cavity of abdomen at upper portion of abdominal cavity. The oviduct tortuous, and in relation to the organ as in man, is often of great length. In Rana (frog) the lower portions of tubes dilate into a sac for temporary retention of eggs, to terminate in ureter. The testicles lie upon each side of spinal column upon the fore part of the kidneys. Penis none in Rana; rudimentary in Proteus.

Reptilia.-The ovaries, situated in the loins, are racemose, diffuse, and distinct from oviduct. The latter is, throughout greater portion of length, thickened with numerous follicular glandular appendages, and terminates in urethra immediately in front of the urinary bladder. The testicles are also in loins, and communicate with cloaca by a long flexuous vas deferens. Penis in Ophidia and Sauria is divided along its entire length. The two separate cavernous bodies imperforate and armed with spines. Organ prehensile as well as intromittent. It is penetrated by two canals that run through their long diameter from behind forwards to terminate blindly at the glans. In Chelonia and Crocodilia the cavernous bodies converge and in part unite. There is no production of urethra in the organ, a groove in median line serving for conduction of sperm. Spongy body absent. Erection is secured by muscular action.

Aves.-The ovary of left side is, as a rule, alone developed. Certain birds of prey have both. Originally the organ is flat, and marked with transverse folds. When distended by eggs in various degrees of development it assumes a racemose appearance. Each ovum is surrounded by a vascular ovisac (calyx), which, when mature, is pediculated, 
and disappears after expulsion of egg. The oviduct, when quiescent, is straight, but when the female is under sexual excitement, convoluted. After receiving various glandular appendages designed to secrete accessories to the eggs, it empties into the cloaca. Clitoris well developed in Struthio (ostrich).-The testicles, two in number, are placed at upper extremity of kidney. They vary in color, a shade of yellow being the prevailing hue. Vas deferens generally slightly convoluted, and empties into cloaca. Penis is an extraversion of mucous membrane having erectile tissue in its walls, as in Gallus (cock), or very long, convoluted, and grooved along dorsal surface, as in the Natatores.

Mammalia.-The ovaries are always two in number. Ornithorhynchus (duck-bill), right small and imperfect. Bodies oval, compressed; stroma rather dense, fibroid. In Implacentalia, the oviduct (Fallopian tube) expands at lower portion (uterus) in Monotremata, and afterwards abruptly contracts to open, in common with the urethra, with the fellow of opposite side in a wide passage (urogenital canal), which leads to a second chamber yet in advance, the vestibule. The rectum joins the vestibule at its inferior portion to form the cloaca.-In Marsupialia the oviducts, as they descend, enlarge to open by contracted papillated extremities into the vagina, which is peculiar in having a central pendulous chamber resembling a uterus (vaginal cul-de-sac), which may be large, as in Macropus (kangaroo), or small, as in Didelphis (opossum). From either side of this, at its upper part, two vaginal canals are given off, which, converging, empty into the urogenital canal below.

In Placentalia the two oviducts open into a median muscular cavity, the uterus. This is markedly prolonged at its angles (cornua) in majority of mammals-slightly cornuated in Quadrumana (monkeys), not at all in human female. Uterus opens into a second canal (vagina) which terminates externally, receiving near its verge the urethra. Clitoris, large in Quadrumana, and sometimes possesses a bone. Longitudinal septum occasionally present in vagina. A powerful sphincter vaginæ present in the bitch. 
The testicles are always two in number. In Monotremata, Elephas (elephant), Hyrax (daman), many edentates, and among carnivores, Lutra, (otter), Viverra, (civet), Phoca (seal), and all cetaceous animals, testicles are held in abdomen most generally close to the kidneys. In other mammals they are situated in the groin either concealed beneath the common integument or contained within a pendulous sac (scrotum), which commonly lies beneath the pubic bones, but in Marsupialia is lodged in the inguinal pouch in advance of the penis.-Vas deferens if tortuous, markedly plicated. Prostate gland commonly present; absent in Rodentia, with whom Cowper's glands are more than usually developed. The latter are of two pairs in Didelphis (opossum), three, in $M a$ cropus (kangaroo); large, and lie upon ischii in Erinaceus (hedge-hog), while in Herpestis the ducts are long, and empty into urethra near its extremity. Preputial glands are large in Fiber zibethicus (musk rat), and Castor fiber (beaver). Vesiculæ seminales absent in Marsupialia and Carnivora, and Cetacea; present in man, monkey, bat, shrew, hedge-hog, and elephant.-Penis. Cavernous bodies, with exception of Implacentalia, are attached to ischiatic bones,-the spongy bodies surrounding urethra. A bone often placed in septum between cavernous bodies; present in some Quadrumana, as in Gorilla, and in Carnivora, as in Ursus (bear). The cavernous bodies in Macropus (kangaroo) enclose the spongy body, the latter is also bifid at base and cleft at apex. This is either acuminate, as in Ruminantia,- - and Phocona (porpoise), or capitate. It is provided with spine-like processes in many Felidæ and Cava (guinea-pig); while it is large, irregularly cylindroid, with thickened base in Canis (dog). 


\section{XVI.}

\section{GENERATION,}

Generation is the production of offspring.

Six methods apparent. The first is true generation, the remaining five (agamic) may be considered its accessories.

(1) That of the egg.-This, so far as is known, is constant among animals, hence the aphorism "Omne vivum ex ovo." (Harvey.)

(2) Conjugation.-This is the result of union of two organisms apparently without intervention of sexual apparatus, as in Gregarinæ.

(3) Encapsulation.-This is the formation of a capsule within the parent tending to engross the area of the entire animal, from the changes within which a new being arises, as in Infusoria.

(4) Fissuration.-This is spontaneous division of parent; each half assuming the shape and properties of the original form, as in Infusoria.

(5) Gemmation.-This is the formation of buds (gemmæ), which after acquiring the characters of the stock from which they spring, may retain their connection with the parent, as in hydra buds of Eucope, or become detached-free gemmæ, as in Hydra. Buds may arise beneath the integument-the common way-or originate from the interior, forming curious ova-like masses, as in Aphis and Cecidomyia.

(6) Alternate Generation (larval generation, asexual generation, virgin generation, parthenogenesis, polymorphism, metagenesis). - When from a freed gemma one or more dissimilar forms arise, and when from these-constituting broods of sexless beings-other unlike forms issue,-either through repetition of the process of gemmation, as in Coryne, or by fissuration, as in Aurelia,-and when within these beings, in turn, sexual organs are developed, and propagation 
occurs through ova, - the animal is said to produce by alternate generation.*

The changes which take place in the impregnated egg in the evolution of the embryo are said to be due to the presence of a peculiar force, recognized as the germ force. $t$

Since this is equally pronounced in all ova, and the tissues of the embryo in each case are obtained at its expense, it follows that in comparatively simple animals a large surplus of power is held over and above that actually employed in the maintenance of the adult form, and which is capable of being expressed by fissuration or gemmation in new organisms resembling the parent. But when the force is in a measure exhausted by the evolution of a complex organization, repetition of the form of the animal can be effected only by the development consequent upon the union of new sexual elements. It may, therefore, be stated in general terms, that the amount of germ force present in a mature organism is in inverse ratio to the extent to which tissues have been developed, or, in other words, to the degree to which functional labor has been divided.-In Infusoria, where this specialization is

* This term was introduced by the discoverer of the method, Steenstrup, who entertained the opinion that the first brood of larvæ retained the power of producing young, without themselves possessing sexual organs. The following is his original definition: "Alternate generation is the phenomenon of an animal producing an offspring which at no time resembles the parent, but which on the other hand, itself brings forth a progeny which returns in its form and nature to the parent animal, so that the maternal animal does not meet with its resemblance in its own brood, but in its descendants of the second, third, and fourth degrees of generation."

The author would consider the phenomena of alternate generation as true larval changes, differing in degree only from those of more direct development, and producing, as the result of a single impregnation, not one, but it may be, many sexual forms.

$\dagger$ "Of this force, by whatever name we designate it, whether as the formative or the plastic, or, more explicitly, as the force by which organic matter, in appropriate conditions, is shaped and arranged into organic structures; of this force, and of those that co-operate with it, we can, I think, only apprehend that they are in the completed organism, the same with those which actuated the formation of the original tissues in the development of the germ and of the embryo." (Paget.) 
small, fissuration and gemmation occur; but neither are seen in Vertebrata, where the specialization is great.

The application of these facts to a proper appreciation of the process of repair is extensive. It will be seen that when the reserved force is large that losses sustained by mutilation - which may be carried to an indefinite extent-are at once recovered by the evolution of new individuals from the severed portions; as is seen in Infusoria, Hydra, Actinia, and in a less degree in Lumbricus (earthworm). When the force is smaller, limited portions only of an individual can be restored after such injury. Thus the viscera of Holothuria (sea-cucumber), limbs of Ophiura and Lupa (crab), head of Helix (snail), eye and limb of Proteus (salamander), fin of fish and tail of lizard, are the only portions capable of being reproduced; for death may ensue if the injury prove extensive. In Aves and Mammalia, so perfect is the specialization of function that the power named operates but feebly; instances of its sustained activity are rare.*

Protozoa. Rhizopoda.-Generation imperfectly known. Foraminifera increase in size by gemmation. Ova-like bodies have been detected in the same group. (Wallich.)

Infusoria.-Generally propagate by tissuration and gemmation. Fissuration frequently occurs-longitudinally, as in Vorticella, transversely with others, as in Stentor, and in others again by both methods, as in Paramecium.-Gemmation is more rare, as in Vorticella. The 'nucleus' is always present in Infusoria. It may be single, as in Paramecium, or multiple, as in Stylonychia. It is always divided in the act of fissuration.In Vorticella, in addition to the above methods, encapsulation occurs. The animal about to undergo this process loses its identity by becoming, for the most part, converted into a capsule having thickened walls. The nucleus assumes a band-like form, which after a time divides into a number of disciform bodies, giving the capsule a sacculated appearance. Within

* These truths remind us that it is an error to endeavor to explain too exactly the morbid processes going on in man by what is observed in apparently similar conditions among lower animals. 
this, numerous motile larvæ are developed, which after a time escape by rupture of the wall of the cyst, subsequently to assume the form of the parent, most probably without metamorphosis. Occasionally from the sacculated stage an acinetiform larva (so called from its general resemblance to the genus Acineta) arises, from the interior mass of which Vorticelloe successively escape.* In Paramecium true generation may occur following coition. Entire segmentation of the ovum occurs, and the young almost directly assume the form of the parent.-In Trichodes an encapsulated stage apparently intervenes between the first larval and mature condition.

Radiata. Cœlenterata. - Reproduction in Polypi by fissuration, gemmation, and true generation. In addition to remarkable capacity to multiply by fissuration and gemmation, the Hydra periodically produces young by true generation. It may be hermaphroditic or unisexual, but more commonly the former. The development is without metamorphosis. In Actinia (sea-anemone), which is hermaphroditic, the egg is impregnated in the water. After complete segmentation it becomes ciliated. The embryo in time assumes a horseshoe form, the outer boundary of which eventually constitutes the periphery of the animal, the inner boundary, the common visceral cavity.

In Acalephæ are witnessed some of the most remarkable methods of development known in the animal kingdom. They are for the most part examples of alternate generation. In Hydroida this process is particularly complicated. The following terms will be employed in its description:

Planula. The freed embryo.

* Encapsulation resembles true generation in the following particulars :

1st. The 'nucleus' contained within the capsule is analogous to an ovum. During encapsulation this undergoes segmentation, producing numbers of distinct larval forms.

$2 \mathrm{~d}$. The presence of male and female organs within the capsule being assumed, animals undergoing encapsulation are hermaphroditic,-a conclusion in harmony with facts observed in closely allied animals, the Spongida, as in Tethya. 
Hydroid stock (stolon). Its second stage of development. It may be free, as in Nanomia, or fixed, as in Eucope.

Hydra. A sexual bud (so called from its resemblance to the genus Hydra) attached to the hydroid stock.

Medusa bud (special gemma). A bud springing from the hydroid stock, possessing the form of the Medusce.* It may be permanently asexual, as in Nanomia, or possess power of developing into sexual form, as in Eucope. It may remain attached to hydroid, as in Nanomia, or become detached, as in Eucope. Occasionally successive medusa buds arise from it by gemmation, as in Coryne.

Calyx. A capsule developed in the axils of the branched hydroid stock, having for contents medusa buds, as in Campanularia, or male or female organs, as in Cordylophora.

Hydroids pass the earlier stages of their existence as little shrub-like communities, as in Eucope, or remain in that condition through life, as in Cordylophora. Hydræ are transformed into jelly-fishes, which, in some instances, break off when mature, and swim away as free animals, as in Eucope, while in others, as in Laomedea, they remain permanent members of the hydroid stock, never assuming a free mode of life. All these buds, when mature, whether free or fixed, lay eggs in their turn, from which a fresh stock arises to renew the singular cycle. (E. C. \& A. Agassiz.)

In Nanomia the planula is of an elliptical shape without cilia, and contains an oval chamber filled with an oily fluid which buoys the embryo. The planula develops directly into a short hydroid stock, the oil chamber being retained. Three kinds of hydræ are evolved from the stock, as follows: (1) An open proboscidiform bud, with numerous long and delicate tentacles springing from its base, each knobbed at the end and paved with lasso cells. (2) Similar to the preceding excepting tentacles are short and twisted. (3) A closed hydra with a single pendent tentacle of moderate length. The first two forms are held to be feeders to the stock; the function

* 'Medusa,' a genus of Discophora, is here employed in the plural to include a variety of medusiform zooids. 
of the last is unknown.-Two kinds of medusa buds also spring from the stock. The first of these (swimming bells) are asexual. They remain attached to and move the stock by the contractility of their walls. In the second kind, more numerous than the preceding, the bells are of smaller size, remain attached to stock, and at breeding seasons develop sexual organs. Male and female elements contained in separate capsules. The impregnated egg gives birth to planulæ as before.

In Cordylophora the planula is ciliated and of an oval form. It soon becomes fixed, and develops through the winter a fixed hydroid stock. From this numerous hydræ arise by gemmation, each consisting of an elongated conoidal form surmounted by tentacles. The following spring, two forms of calyces are seen, one for the development of ova, the other for spermatozoa. Impregnation occurring after a method imperfectly understood, the contents of the ovisac undergo segmentation, and a number of planulæ escape, each of these in turn to become fixed and develop the stock as before. (Allman.)

Rhizogeton resembles Cordylophora in having hydræ and male and female calyces developed from hydroid stock. But is peculiar in the stock not being shrub-like, but trailing;each hydra and generative capsule (calyx) arises by its own trunk. It appears probable that the calyces may be produced from hydræ. The method of development of ova is not known. (Clark.)

In Eucope the form of the planulæ and the stock are the same as in Cordylophora. But when the special gemmæ are developed, but one form of calyx is seen, namely: that for the development of the Medusæ. Each capsule contains about twenty to thirty buds, which, becoming detached, escape and develop organs of generation, to bring forth in their turn planulæ.

In Perigonimus no calyces are seen, the medusa buds springing directly from the sides of the stock, subsequently to become detached.

In Tubularia the hyd:æ are covered in by an extension of 
the sheath of the stock. The medusa buds arise without true calyces, and assume the form of the genus Beroe, causing this form to resemble the ctenophorous cœlenteratates, as those having true medusa buds resemble the discophorous. At other times in the same genus a hydraform bud escapes from a simple calyx. It is not known which of these special gemmæ produce the organs of generation.

In Coryne, Hydra is a club-shape appendage to stock or the medusa bud (Sarsia), develops eggs, as in Eucope, is asexual, and develops other medusa buds from its proboscis, its ovaries, or from the base of its tentacles (see Salpa, p. 128). These remain attached for some time, but becoming separated, develop organs of generation to bring forth planulæ.

In Hybocodon the medusa bud is developed directly from the stock without calyx. It is peculiar in being asexual and in possessing but one fully-developed tentacle. From the base of this from ten to twelve other medusa buds arise to remain attached. At this period the asexual bud becomes free and swims off with its burden of special gemmæ, each of which erolves sexual organs to bring forth planulæ. (E. C. \& A. Agassiz.)

In Dicoryne male and female medusa buds arise from capsules. They are of oblong form, but in place of disk present two ciliated tentacles. (Allman.)

The Discophoræ, with some few exceptions, as in Campanella, in which they develop, like the Ctenophoræ, from eggs, begin life as Hydra-like animals, the subsequent self-division of which gives rise, by a singular process, to a number of distinct jelly-fishes. (E. C. \& A. Agassiz.)

In Aurelia, the impregnated egg is conveyed to a marginal pouch from the ovarian chamber after a manner unknown. It here develops into a hydraform larva (strobila, Scyphostoma), which subsequently undergoes transverse fissuration, each segment (Ephyra) assuming, during the process of division, the form of the parent, afterward to develop sexual organs and produce strobilæ as before.

Ctenophoræ grow from eggs by a direct, continuous process of development, without undergoing any striking metamorphosis. (E. C. \& A. Agassiz.) 
Echinodermata.-The first condition of every Echinoderm is the same,-an oval, ciliated body, resembling an infusorial animalcule, and without external organs or distinction of parts. Upon this form are developed, at one part, peduncles for its attachment to other bodies, while the rest of the germ increases in size and assumes a star-fish form. The larvæ may be divided into two groups:

(1) The first-including the Ophiuridæ and Echinidæ-are somewhat hemispherical bodies, with one edge of their truncated side prolonged into a single flat and wide process, which carries the mouth and œsophagus; while from the opposite extremity project rods, four, eight, or more in number, which form the internal skeleton. These larvæ have a globular stomach in their hemispherical portion, from which proceeds a short intestine, terminating in a circular anus. They have, moreover, a ciliated fringe, which consists of a ridge covered with large cilia, passing around the mouth and before the arms, completely encircling the body in an oblique manner. The larval form of the Echinidæ is often spoken of as the Pluteus.

(2) The second group-including the Holothuridæ and Asteroidæ-differs from the above in not possessing an internal skeleton. The larvæ of the Holothuridæ are concavoconvex bean-shaped bodies, with an irregular transverse fissure answering to the hilum of the bean, in which the mouth is placed. The margins of this fissure are ciliated; the anus opens on the ventral surface. Those of the Asteroidæ closely resemble these last, but they have a distinct ciliated circle in front of the mouth; as they increase in size, the anterior part of their body is covered with long processes, which vary according to different forms. The names Auricularia and Bipinnaria are often applied to these larvæ respectively. (Burnett.) Brachiolaria is the larva of Asteracanthion.

Mollusca. Polyzoa.- In addition to a direct egg-development, the Polyzoa multiply by gemmation.

Tunicata.-Reproduction by budding sometimes occurs, as in the compound Ascidians; but true generation is more frequently recognized. After complete segmentation an ob- 
long, tailed embryo* is developed, which escaping from egg moves freely in the water. After a few hours it becomes fixed, loses its caudal appendage, and without further change is developed into the sexual form.

The phenomena of alternate generation are witnessed in Salpa. The egg undergoing complete segmentation evolves a larva which assumes a form recalling that of the parent, to which it remains for some time attached by a placenta-like structure. Rupturing the connection, a curious process of gemmation, which was commenced while the larva was yet confined, is completed. This consists in the formation from a central cylindroid stem (stolon) of numbers of buds, all of which being evolved at about the same time 'adhere together by their external surfaces or special organs of attachment' forming chains or clusters of sexual individuals. These are generally composed of two rows joined together by several cords and enveloped in a common membranous tube. The sexual form is known as the 'aggregated Salpo' or 'stock,' the larval or non-sexual, as the 'solitary Salpa.'

In Pyrosoma, the yolk is diffused within ovisac at an early stage of development, and while the embryonal mass is yet newly formed, it partially segments transversely into five divisions. The first of these is a provisional structure; the other four are permanent ones, and each subsequently attains the sexual form. While within the parent they are joined together by a connecting band. The subsequent growth of each of the embryos into a compound animal has not been traced.

Brachiopoda.-Development but little known. In Crania the young possesses four pairs of ciliated processes, situated around the mouth, and which, together with the gullet, can be protruded from the cavity of the shell. It bears a strong resemblance to the permanent condition of Polyzoa.

Lamellibranchiata. - Egg not uncommonly possesses a mi-

* To avoid multiplication of terms 'embryonal' and 'larval forms' will be used indifferently, though in so doing a lack of precision is acknowledged. 
cropyle,* as in Anodonta (mussel). Segmentation partial. Superficial layer not participating in the process. The ciliated and revolving embryo divides, and is crowned with a valvular appendage developed from the unsegmented superficies. The embryo divides into halves, each half being covered by a valve. In the middle of the angle formed by these valves is raised a short hollow cylinder-the byssus-forming organ-and out of which projects a long transparent byssus. (Siebold.)

Gasteropoda.-Segmentation of vitellus complete, excepting a few hyaline corpuscles. Embryo oblong, indented, and ciliated at one extremity. The indentation deepens in Eolis and Doris, forming two lobules upon whose borders very long cilia are developed. The crests are absent in certain pulmonates. A third eminence is developed between these two pinions, and ultimately changed into a foot. A spiral shell and operculum are very constantly present, whether the mature form be conchiferous or not. Subsequently the pinions disappear, and in the naked species the shell and operculum are lost. From an early time in development the embryo rotates upon its axis by alternate revolutions. In naked pulmonates a sac analogous to umbilical vesicle is formed at caudal region of embryo, which, during development, alternately contracts with embryo.

Cephalopoda.-Segmentation partial. In the germinative area upon the upper portion of the egg a two-layered blastodermic membrane originates, from the central and outer portion of which a disciform embryo arises. Various irregularities mark its surface. An irregular median fold represents the mantle enclosing the future visceral cavity. Upon either side of it are seen the gills, the halves of the funnel, cephalic lobes, and the rudimentary arms and eyes. The mouth is not situated between these organs, but at the pos-

* The micropyle is the remains of the pedicle which, in the development of egg, connects it with the ovary. It is believed to be the point at which entrance is effected by the spermatic filament, and is closed prior to act of conception. 
terior or dorsal surface. A portion of the vitellus becomes surrounded by the large median layer of tissue. The remaining unappropriated area is defined externally by a membrane derived from the inner layer of the blastodermic membrane, and communicates with the œsophagus through a narrow canal. It resembles in form the umbilical vesicle of vertebrates, from which, however, it markedly differs in absence of connection with the abdomen. The embryo is more fully developed before it is made independent of its capsule than is the case in other Invertebrata.

Articulata. The following changes are observed subsequent to impregnation in the egg of an articulate animal. After segmentation, which may be either complete or partial, a clear albuminoid space (germinative area) is found toward the ventral surface of egg, and the yolk, or vitelline area, upon the dorsal. The first trace of organization is seen in the formation of the germinal layer (blastodermic membrane), which in time surrounds the yolk,-its thickened portion of the area within the germinative area being called the germinal disk. This layer divides into two ; the outer (animal, serous or nervous) layer is devoted to the development of the skeleton and nervous system,- - the inner (vegetative, mucous or subsidiary) layer is given to the evolution of the organs of nutrition. This disk soon becomes transversely wrinkled, indicating the points of formation of the future segments. From the ventral sides of the disk two folds descend to form a groove, within which is developed the ganglionic chain of nerves.

Entozoa.-See p. 161.

Annelida.-Segmentation complete. Eggs spherical and ciliated. Two types with Hirudinei. After the vitellus has divided into many large cells, a central one becomes distinguished from the others by its still further division. This becomes the digestive tube. The others, still dividing, form a primitive embryonic part, in which appear the future ventral and nervous portions. With the Branchiata there is a complete metamorphosis. The segmentation of the vitellus is uniform throughout, and this last is finally changed into a 
round embryo. The embryo lengthens, and the epithelinm disappears, except in the belt-like parts of the two extremities. (Siebold.)

In Autolytus, the egg undergoing segmentation produces a sexless larva (parent stock) which resembles the female in general outline. Successive pairs of males and females are developed from the posterior extremity of the parent stock; the exact number has not been ascertained. (A. Agassiz.)

Crustacea.-Embryos are often dissimilar from the adult form. The most conspicuous of these is the larva (Zoe) of the Decapoda, and the active zoeform young of Cirripedia (barnacles) and Lernæacea (lerneans). The latter groups are inclusive of animals with sexual forms so degraded that their position among articulates can be determined only by observing their larval conditions.

Myriapoda. - The larval form differs from the adult chiefly in possessing a smaller number of segments.

Arachnida.-The young of certain Acarina (ticks) have but six legs, as in Trombidium.

Insecta.-The metamorphoses of insects are various, though fixed within natural groups. Some, however, are without proper metamorphosis, as in Pediculus (louse), and Lepisna (silver-moth).

Metamorphosis is incomplete when the larval condition closely resembles the parent, as in Hemiptera (bug) and Orthoptera (locust). It is complete when the embryo passes through two distinct stages prior to assuming the sexual form. The first of these is the larva proper (caterpillar); the second, the pupa (chrysalis). The sexual, commonly winged form, is the imago. Examples are seen in Diptera (fly), Lepidoptera (butterfly), Hymenoptera (bee), Neuroptera (dragonfly), and Coleoptera (beetle). The time required for the completion of these life-phases is subject to variation. Thus in Musca vomitoria (meat-fly) the entire development is completed within thirty-one days, while in Cicada septendecim (seventeen-year locust) seventeen years are required. The quantity and quality of food consumed exercises great influence upon the embryo-hastening or retarding development as it is 
present in sufficient or insufficient quantities, as in Apis (bee).

In the Aphides (plant-lice) an example of alternate generation is exhibited. The egg, which is laid by the parent in the fall, develops the following spring, at which time it undergoes segmentation, the resultant larva resembling the parent in being active and provided with limbs. It markedly differs, however, from apparently similar forms of other insects in its power of giving birth, through a phase of the process of gemmation, to a progeny like itself. Ova-like buds are formed in the neighborhood of the ovaries, which subsequently assume the outline of the parent insect. Such individuals-eight in number-are free, active, and each in its turn brings forth eight others like itself. This process is successively repeated within each active gemma as long as the surrounding conditions, which are generally maintained to the eighth or ninth generation, are favorable. In the last brood, brought forth toward the close of the summer, the sexes are for the first time distinct, and the males provided with wings. From each of these forms ova are produced which, after lying inactive during the winter, undergo development in the following spring as before. It has been estimated that in five generations of offspring a single Aphis may be the progenitor of $5,904,900,000$ descendants.

In Cecidomyia (Hessian-fly) - a genus of dipterous insectsthe mature female deposits ova, each having a smooth shell and furnished with a micropyle, beneath the bark of dead ash-trees. They here soon develop into larvæ, having no peculiar external characters, but possessing in the posterior portion of their visceral cavity (in inmediate relation to, and perhaps having their origin within a fatty tissue), two ovarylike bodies, one on either side. Within these are developed spherical masses which, from their resemblance to eggs, are known as pseudova. Each pseudovum evolves another larval form, so that in time there exists within the tissues of the primary larva as many secondary larvæ as there were originally pseudova developed. The parent larva, after changing its exterior into a pupa-like case, dies. The brood remaining 
within the case throughout the winter, escapes the following spring, to undergo the usual metamorphic change common to dipterous insects.

Vertebrata. Within the germinative area, which is placed toward the dorsal surface of the egg, the germinal membrane (blastodermic membrane) is formed, soon to divide into an external and an internal layer. The former, in which are subsequently found the organs of animal life, namely, the nerrous system, the muscles, the skeleton, etc., has received the name of the serous, animal or nervous layer. The latter, which gives origin to the organs of vegetative life, and especially the intestines, is called the mucous or vegetative layer. By subdivision of the inner layer, a third or intermediate layer is formed, in which is developed the circulatory system. - The first important subsequent change is observed in the external layer, where within a translucent space, a longitudinal (primitive) groove is formed, upon each side of which a fold (dorsal lamina, dorsal plate) arises. Such folds being converged join at the median line to convert the groove into a canal (neural canal) subsequently to contain the cerebro-spinal axis. Immediately beneath the spinal groove, indeed formed within its lower wall, a peculiar cartilaginous body, the 'chorda dorsalis,' is seen. The vertebral column is commonly developed within the sheath of this structure, which, as a rule, soon thereafter disappears. While these changes are being effected the animal layer also extends laterally, partially, or entirely to enclose the yolk cavity.

Two types of development: (1) aquatic, and (2) terrestrial.

(1) Pisces - In cartilaginous fishes an osseous vertebral canal never appears. With such the chorda dorsalis is persistent. When an osseous fish is just escaped from the egg, the remains of the vitelline sac, now called the umbilical vesicle, are not yet absorbed, and often of large size; the gill covers are not completely formed; the fins are without rays, the mouth, which is placed transversely, is without teeth. External or false gills are occasionally appended to the sides of the head, as in Carcharias (white shark).

Batrachia.-The general resemblance in development to 
that of the preceding class marked. A distinct metamorphosis seen in young of Rana (tadpole). The features of this stage, viz., presence of gills and tail, are persistent in many batrachians, as Axoltt. Then ob anchns

(2) After the formation of the neural canal, and the enclosure of the vitelline sac by the outer germinal layer is complete, a fold of the same layer arises up around the embryo (amniotic fold) which, uniting above, forms a distinct eavity (amnion), in which is contained a clear fluid. Soon after the development of this eavity, a pouch-like depression of the internal layer of germinal membrane is seen to one side of the umbilical sac at the posterior and inferior part of the visceral cavity. It extends outward and upward parallel with the curve of the amniotic fold, and is called the allantois.*

Reptilia and Aves.-Here the ova are developed independent of maternal connection. The allantois is of proportionately large size, covering the upper portion of the embryo and lying between it and the porous shell. It is at once a respiratory and excretory organ to the embryo.

Mammalia.-Here the ova are borne by the mother either during a portion or the whole of the period of development; the allantois presenting two varieties of structure. The first of these is of comparatively small size, and free, as in implacental mammals. In the second the organ, often completely surrounding the egg, early becomes united with the chorion, as in placental mammals. In the implacental, the chorion is either smooth (Monotremata) or transversely wrinkled (Marsupialia), and has little or no means of retention to the uterine wall. In the placental, on the other hand, the chorion is shaggy and has partial or entire connection with the aualogous formation of the mucous membrane of the uterus.

The placenta is the organ of respiration in mammals, as

* Prof. Huxley gives a different account of the formation of this organ : "The allantois is developed much later than the amnion, neither from the serous nor from the mucous layers of the germ, but from that intermediate stratum whence the bones, muscles, and vessels are evolved. It arises as a solid mass from the under part of the body of the embryo behind the primitive intestinal cavity." 
the allantois is in reptiles and birds. (See Respiration, p. 62.)

The form of the placenta varies in different orders of Mammalia. The shaggy coat may disappear except a comparatively small circular area forming discoidal placenta, as in Bimana (man), Quadrumana (monkey), Cheiroptera (bat), Insectivora (mole), Rodentia (rat). The shaggy coat may remain entire, and be at all points in contact with decidua vera, and is (1) diffuse with cotyledons, as in Ruminantia (sheep), or diffuse without cotyledons, as in Omnivora (hog), Cetacea (whale), Edentata (sloth); or (2) modified in the form of a ring running transversely round the fetus-zonular-as in Carnivora (dog).

In implacental mammals the young, at an early period, is removed from the uterus, to be attached to the nipple of a mammary gland within an inguinal pouch, as in Marsupialia,* or in the absence of a pouch, after a manner imperfectly understood, as in Monotremata.

Mammary gland.-This is a cutaneous gland belonging to the racemose type, composed of aggregations of numbers of simple glands, analogous to sebaceous follicles. Lacteal ducts from the lobules converge to a central space to form a conical spongy prominence, the nipple ('teat,' 'dug,' 'pap').

* It is not known in what manner the embryo is transferred from the uterus to the marsupium. From observation made upon the female kangaroo by Prof. Owen at the Zoological Gardens, London, in 1830, it was shown that the removal was effected during night of the thirty-ninth day of gestation. The following is a description by Prof. Owen of the embryo on the day after its transfer:

"The new-born kangaroo was attached to the left superior nipple, to the point of which it adhered pretty firmly. It measured one inch from the mouth to the root of the tail, was quite naked, and covered by a thin semitransparent vascular integument; the place of attachment of the umbilical cord was obscurely indicated by a longitudinal linear cicatrix. 'The fore legs were longer and stronger than the hind ones, and the digits were provided with claws; the toes were developed on the hind legs: the body was bent forward, and the short tail tucked in between the hind legs. This little animal breathes strongly, but slowly : no direct act of sucking could be perceived. Such, after a gestation of thirty-eight days, is the condition of the new-born young of a species of kangaroo of which the adult, when standing erect on his hind feet and tail, can reach to a height of seven feet." 
Nipples are four in number in Macropus (kangaroo), concealed within fissure in Cetacea, absent in Ornithorhynchus.* With some mammals the glands are situated in the ventral region, as in Sus (hog), restricted to inguinal region, as in Ruminantia, while with others they are exclusively confined to the pectoral, as in Cheiroptera (bat), Quadrumana, and man.

* The cow, ewe, goat, guinea-pig, and porpoise have one tube in each teat. The pig has two, the rhinoceros has twelve, and the hare and rabbit, and the cat and bitch have several. In the Ruminantia the reservoirs (ampullæ) are enormously enlarged, with Carnivora comparatively small. In the pig there is scarcely any reservoir ; in the porpoise the great enlargement of the milk tube is a substitute for the reservoir. (Astley Cooper.) 


\section{MEDICAL Z00LOGY.}

\section{MAMMALIA.}

Moschus (Musk Deer).-Order Ruminantia. Family Moschidæ.

Characters.-Placenta cotyledonous. Head without horns.

Dental formula: mol. $6-6$; can. $1-0$; incis. $0-4$; incis. $0-4$; can. $1-0$; mol. $6-6=14-20$.

Canines conspicuously developed in male so as to protrude below the level of the lips. Incisors spatuliform, arranged in a continuous series. Stomach with four chambers. Musk sac apparatus present in male.

M. moschiferus, Avicenna. - Head small and short; muzzle pointed, naked, and blackish; nostrils crescentic, very open; lower lip nearly deprived of hair; ears large; neck thick and of moderate length; tail very short, thick, conical, and soft; - with the female and the young it is hairy above and woolly beneath; while that of the male of the second year is entirely naked and red. 'The front paws are so short that the distance between the chest and the ground is less than that comprised between the withers and the inferior face of the thorax. The relation between the anterior and posterior extremities indicates that the animal is adapted for leaping rather than walking. Hoofs small, compressed, subtriangular, and pointed. Lateral (supplementary) hoofs, elongated, but not reaching the ground. The thickset appearance of the musk deer depends in part upon the nature of the fur, which upon the body is very thick, velvety. Fur thick, short, and soft about the head and ears. Upon the belly or each side of the umbilical region longer, becoming more slender, and forming through this part of the trunk a large pendant tuft in front of the thighs. Upon the legs it is short, and especially compact, inferiorly. The general color of animal reddish-brown with adnixture of gray and white, the hues varying with age and season. The hair is always white at the base, brown or gray above greater or less distance of the shaft, to again become white toward the tip. This variety of coloring gives a grizzled appearance to the whole body. Upon the claws the hairs become shorter, more compressed, and of a darker color than elsewhere. (Alphonse Milne Edwards.)

Measurements.-From muzzle to anus, $2^{\prime} 11^{\prime \prime} 4^{\prime \prime \prime}$; length of tail, $1^{\prime \prime} 2^{\prime \prime \prime}$; length of head, $6^{\prime \prime} 2^{\prime \prime \prime}$; length of ear, $3^{\prime \prime} 4_{3}^{2 \prime \prime}$; length of neck, $6^{\prime \prime} 6^{\prime \prime \prime}$; height 
of anterior part of body from back to hoof, $1^{\prime \prime} 10^{\prime \prime}$; height of posterior part from rump to hoof, $2^{\prime} 2^{\prime \prime} 6^{\prime \prime \prime}$. (Pallas.)

The skeleton bears a close resemblance to that of Cervus (deer). Cervicals, 7 ; dorsals, $14-15$; lumbars, 6 . Metatarsal and metacarpal bones, two in number, in each limb, but anchylosed along their entire length-a groove more apparent in posterior than the anterior limbs indicating the line of original division. The former bones much longer than the latter. The toes articulate by distinct condyles to the 'canon bone,"* each toe being composed of three phalanges, the terminal ones being hoofed. Placed in connection with the 'canon bone,' two supplementary toes are seen, as in other bi-sulcate ruminants, but here are larger than usual, project downwards, each composed of three segments, the terminal one furnished with a delicate hoof closely resembling that of the hog. In the hind limb a rounded rudiment of a tarsal bone intervenes between the first phalanx and the shaft of the 'canon.' But in the front limb the corresponding toe is in relation with a bone of greater size in the form of a conical mass which is firmly secured to the canon by means of ligaments.

The disposition of the viscera agrees in its main features with that of the true bi-sulcate ruminants. The musk apparatus is peculiar to the male. It is situated in the median line of inguinal region midway between the navel and orifice of the prepuce, but nearer the latter. It apparently consists of an inversion of skin at the position of the prepuce, forming a sac-like chamber of a rounded oval shape, flat above, convex beneath. It is longer than wide, and rests posteriorly upon the penis, for the reception of which it presents beneath a deep median groove. Smooth upon its superior border, where it is in constant contact with the abdominal muscle, the inferior aspect is in relation with the skin. The sac is sparsely covered with hairs, which converge obliquely to the circular excretory opening.

The affinities of the Moschidæ are with the Cervidæ† and Tragulidæ. $\neq$ They resemble the Cervidæ in structure of canon bone, number and arrangement

* 'Canon bone' is the representative of the metacarpus in the anterior and the metatarsus in the posterior extremity.

† Cervidæ.- Upper canine teeth in many. Horns cast annually, peculiar to males (in females none, one species excepted). Sebaceous glands in front of eye. A soft layer of hair at the hind feet in most. Tail short, sometimes very short. (Van der Hoeven.)

† Tragulidæ.-Placenta diffuse. Incisors in an interrupted series. Space in median line. Central incisors very large, with wide flattened crowns. Stomach with three chambers only (the psalterium being absent). Musk sac none.

Genera. Tragulus.-Metatarsal and metacarpal bones (os canon) nnited in median line. Lateral digits well developed, and prolonged. Intermaxillaries articulating with the nasal bones. Habitat.-Java and Sumatra.

Hyæmoschus.-Mcdian metacarpal bones distinct throughout life. Metatarsals at first distinct, afterwards become united in median line. Lateral digits well developed, robust, and attached along the entire length of the median metatarsals. Intermaxillaries do not articulate with nasal bones. Habitat.-Africa. (A. Milne Edwards.) 
of incisor teeth, stracture of stomach and placenta, and in general style of movement and coloring; - with the Tragulidæ in absence of horns, presence of large canine teeth in the males, and in the development of the lateral digits. This last feature-dependent as it is upon others in the anatomy of the extremities-recalls the construction of the foot of the hog. 'The relation of the musk deer to the hog through the Hyamoschus is by no means remote. Several fossil genera-Oreodon, Anoplotherium, etc.-apparently connect the Ruminantia with the Omnivora.

\section{Viverra (Civet Cat).-Order Carnivora. Family Viverrina.}

Characters.-Molars mostly $\frac{6-6}{6-6}$ three false on each side in apper jaw, three or four in lower. Only a single tuberculate tooth on each side in lower jaw or none. Almost always two tuberculated teeth on each side of lower jaw. Feet mostly digitigrade, either pentadactylous or tetradactylous, with claws often semi-retractile. Back of tarsus hairy. Glandular follicles between anus and genitals secreting a sebaceous matter of disagreeable odor.

Viverra. Feet pentadactylous, with claws small, curved, semi-retractile; back of tarsus end underside of feet, excepting pads of toes and metatarsus, hairy; body slender, head elongate, muzzle acute, legs of moderate length, tail conical, generally ringed; back crested; orbit incomplete.

Dental formula.-M. $2-2$; prem. $4-4$; c. $1-1$; in. $3-3$; in. $3-3$; c. $1-1 ;$ prem. $4-4 ; \mathrm{m} .2-2=20-20$.

Vertebræ.-Cervical, 7 ; dorsal, 13 ; lumbar, 7. .

V. civetta, Schreber.-Light brownish-gray, with large black spots; the tail short, long-haired, with some whitish spots, at the tip black; upon the back long hairs (mane).

Measurements.-Length of body, $2^{\prime} 9^{\prime \prime} 6^{\prime \prime \prime}$; of tail, $1^{\prime} 3^{\prime \prime \prime}$; head, $6^{\prime \prime}$; ears, $2^{\prime \prime}$. Height of body anteriorly, $11^{\prime \prime} 5^{\prime \prime \prime}$; posteriorly, $10^{\prime \prime} 6^{\prime \prime \prime}$.

Habitat.-Africa, from $31^{\circ} \mathrm{N}$. lat. to $25^{\circ} \mathrm{S}$. lat.

$V$.zibetha, Linn.-Light brownish-gray with brown spots; the throat whitish, with oblique dark stripes; tail shorter than body, short-haired, with black and light brown rings. (Van der Hoeven.)

Measurements.-Length of body, from tip of nose to base of tail, $2^{\prime} 5^{\prime \prime}$; head, $5^{\prime \prime} 7^{\prime \prime \prime}$; tail, $1^{\prime} 3^{\prime \prime \prime}$.

Habitat.-East Indies.

In each species there is placed on either side of the opening of the genital apparatus an oblong sac, with thickened walls, presenting upon its inner surface openings of mucous glandular follicles, in which is secreted the civet. On either side of the anus a pair of small anal glands empty a fetid secretion.

Castor (Beaver)._-Order Rodentia. Family Sciuridæ. Sub-family Castorinæ. 
Characters.-A double claw on second hind toe. Hind feet webbed. Tail broad, flat and scaly. Molars $\frac{4-4}{4-4}$, complicated or folded, with one groove on the inner side of each upper molar, and three on the outer, and vice versa below; the anterior molars sometimes with more. (Baird.)

C. canadensis, Kuhl.-Head large and broad; nussle naked; nostrils lateral, subcrescentic. Upper lip acutely emarginated, though scarcely bifid. Eyes small, placed midway between the end of the snout and the auditory aperture. Ears of moderate size (infra), thick and nearly orbicular, densely covered with hair on both surfaces. Limbs large and stout; the under surfaces of all the feet entirely naked; the upper surfaces coated with short, stiff silky hairs; the fore claws are about as large as hinder ones. Front foot with five distinct fingers, each armed with curved, rounded claw; third finger longest, the fourth a little shorter; then in order to second and fifth; the claw of the first reaches as far as the cleft between the third and fourth. The claw of second toe possesses a claw-like appendage. There are only two tubercles on the palm, both large, and placed side by side; the exterior twice as large as the interior, and extending further back. Hind feet large, their plane oblique to body. Toes connected by thickened naked web extending between their tips. In walking the whole plantar surface touches the ground. Tail conical at base, where it is densely covered with hair, but suddenly becomes very tlat and depressed. It is for the greater part covered with transversely elongated subhexagonal scales arranged in quincum with tolerable regularity on each side. Short downy hairs project between the scales, obscuring but not concealing them. Fur of two kinds; upper and longer hair coarse, smooth, and glossy; under coat dense, smooth, and silky. Usual color reddish brown; on back of a shiny chestnut color; on the under surface and around mouth and throat, a shade lighter; sometimes quite dark, and again of rather a light yellowish tint of the same. (Baird.)

Skull.-Facial portion but little smaller than brain-case, narrow between the eyes. Incisive foramina long and narrow, occupying rather less than one-third of interval between incisors and molars. Zygomatic arches bold, thicker in centre than toward extremities. The infraorbital foramen a small slit, gives no transmission to muscle; not seen from the side. Ext. auditory passage, a well-pronounced tube, directed forward and outward. The lower jaw with articular surface broadly oval, the coronoid process thick, angle broad and rounded. (Wagner's Schreber.)

Teeth.-Line of upper molars decidedly convergent. Palate hollowed out between incisors and molars. Inner side of upper molar with one groove, the outer three; this being reversed in the lower jaw, which shows four grooves on the inner side. The anterior molars in both jaws are largest, the rest diminishing backward very gradually; the anterior molar is, however, longer, proportionally, than the corresponding upper one, and the lower line of molars exceeds considerably the upper. (Baird.)

Cervical vertebræ, 7 ; dorsal, 14 ; lumbar, 5 ; sacral, 4 ; caudal 28. Thorax 
wide and bulging; seven true and seren false ribs. Sternum of seven pieces.

The glandular accessories to the mouth are numerous. In addition to the salivary glands, which are relatively larger than in any other rodent, other follicles, varying from fifty to sixty in number, pour a slimy, mucoid secretion into the mouth. A spongy mass of follicular glands occupies a portion of the mucous membrane along the lesser curvature of the stomach. Cæcum large; anus distinct from the opening for genital apparatus,-both, however, lie within a common cutaneous depression.

The castoreum sacs are found in both sexes. In the male they lie near the pubis, are oval, flattened, of a light color like parchment, and communicate freely with one another by their transverse portion. (Ely.) Each measures from $2^{\prime \prime}-4^{\prime \prime}$ in length, and placed alongside the elongated prepuce, into which it empties by a distinct opening. The walls of the gland are composed of an external fibrous coat, a muscular and vascular coat, with an internal mucous lining, the whole being bound together by fibrous processes extending inward. The mucous membrane is thrown into folds, and furnished with numerous scale-like processes, beneath which, in relation with the epithelium, the castoreum is secreted. Opening into the depression about the anus are the openings of several pairs of anal glands, one of which is generally partite or larger than the others. (Brandt and Ratzeburg.) They elaborate a fatty secretion with no properties of castorenm. The glans penis is flattened. It contains a bone equal to its length, and largest at its base. The racemose glands appended to urethra are analogous to Cowper's glands.-In the female the sacs are similarly situated to those of the male, but open upon either side of the entrance of vagina. (Ely.) The anal glands closely resemble those of the male.

Measurements.-From nose to root of tail, $23^{\prime \prime}$; tail, $10^{\prime \prime}$; from heel to end of middle claw, $5^{\prime \prime} 6^{\prime \prime \prime}$; breadth of tail, $3^{\prime \prime} 3^{\prime \prime \prime}$; thickness of tail, $10^{\prime \prime \prime}$; average weight, $11 \frac{1}{4} \mathrm{lbs}$. (Aud. and Bachman.)

Habitat.-North America from Upper British America to Mexico; and Northern Europe.

\section{Hyrax (Daman, Cony). Order Perissodactyla. Family Lamnungia.}

Characters.-Body hairy, bristles on face around nostrils and above orbit ; long setæ scattered among shorter hairs of body. Tubercle in place of tail. Dental formula: m. $4-3$; prem. $3-3$; c. $0-0$; in. $1-2$; in. $1-2$; c. $0-0$; prem. $3-3 ; \mathrm{m} .4-3=16-16$. A single small false molar each side, deciduous. Crown of upper molars with two eminences joined by a crest to the outer margin; crown of lower molars with two lunate lines, convex outwards. In many animals two very small canines.

H. capensis-Head small, muzzle short, thick. Form heavy, short, and low on feet. Ears short, round, and bordered by fine hairs. Neck short, and wider than long,- on the upper lip, beneath eyebrows and throat, are a number of long hairs. Palms of fect naked and covered with soft skin 
Fore feet with four toes; hind feet three; these toes terminate in small rounded hoofs, excepting the innermost toe of the hind foot, which is armed with an oblique hooked claw. Tail a mere tubercle. Three mammæ on each side; the anterior is axillary, the two other inguinal.

Vertebræ.-Cervical, 7 ; dorsal, 20-21; lumbars, 8; caudal, 6. Stomach divided into two chambers; cæcum very large, and colon with numerous dilatations, with two cæcal appendages recalling those of certain birds. ( $\mathrm{Cu}$ vier.) The hyrax has close affinities with Rhinoceros. The latter animal differing in being naked, in each foot having three toes, and in the horn-like appendage to nose.

The hyrax yields hyraceum. Its origin is not certainly known. From analysis, it would appear to be derived from the urine and fæees.

Catodon (Spermaceti Whale). Nostrils longitudinal, parallel or diverging, covered with a valve, often larger and more developed. Pectoral, broad, truncate. Fingers, 5. Physeteroidia.

Family 3-Catodontidæ.- (Head large, subcylindrical, blunt. Lower jaw narrow. Teeth large, in the lower jaw only, fitting into pits in the gums of the upper one. Nostrils separate, one often abortive. The hinder edge of the maxillary elevated, forming a concavity on the forehead of the skull. Pectoral broad, truncated. Fingers 5. Eye and limb left side smaller; left nostril very large. The lower jaw is early joined in front into a subcylindrical mass; the branches converge and are nearly straight.)

Catodon. Head rather compressed in the front and truncated, with the blowers close together in the front of the upper edge, separated from the head by an indentation. Nose of skull elongate, broad, depressed. Lower jaw shorter than the upper one, very narrow, cylindrical in front, and the rami united by a symphysis for nearly half its length. Back with a roundish tubercle in front over the eyes, called the 'bunch,' and a rounded ridge of fat behind, highest in front over the genital organs, called the 'hump,' and continued in a ridge to the tail. No true dorsal fin. Pectoral broad, truncated. Teeth conical, often worn down. Males larger than females. The atlas is distinct; the other cervical vertebræ are soldered together. (Gray.)

C. macrocephalus.-The northern sperm whale. 


\section{REPTILIA,}

OpHIDra.-Cold-blooded vertebrates having palatine bone united with pterygoid bone only. Continuity of parietal and sphenoid bones complete. Rami of lower jaw united by ligament. Eyes with simple epidermic eyelids. (Cope.)

Prominent Anatomical Features.-Limbless; bodies of vertebræ articulated by ball-and-socket joints. Progression effected by muscular action upon the abdominal scales and ribs.

Disposition of internal organs.

The tongue exsertile, generally bifid.

Solenoglypha.-Superior maxillary short, united to prefrontal. Tympanic bone elongated. Fangs without external canal. Pupils elliptical. Occipital region scaly. (Cope.)

(1) Crotalidæ.-Erectile poison fangs in front. Few teeth in upper jaw. A deep pit between eye and nostril. Head scaly.

Caudisona.-Upper surface of head covered with small plates, scale-like, with a few larger ones in front. The tail is terminated by a well-developed rattle. Subcandal scutellæ entire. Temporal and labial shields small and convex.

C. horrida (rattlesnake), Linn.-Head angular. Scales between the superciliaries small, numerous, nniform. Plates above snout, 2 anterior frontal and 5 post frontal. Suborbital chain continuous, of large scales. Two rows between this and labials. Labials 12-14 above, 5th largest; 13-15 below. Scales on the back 23-25, all carinated; carination on outer row obsolete. Tail black. Above sulphur-brown, with two rows of confluent brown lozenges. Light line from superciliary to angle of mouth. Behind this a dark patch. Rattle acuminate.

Habitat.-North America, warm rocky exposures.

Other Species. C. durissa (Eastern rattlesnake).

C. confluenta. Western.

C. lucifer. California.

C. atrox. Texas.

Crotalus, Linn.- Upper surface of the head covered with nine large plates. The tail terminates in a rattle, generally smaller than in Candisona. Subcaudal scutella entire, except a few at the end of the tail, which are bifid.

C. miliaris, Hall - Twenty-two or twenty-three dorsal rows of scales, all of which are carinated, the lateral and first rows but slightly; a vertebral brownish-red line; seven series of blotches, one dorsal and three lateral, on each side, the uppermost of which is obsolete and the lowest subject to irregularities. Vertical plates subcordiform, occipital oblong and elongated. A narrow white line commences at the lowest point of the orbit and passes obliquely backward to angle of mouth.

Habitat.-Southern States. 
Other Species. C. consors (Kansas). C. tergeminus (Western States). C. edwardsii (New Mexico and Texas). C. kirtlandii (Western States).

Ancistrodon. Nine plates on top of head. No rattle. One pair of occipitals; larval between the nasal and anterior orbitals. Labials excluded from orbit by the presence of suborbital plates. Scales carinated; rows 23 in number. Subcaudal scutellæ divided posteriorly. Sometimes a small plate between the vertical and post frontal.

A. contortrix (Copperhead), Baird and Girard.

Loral plate present. Labials not entering into orbit. Dorsal rows of scales 23. Color light chestnut, with inverted darker blotches on the sides. Labials yellowish white.

Habitat.-United States. Terrestrial.

A. piscivorus (Water moccasin), Baird and Girard.

No loral. Inferior wall of orbit constituted by third labial; 25 dorsal rows. Dark chestnut brown, with indistinct vertical dark bars. Line from superciliary along edge of head through middle of second supralabial row. A second line from the lowest point of the orbit parallel to the first.

Habitat.-United States. Aquatic.

(2) Viperidae. No pit on side of face. Head plated. Upper jaw toothless, with large fangs in front; lower toothed. Ventral shields broad, band-like. Head large behind; subcaudal scutes single.

Vipera (Viper). Vertebral, occipital, and superciliary plates sometimes distinct; front of head with small shields; nose blunt.

$V$. berus.

V. aspis.

Habitat.- Western and Southern Europe. (Gray.)

Cerastes.-Subcaudal plates two-rowed; nostrils lunate, in the hinder part of a small nasal plate; superciliary shields very small, scale-like. Scales keeled, broad, ovate, rounded at end, placed in oblique, cross series; keel not reaching the tip. (Gray.) C. cornutus.-N. Africa.

Proteroglypha.-Maxilla horizontal, thickened, and not reaching premaxillaries anteriorly, in contact with prefrontal, bearing a perforate and usually grooved, immovable tooth. Head generally quadrangular, with flat crown and moderate or short muzzle. Loral plate none. (Cope.)

Naja.-Head high, quadrangular, not very distinct from neck, with rather short, rounded muzzle. Rostral moderate, rounded, sometimes produced backwards and pointed; anal scutes entire; subcaudal two-rowed; one or two fangs behind large anterior teeth, not grooved.

$N$. haje (Cleopatra's asp), Seba.--Sixth upper labial united with temporals, and forming a very large shield in contact with oculars; generally without marks on neck.

Habitat.-Northwestern Africa.

N. tripudians (Cobra di capello), Scheuz.

Sixth upper labial small, forming a suture with a very large temporal; generally with a spectacle mark on neck. 
Habitat.-East Indies.

Hydrophis, Daud.--Rostral plate broad, transverse; lower triangular; nasal truncated or notched in front; ventral shield flat; head short; eyes small.

H. obscura (Sea snake).-East Indies.

\section{PISOES.}

Gados (Cod). Order Jugulares. Family Gadidæ. Characters.-Body elongate, but little compressed, covered with soft scales not very voluminous; head well proportioned and without scales; fins soft; jaws and front of romer armed with pointed, irregular tceth, middling or small-sized, in several rows, forming a sort of curry comb or rasp; gills large, with seven rays. Fins. Ventrals separate, jugular; generally with two or three fins on back; one or two behind anus; and distinct caudal. Stomach in form of a large, strong sac; cæca numerous and long; air-bladder large, with thick walls (without duct), and often dentated upon sides. (Cuvier.)

G. morrhua, Linn.-Barbel rather long, as long as, or longer than the eye, which is one-seventh of the length of the head, and one-half, or rather more than one-half, of the width of the interorbital space. Snout more than twice as long as the eyes, obtuse, with the upper end longest. The height of the body is less than the length of the head, which is two-sevenths of the total (without caudal). The vent is situated vertically below the anterior rays of the second dorsal. The two anal fins separated from each other by an interspace. Proportions of the fins :

$\begin{array}{ccccc}1 \mathrm{D} . & 2 \mathrm{D} . & 3 \mathrm{D} . & 1 \mathrm{~A} . & 2 \mathrm{~A} . \\ 1 & 1-3 & 1-1 & 1-2 & 1-0.9\end{array}$

Greenish or brownish olive, with numerons yellowish or brown spots on the back and on the side.

Swim bladder large, broad, and having at its anterior extremity a wormlike process, which is held in relation to the muscles of the vertebral column. At the upper third of the interior surface of the bladder a congerie of vessels (wonder net) is seen, giving a reddish color to the lining membrane. Kidneys of a blackish red, thickest at upper portions. Urinary bladder small, with two appendages. Spleen long, small, triangular. Liver of a clear yellow color, very large, of three lobes, the smallest of which lies beneath the stomach. Gall bladder in the middle of the right lobe. (Brandt and Ratzeburg.)

Habitat.-The cod is found in the seas of the northern hemisphere from the fortieth to the seventy-fifth degree. Coast of North Europe, Iceland, and Greenland, southward to New York. (Günther.)

Acipenser. Class Ganoidei (Müller). Fishes with tabular or angular 
scales, or perfectly naked. Tail apt to be heterocercal; opercular gill in many; several valves in the arterial trunk; optic nerves not decussating; spiral valve in intestine; swimming bladder and air tube; skeleton generally cartilaginous; ventral fins abdominal. (Thymus gland in sturgeon and shark.)

Acipenser.-Sqúaloid; dorsal and anal fins opposite; pancreas conglomerate; one gill opening; no rays. "Upper jaw formed by palatine bones, firmly united to the maxillary ; intermaxillary rudimentary." (Storer.)

Mouth toothless. Operculum surrounded by a semicircular fold of integument. Head more or less distinctly quadrangular or club-shaped, the bones of the skin concealed by a number of superficial plates. Eyes and nares to side of head. The latter are two in number on either side, superior rounded, inferior elliptical. Muzzle produced, furnished beneath with four barbels. Malar bone (!) rightangular, outer half covered with bones of the exoskeleton surrounding the posterior part of the orbital opening. Mouth transversely oval, placed behind the eyes, upon the under side of the muzzle, in a depression. Under lip cleft in middle. Body long, covered with small scales or plates, skin rarely smooth, furnished with five rows of dermal plates, commonly assuming a pentangular form. One row occupies the median line of back, two others (one on either side) lie directly behind this, starting from the region of shoulder-blade and extending along the lateral aspect of body; and two (one on either side) extending from base of coracoid bones along the ventral region. The dermal plates composing these lines are largest above, smallest beneath. Anal fin near caudal. Ventral fin nearer anal than pectoral. Dorsal fin about opposite anal. Caudal fin heterocercal, unequally forked, the upper portion being the larger. Branchial arches five. The swimming bladder communicates with the stomach. Pancreas consisting of a single mass. Intestine furnished with spiral folds.

The sturgeon is a fresh water fish. It is found in the rivers of Northern Europe, Asia, America, and Western Africa. It may at times, however, descend to the sea.

1. A. rubicundus, Les.-Body ruddy; flat between eyes; lateral semiplates oblique $39 ; 4$ feet long. Great Lakes, U. S.

2. A. brevirostris, Mitch.--Snout blunt and short; dorsal scutes 9-12; lateral 23-29; length 2-5 feet. Eastern Rivers, U.S.

3. A. oxyrhyncus, Mitch.-Snout elongated, spatula-like, covered with strong bony plates; length 2-7 feet. Eastern Rivers, U.S.

4. A. huso. Northern Russia. 


\section{INSECTA.}

CANTHARIs.* Vesicating or blistering insects are those having the power, when locally applied, of exciting that form of inflammation terminating in a copious formation of serum under the cuticle. Very many species possess this peculiar power, all belonging to the large Order called Coleoptera or Beetles. The name 'fly,' as applied to them, is altogether a misnomer, Hies having but two wings and a suctorial mouth, while beetles, in addition to their wings, have wing-cases or elytra and a masticatory mouth.

\section{CLASSIFICATION.}

The vesicants form by themselves a family in the great order of beetles, and belong to that section characterized by heteromerous tarsi; that is, the four anterior feet or tarsi are five-jointed and the posterior pair fourjointed.

From all other heteromerous beetles they may be distinguished by the anterior coxal cavities being open behind and the coxæ themselves prominent, the head constricted behind, and the claws of the tarsi cleft or toothed. The thorax at base is always narrower than the elytra. The family thus constituted is called MELOIDe, and is divided into two tribes, as follows :

Side pieces of meso- and metathorax covered by elytra . Melorn.

Side pieces of meso- and metathorax not covered by elytra . Lytrini.

The first tribe contains five genera in our conntry, distinguished from each other by the following characters :

Elytra short, imbricated . . . . . . MELö̈.

Elytra not imbricated.

Elytra shorter than abdomen.

Elytra strongly divergent. . . . . MEgETRA.

Elytra contiguous at basal fourth . . . Nomaspis.

Elytra nearly or totally concealing abdomen above.

Elytra connate, much inflated . . . Cysteodemus.

Elytra sub-connate pubescent . . . . Hexous.

The insects of this tribe are all without wings, and will consequently never be taken in flight. Species of Meloë are found in all parts of our country. In early spring they occur under stones, while later in the season great numbers are frequently met with on certain favorite plants. They are all either dull-black or bluish black, seldom with any lustre, and in many species the males have the antennæ distorted. Megetra is New Mexican. The two

* Contributed by Dr. Geo. H. Horn. 
known species have very rugose elytra, with a more or less irregular yellow stripe; otherwise they are black, with the head sometimes red. Nomaspis occurs in Colorado; it resembles Meloë. Cysteodemus contains two species, the most singular of the family. The elytra are much inflated and deeply pitted; in one species dull-blue, and in the other more brilliant in color. They are found in the southern deserts of California and Arizona. One species at least is excessively abundant, and possesses moderate power as a vesicant. Henous occurs on our western plains and in Texas. It is deep black in color, and the only pubescent species in the group.

The second tribe of the family, Lyttini, contains by far the greater number of species and genera, the latter numbering already sixteen in our own country, divided into three sub-tribes.

Front of head not prolonged below insertion of antennæ . HorIINI.

Front prolonged, frontal suture evident.

Mandibles prolonged, acute

Nemognathin.

Mandibles obtuse, short . . . . . . Lytrini.

The first sub-tribe contains rare species, the one found in the eastern regions is black with red wing-cases, and though destitute of wings, has been seen flying by means of the elytra alone. All belong to the genus Tricrania. The Nemognathini are divided into three genera:

Maxillæ with the outer lobe prolonged.

Antennæ not thickened externally . . . Nemognatha.

Antennæ thicker towards tip, thorax conical . . GNathiom.

Maxillæ with the outer lobe not prolonged . . . Zonitis.

The prolongation of the maxillæ, in the first two genera, is a curious character, and enables the insect to obtain its food from the flowers on which it lives in the same manner as bees and suctorial insects generally. These insects are for the most part western, occurring abundantly on the plains and in California on flowering plants. The sub-tribe, Lyttini, contains twelve genera, divided into four groups :

Vertex not elevated.

Second joint of antennæ long . . . . MACrobases.

Second joint of antennæ much shorter than third . LytT $\approx$.

Vertex elevated.

Antennæ filiform, of moderate length . . . EбромРнж.

Antennæ very short, not longer than head . Phodages.

The group Macrobases contains two genera, Macrobasis with wings, and Apterospasta without. They contain some of our largest species. The third and fourth groups contain each one genus and species, and are of such rarity as never to have been experimented with. They are found in Arizona and California in desert regions. The Lyttæ are more numerous, and form eight genera : 
Penultimate joint of tarsi bilobed . . . . Tetraonyx.

Penultimate joint of tarsi cylindrical.

Lower portion of claws equal to npper.

Anterior thighs with a sericeous* hairy spot.

- Second joint of antennæ equal to half the third . . . . . . Pleuropompha.

Second joint of antennæ very short . EPICAUta.

Anterior thighs glabrous, no sericeous spot.

Antennæ filiform, outer joints cylindrical Pyrota.

Antennæ thicker externally, outer joints rounded.

Labrum decply emarginate . PoMphopea.

Labrum slightly emarginate . . LYTTA.

Lower portion of claws shorter than upper.

Labrum not emarginate, body pubescent . Calospasta.

Labrum emarginate, body not pubescent . TEGRODERA.

By the above table of characters, all the genera from our own and neighboring countries may be recognized. Lytta is equivalent to Cantharis of older authors, the latter name having been dropped on account of the confusion of species adopted at various times as its type. As several of the above genera are rare, eren in the cabinets of entomologists, it would be well to notice from among them various species capable of being used in medicine as a substitute for the Lytta vesicatoria of Europe.

Macrobasis fabricii is our common American species, nearly one-half inch long, found on various plants during the early summer months, in all parts of the country. 'The color is ashy gray with darker antennæ.

M. luteicornis is a large Texan species, occurring in very great abundance when found. It is of a light ashy-gray color, with reddish-brown antennæ, the first joint being (in the males) large and broad.

Epicauta vitatta is our common potato fly, and occurs abundantly during June and July on the potato and tomato plants. It is an elongated insect, black in color, with yellowish stripes on the thorax and elytra. This insect must not be confounded with the potato bug of the West, a short, robust insect of a different group and not at all vesicant.

Epicauta Pennsylvanica is smaller than the above and totally black.

Epicauta ferruginea and maculata are found abundantly in the plains of the West; the latter is gray, with black spots, the former ferruginous in color; both are small.

Pyrota contains many moderate or large species, characterized by a yellow body and legs; the elytra have large spots or bands of black. These all occur in our Southern States and have good vesicatory power.

Pomphopoea contains several species, occurring rarely in abnndance. They all have æneous elytra and yellow legs. One species is occasionally

* Sericeous-covered with a fine silken recumbent pubescence. 
injurious to pear-trees, and has been collected and used medicinally with most excellent effect.

Lytta contains, besides the vesicatoria of Europe, many species in all parts of the world, and all the species thus far tried have proved efficacious. In our own country every section affords species, and many are large and beautiful.

Lytta nuttalli is a very abundant species on the plains and in Oregon. It resembles the vesicatoria so closely as to have been mistaken for it. It was reported by one of the early government expeditions that bushels could have been collected at one place, and that many were swept up and destroyed to afford room for camping purposes. This is no exaggeration, as I have seen, in Calfornia, many hundreds of thousands that could have been gathered in very few minutes. Lytta nuttalli could readily be substituted for the vesicatoria and would defy detection either by the color of the powder or by its effects.

Lytta vulnerata and meloena are found in California and are those spoken of above. Numerous experiments have been tried with them, internally and externally, and the full effect of the medicine produced. Many species could be enumerated from all parts of our territory, but as they all possess the same qualities, the few abore named will suffice.

Tegrodera erosa is a beautiful species found in California, the head and thorax red and elytra yellow with two black bands, one terminal, the other median; the surface is eroded or with a raised network.

\section{SEAT OF VESICATING POWER.}

This matter has long been the subject of conjecture, and to Prof. Joseph Leidy is due the credit of experimenting with more satisfactory results than any preceding investigator. Cantharidin had long been known as the active agent, even before these experiments. A full account is published in the Am. Jour. Med. Sciences for Jan. 1860, and Jour. Pharmacy, March, 1860. In these papers it will be found that the blood is the most effective, then certain glands or appendages of the generative system, and finally the eggs. From this it will be seen that the greater portion of the body, if deprived of blood, would be totally inert. The power of the blood may be realized by any one collecting these insects. They have the habit of causing the rupture of certain of their ligaments, particularly at the knee-joint, froin which a drop will issue capable of producing a large blister on tender skin. The question has occasionally been raised as to whether certain of our species did not produce more unpleasant effects on its external application than the foreign one. There can be but little truth in such suppositions. I have used very many of our native species medicinally, and have experimented on my own person with many others, and can notice no difference. There can be no doubt that our natives are at times the more active and rapid in action. This can be attributed to the freshness of the specimens made use of, as the imported article, particularly in powder, is apt to deteriorate. 
The early history of the Meloidæ is extremely interesting. The female deposits the egg apon flowers. The egg shortly hatches, and a small louselike insect makes its appearance, which very soon attaches itself to the body of some bee or wasp and by it is carried to its nest. The parasite then leares the parent wasp and feeds at the expense of the young, and after undergoing several metamorphoses assumes the state of pupa preparatory to becoming a fully developed insect.

Besides the true vesicants, other insects and spiders have been said to produce vesication. These matters have not yet been sufficiently investigated to pronounce upon their truth. The insects that have been thus used are comparatively rare, and not at all available as substitutes for our more common Meloides.

Species of other genera than those mentioned in the above notes are occasionally used in other parts of the world, as Mylabris, Cerocoma, etc.; but as these are but rarely brought to this country, they deserve no more than a passing notice. The preceding tables have been prepared solely in regard to North American entomology. Species of many of these genera occur in other parts of the world, as well as species of very nearly as many more genera as are here enumerated.

Acantuia (Bedbug), Fabricius.-Order Hemiptera. Mouth suctorial, haustellate; wings two in number, and two wing covers or hemelytra. Exceptions sometimes occur in which the wings and cases are rudimentary or even absent. Sub-order Heteroptera. Section Geocores (antennæ equal to half the length of the body). Family Ductirostres (beak received in a groove and the front without ocelli).

Characters.-Body flat; antennæ terminated abruptly in a slender bristle.

A. lectularia, Linnæus.

The bedbug has an oval body, nearly one-fourth inch in length, somewhat narrow at the head, much flattened, and of a reddish or ferruginous color. It is covered with a very fine pubescence. The head is quadrate, with a slight lobe in front hiding the base of the rostrum. The eyes small and round. The antennæ filiform, of but four joints, of which the first is very short. The thorax is slightly excavated anteriorly and truncate behind; the sides are rather broadly dilated and semi-membranous. There are no true wings, and but short rudimentary hemelytra. 'The legs are moderate in size, rather slender; the tarsi are short, three-jointed, of which the first and third are very small, the latter furnished with two strong hooks. The abdomen is broadly oval, composed of eight segments, and fimbriated at its margin, and generally tipped with black posteriorly.

The odor of these insects is not characteristic, but is found in many other Hemiptera, and is the secretion of a gland in the metathorax opening between the hind legs.

Their eggs are laid during the warm months, and when they are hatched the young represent the old in miniature, without the rudimentary hemelytra.

'The mouth consists of a short three-jointed rostrum which, when at rest, 
occupies a groove on the under side of the thorax. The first and second joints are cylindrical and equal in length; the last is longest and conical. This apparatus is made up of three stiff, pointed setæ.

Habitat.-The bedbug is common in old or carelessly kept houses. Primarily it is an inhabitant of the woods, and may be seen under the bark on old stumps. It insinuates itself in houses by various means, and finds lodgment in cracks and recesses in all kinds of furniture. It studiously avoids light, and is seldom seen from its hiding-place during the day. It will not live on the bodies of persons, although it may take refuge in clothing and be thus transporter from place to place. The odor of the human body appears to attract these insects, though other animals are also subject to their attacks (bais and pigeons). Blood is not drawn by suction, however. After a puncture is made, the insect receives the blood by capillary attraction aided by the attending vertical motion of the several parts of the rostrum. . Those parts of the human body furnished with odiferous glands appear to be free from their attacks. It is very doubtful whether, as has been said, they ever introduce themselves into any of the cavities of the head, especially the ear, with its guard of ceruminous material. The mark from the bite is familiar to all. The irritation produced is doubtless due to the introduction of some of the juices of the insect into the wound.

The bug has its insect enemies. The Reduvius personatus seeks nearly the same habitations with the bedbug, and when in search of prey covers itself with dust and other material, so that it is impossible to recognize it. It attacks the bedbug with its rostrum (it also is a Hemipterous insect) and finds it an easy prey. Ants also seek and eagerly devour bedbugs.

Many other Hemipterous insects have the power of injuring man by the prick of their rostrum. Among the most notable of these are the Prionotus novenarius and several species of Notonecta and Nepa.

Prionotus novenarius may be found during the summer months on fences, etc., in the country. It is generally about one inch long, and covered with a very fine and dense cinereous pubescence. The head and neck are long and cylindrical; the thorax elevated into an acute serrated ridge, convex from front to rear. The sides of the abdomen are reflexed, giving that part of the body a concave appearance. The bug walks very slowly and with meas. ured steps, and when caught by one not expert, inserts his rostrum into the hand, causing a feeling of acute pain which may last for some hours, but gradually passes away, leaving a feeling of numbness in the part.

Notonecta (Boat-fly), Geoff--Hemiptera. Scutellum distinct, rostrum conical and articulate, tarsi of two joints each. The four anterior feet elbowed with the tarsi cylindrical, simple and terminated by two hooks. Antennæ very short and but four-jointed. The thorax wider than long. The hemielytra cover the abdomen abore. The first two pair of legs are very short and constructed on the plan of the land Hemiptera. The hind are, however, very long and fimbriate, acting the purposes of oars, propelling the insect with considerable rapidity under water. Body somewhat fusiform, obtuse in 
front. The whole insect is of a greenish color, with irregular patches of darker hue.

It measures rather more than $6^{\prime \prime \prime}$ in length.

Habitat.-Small streams during the summer.

In their larval condition, and even when adult, these animals feed upon other aquatic insects. The wound occasionally received upon handling the Notonecta is very painful, and rather large, from the obtuseness of their rostrum.

NePa (Water-scorpion).- - Hemiptera. Anterior tarsi of one piece, the four posterior tarsi of two. The antennæ forficulate, short, and threejointed; rostrum short, obtuse, and curved beneath. The two anterior feet with short coxæ, and the femora much larger than the other parts. Body straight, elongate, and presents an elliptical contour. Abdomen terminated by two slender bristles, which are employed in respiration.

In form they are elongate oval, depressed. Their color is testaceous or dark-ash. They vary in length from $\frac{1}{4}$ " to $4^{\prime \prime}$ or 5 ". The larger species are tropical.

Habitat.-Fresh water streams-preferring still water.

The insect is a very poor swimmer, preferring to walk along the bottom of streams. It flies at night with great rapidity, and takes wing by climbing to the upper end of any twig growing in the water. The rostrum, as in Notonecta, is short and obtuse and the wound inflicted very painful but not at all dangerous.

A PHIs. Antennæ, properly speaking, longer than the thorax, composed of seven articles. The tarsi are composed of two articles; the antennæ are filiform, or in the form of setæ, longer than head, and composed of six to eleven articles. Bodies short, oval, and soft, and furnished at the hinder extremity with two little tubes, knobs, or pores, from which exude almost constantly minute drops of a fluid sweet as honey; heads small, beaks long and tubular; eyes globular; upper wings nearly twice as large as the lower, much longer than body, nearly triangular, and gradually widened toward the extremity; they are almost vertical when at rest, and cover the body like a sharp-ridged roof. (Harris.)

Measurement. $-1 \frac{1}{2}{ }^{\prime \prime \prime}-2^{\prime \prime \prime}$ long.

Habitat.-A variety of plants. A. rosa is found on the rose-bush; $A$. brassica, the cabbage. The irritation excited hy the act of the insect securing its food causes excrescences to grow upon various parts of the infected plant. These are technically known as 'galls.' Thus a 'gall case' is obtained from the Dactylium racemosum. The pistachia galls are derived from pistachia tree of Southern Europe. The Chinese galls are the product of an imperfectly known tree.

Coccus.-Hemiptera. Tarsi each with but a single point, with a single hook at end. Male without rostrum, but possessed of two wings, which lie horizontally upon the body; abdomen terminated by two setæ. The female without wings, and provided with a rostrum. Anten composed

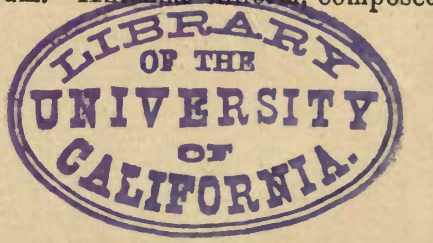


often of eleven articles. (Regne Animal.) These insects vary very much in form; some of them are oval and slightly convex scales, and others have the shape of a muscle; some are quite convex, and either formed like a boat turned bottom upwards, or are kidney-shaped, or globular.

Measurements. $-1^{\prime \prime \prime}-1_{\frac{1}{2}}^{\prime \prime \prime}$ in length.

Habitat.--They live mostly upon the bark of the stems of plants; some, however, are habitually found under leaves, and some on roots. The supply for commercial purposes is received from Mexico. Specimens have been seen on Opuntia in Nevada, by Mr. Wm. M. Gabb, and in Idaho by Lt.-Col. A. W. Bowman, U. S. A.

Species mentioned in connection with medicine: C. cacti; C.illicis; C. lacca. (Moquin-Tandon.)

ApIs.-Hymenoptera. Neuter. Body nearly cylindrical, and subpubescent. Head transverse, about as wide as the thorax; vertex and face deeply longitudinally channeled in the centre; the ocelli rather large; compound eyes very pubescent; antennæ short, filiform, geniculated; the scape (basal joint) nearly half the length of the flagellum (remaining joints), and subfusiform; clypeus (piece behind labrum) quadrate, convex; labrum transverse, linear, slightly waved in front; mandibles broad at apex ; cibarial apparatus short. ish; tongue nearly twice the length of the labrum, linear, pubescent, and terminating in a small knob; labial palpi not quite so long as tongue ; maxillæ broad, hastate (triangular); maxillary palpi extremely short, the basal one the shortest. Thorax subglobose; prothorax inconspicuous; metathorax truncated; legs slender, subpilose ; the anterior and intermediate tibiæ with a spur; their plantæ (under surface of first tarsal joint) with a dense short close brush all round; the posterior tibiæ triangular, glabrous within, externally smooth, shining, and irregularly concave, the edges fringed longitudinally with long hair curving inwards, and forming the sides of the corbiculum (receptacle), which conveys the material of the nest; the apex transverse and pectinated with short rigid setæ, but wholly without spurs; the plantæe oblong, not quite as long as the tibiæ, the sides nearly parallel, the upper edge fringed with long, loose hair, subglabrous externally, but furnished internally with ten transverse parallel rows of short hair; the remainder of the tarsal joints short, the fourth the shortest, and the claw-joint the longest; the claws short, robust, and bifid. Abdomen retuse (obliquely truncate at base), subcylindrical, convex above, and terminating conically, the first segment very short, the second the longest, the ventral segments rigid longitudinally in the centre.

Female (Queen) head not so wide as thorax, in having the cibarial apparatus very much shorter; the mandibles distinctly bidentate, the inner edge of the inner tooth stretching obliquely to the acute inner extremity of the broad apex of the organ; the labial palpi as long as the tongue, with all the joints conterminous, the basal one slightly acuminate, the second linear, the two terminal ones more slender and shorter, the pubescence of the eyes very much longer than in the neuter; the legs more robust and less pilose; 
the posterior tibix convex externally, without the lateral fringes of hair, and their plantæ merely oblong, without the external basal auricle. The abdomen is also considerably relatively longer, and has not the central ventral ridge.

The male (Drone) differs from both in being considerably more robust and more completely cylindrical, and very much more densely pubescent; the compound eyes contiguous at the summit, occupying the whole of the vertex and nearly all the lateral portions of the face, extending below the articulation of the mandibles, their pubescence much shorter, but denser than in the other sex; the ocelli large, and seated at the top of the central portion of the face in a close triangle, a little above the insertion of the antenuæ, and in front of the conjunction of the compound eyes; the antennæe are more robust and rather longer; the cibarial apparatus rather short; the labial palpi about three-fourths the length of the tongue, and the joints conterminous, the tongue robust; the thorax nearly quadrate, the legs nearly naked, the four anterior very slender; the posterior tibiæ slightly curved, convex externally; the posterior plantæ more robust, and more convex externally than their tibiæ,- they are regularly oblong, and without the basal auricles,-the rest of the joints of the tarsi are very short. The abdomen robust, and obtuse at its extremity, but its seventh segment is concealed beneath; the ventral segments concave longitudinally, (Shuckard.)

\section{A. mellifica,-Linnæus.}

Crnsps (Gall-fly).-Hymenoptera. Antennæ 13 to 14 pieces; wings not markedly nervose; their palpi short, and ovipositors longer than abdomen. Head transverse, small; the thorax large; abdomen compressed, the profile somewhat circular and generally furnished with a short pedicle. Antennæ inserted upon the middle of face; those of the $q$ are ordinarily shorter and thicker than the $\delta$. Ist joint is thick, $2 d$ short, $3 d$ is larger than the other two and often scalloped or curved in the $\hat{\delta}$. The upper lip is very small; mandible short, thick, with extremity armed with small teeth; jaws terminating in a membranous lobe (galea); maxillary palpi have five joints, and the labial palpi two or three.

The greater part of the thorax is from the mesothorax. Wings are cellular, the greater portion being made up of cells at the radial or cubital margins. The $2 d$ pair leave up a single very thick nerve.

The 1st segment of the abdomen is large, while the others are short. The superior is arched and prolonged under the ventral face. One segment forms a salient point, and directed posteriorly protects the position of ovipositor. This latter is extremely slender and lodged in the abdomen, or it is protected by two valves or two semi-straight. The organ itself is extremely short and composed of a single incomplete cylinder, which is lodged in two slits or spicules composing the ovipositor proper. It resembles the ovipositor of other Hymenoptera. It is moved by strong muscles, and is not seen externally in a state of repose. 
The larvæ of the gall insect are apodal. Some live five and six months, then descend to earth and assume the condition of nymph. Others go through all their changes in the gall itself.

Species.-C. quercus tinctoria, C. kollari, C. rosce, C. longipennis, C. insana, C. polycera, C. hungarica.

Pulex (Flea). Hemiptera. Mandibles and lingua long, setiform; maxillæ small, triangular, palpi four-jointed; labium minute, palpi three-jointed. Body compressed. Antennæ short with three joints, the last large, flat, serrated, received in a small cavity, and covered with a scale. Max. palpi with four joints, porrect. Post. feet saltatory. Tarsi with five joints.

Four small round plates, situated between last two segments of thorax; post. pair largest, and represent rudiments of wings. Eyes two, simple; wanting in $P$. vespertilionis. No marked distinction between thorax and abdomen.

Development.-- $q$ twelve eggs, rounded, whitish color; larvæ, grubs with thirteen joints, last two hooked. Twelve days as inactive pupæ.

$P$. irritans (Common flea).

$P$. penetrans (chigue, chigger, jigger). The $q$ and $\delta$ do not attack man prior to impregnation. After this, $q$ introduces itself under the nails or between toes of feet; causes a white globular vesicle, by rapid growth of larvæ, which are contained in a sac attached to abdomen by mother. In treating this condition the small orifice is gradually dilated and the objects removed. Scotch snuff or capsicum then placed in wound.

Pediculus (Louse).-Diptera. Antennæ as long as thorax; sucker is an inarticulate sheath, armed with retractile hooks; eyes simple; abdomen notched at borders.

$P$.capitis.--Thorax distinct, elongate, quadrangular, narrower than abdomen; seven segments notched at margin ; stigmata upon six ant. segments, circular, and furnished with a small opening in the middle. Stigma between first and second pairs of feet is often indistinct, and resembles a papilla. Color varies, livid or pale gray, and is said to adapt itself to that of the hair; all the segments are blackish on the margins. In the human louse, transverse ridges; feet similar; tarsus one joint,--bears a large claw on its outside, and on its inside two straight, thick, horny stumps, and a large bristle. Essophagus short; stomach longish; two cæcal appendages; intestine slightly sigmoid,-receives four urinary vessels at its extremity, and passes on into the pyriform large intestine.

$\hat{~}$ fewer; last abdominal segment is prominent and rounded off, furnished on its dorsal surface with a valvular opening, beset with an abundance of asperities, anal and vaginal ; two pairs testes; simple, wedge-shape penis, base upwards, apex outwards, opens on back,--chitinous.

$q$ apex caudal not notched; two lobes, between which is the anal aperture; two ovaries consist of five tubes each, forming two oviducts emptying 
into a common vagina, into which two seminal receptacles open; genital pore on ventral surface between penultimate and last segment. Its lower surface forms a transverse ridge. Copulation by $\hat{\delta}$ beneath $\uparrow$. Eggs pyriform, $\frac{1}{4}$ "'; in six days young escape; a louse fifteen days old can lay. $\nmid$ lays fifty eggs.

Two $q$ might become progenitors of 10,000 lice in eight weeks; a single generation may furnish 2500 lice, the third 125,000 . (Leuwenhoek.)

$P$.vestimenti.-Body louse pretty near preceding. Head exserted, elongated in second joint; antennæ elongated; thorax divided into segments; dirty white, blacker on margins; principal distinctions between body and head louse pertaining to size. joints.

Phthirius.pubis. - Fiddle-shaped head; prominent eyes; antennæ five

Habitat.-Pubis, hairs of breast, eyebrows, eyelashes.

Schultz regards lice beneficial; couriers cherish them, to place them under the prepuce of their horses to excite animation.

(Pyrethrum caucaseum, Persian insect powder.)

\section{ARACHNIDA.}

Sarcoptes. Body circular, indented towards centre and obtase posteriorly, soft, shiny, slightly transparent, of a whitish color. Dorsal surface convex, ventral less so. Margin slightly undulating, and the surface of abdomen is marked by more or less parallel, irregular, but curved lines or ridges. Rostrum anterior and straight, somewhat oval, obtuse, two setæ at base. Limbs eight in number, two pairs in front, and two placed farther back. Limbs short, conical, distinctly jointed and furnished with hair-like processes. The two anterior pair arise from the thorax; they have thighs divergent; the feet terminate in slender, straight, rigid, setæ, tubular segment provided at its extremity with a sucker. The four posterior feet pertain to the abdomen; they terminate in a long, curved, pointed thread, without sucker. The body of the insect has a few hair-like processes scattered here and there, and on its dorsal surface are three kinds of horny appendages or spires; the first fourteen in number are arranged symmetrically on its central and posterior parts, of a conical form, are traversed by a canal, and furnished with a dilatation or basal follicle; the second are sinaller, and placed near the first; the third are still more minute; they are arranged in concentric lines, have no canal, and resemble conical-pointed tubercles.

The parts about the mouth are surrounded at their commencement by a thin sinuous margin, portions of which extend as far as the organs themselves. These are as follows: 1st. A pair of strong mandibles, carrying toward their extremity and on thair upper side a small movable hook; this 
is pointed, somewhat curved, and when not in use is received into an oblique groove, with irregular dentated margins, situated on the opposite side of the prolonged portion of the organ. 2d. The maxillæ,--these are small, narrow, and curved from without inwards. Their base is articulated to a small square piece, the chin. Their palpi are large pieces supported by the maxillæ, curve-pointed, and composed of three unequal joints. The terminal joint, which is the smallest, presents externally a single long hair, while the middle joint has two. 3d. The labium; this is nearly triangular and somewhat pointed. Toward its base and on both sides there is very long hair. 4th. The tongue; this is lancet-shaped, and placed in median line.

The œsophagus is long and straight. Arrived at the anterior third of the body, this canal terminates in an oblique reniform stomach, transparent and difficult to observe. Intestine short and slightly undulating; it contains a number of brown granules, which occasionally accumulate toward its termination. Respiration effected in skin. Sexes on separate individuals. Male smaller, more oblong, flatter, of a darker color, and more active; the rostrum is proportionately smaller and less triangular; they have not so many horny appendages on the dorsal surface. The anterior feet extend beyond the anterior third of the body, reaching nearly to its centre; the posterior limbs are not so wide apart; the third pair of feet are furnished with longer hairs ; lastly, the fourth pair are much shorter, and have ambulacra furnished with a sucker. The genital apparatus is placed toward the middle of the body, near the third pair of limbs. The testicles are simple, the vas deferens with two median glandular bodies attached; the penis of tolerable length, contained within a groove; genital pore a little in front of the posterior margin of body. Males fewer in number than the females, the proportion being about one of the former to ten of the latter.

With the female the genital pore is situated on ventral surface at a short distance from the sternal plates. It communicates with a granular body hardly discernible except at the period of reproduction. The female is oviparous, laying one egg at a time. The young Sarcoptes are active, and possess but six legs. (Moquin-Tandon.)

S. scabei.

Demodex. D. folliculorum.--Body grayish white, semi-transparent; head compounded with thorax (cephalothorax); rostrum small, two lateral palpi with sucker placed between them; last terminal joint seven palpi notched; lip two slender pieces ; abdomen vermiform ; feet of three joints, last provided with three hooks, one long, two short; young animal with six feet; eggs elliptical; $q$ oviparous-three varieties seen in relation to development of abdomen, either shorter than, as long as, or longer than cephalothorax.

Habitat.-Sebaceous follicles of face, nose, and auditory canal.

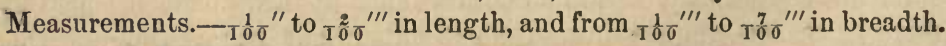

Simon and Henle found them in ext. aud. meatus. Found present in one in ten individuals. Greasy freckled faces more liable. Live in colonies, fifteen to eighteen being found in a single follicle. 


\section{MYRIAPODA.}

Scolopendra. The mouth of the Scolopendra is composed of a squareshaped lip, of two mandibles, of two palpi, or small foot jaws, and of a second lip formed by another pair of dilated foot jaws, which are joined together at their commencement. The latter are the organs which constitute the formidable weapons of the animal. The poison gland is lodged in the interior of these organs towards the base. It is oval, oblong, and provided with a long, narrow excretory canal. The forceps terminate in a strong, pointed, movable hook; the claw is provided with a small oblong aperture on its under surface, which allows of the exit of the poison. (Moquin-Tandon.)

S. scopoliana, Europe; S.heros, Texas.

\section{ANNELIDA.}

Hrrudo (Leech):-Sub-class Discophora. Order Hirudinea.

Characters.-Elongate-articulates, with flattened bodies, narrowed anteriorly, broadened posteriorly, composed of ninety-five equal and distinct rings, which project at the sides. The dorsal surface is marked with six parallel longitudinal bands of a reddish or brownish hue, spotted with black, continuous or intercepted, and sometimes reduced to mere points. The ventral surface is either of a uniform color or spotted with black, and bordered on each side by a straight or undulating line of the same color. The anterior extremity is provided with an oral sucker, having an acuminate upper lip. The posterior extremity bears a round, obliquely placed sucker, at the base and upper part of which is the anus. Within the month are three pairs of jaws, furnished with minute teeth. The eyes are ten in number, small: they are placed on the upper lip, where they form a curved line, the six anterior being the largest. Leeches are androgynous. The sexual orifices are placed on the anterior third of the belly; the male orifice between the twenty-seventh and twenty-eighth ring, and the female five rings farther back. The first is a minute pore surrounded by a thickened margin; the second, a small transverse slit.

H. medicinalis (Gray lcech), Linn. Body olive green mixed with gray. Six rusty red longitudinal stripes mark the dorsal surface. The sides are olive green; the belly is spotted with black.

Habitat.-Northern Europe and certain parts of northern Africa.

H. officinalis (Green leech). Body of a clear olive or green color. Dorsal surface distinguished by six rusty red longitudinal bands, generally con- 
tinuous. The margins are of an olive color both on the back and belly. This species closely resembles the above, and is found in the same localities.

H. decora (American leech), Say.

Body livid, with a dorsal series of twenty-two small red dots, and a lateral series of the same number of black dots of a similar size; a transverse line of ocular points in close order before; on each side of which, and at a short distance from them and from each other, are two points of the same kind; hence the fulvous with a few black spots.

Anatomy.-The jaws of the leech are three in number, placed longitudinally : one superior and median, two others inferior or lateral. Each jaw is semicircular, thin, smooth, and moderately strong. The free convex surface is furnished with forty-six to eighty-three teeth-like chevron-shaped processes, arranged parallel to each other and placed across the cutting edge of the jaw, having the angle turned toward the axis of the mouth. (MoquinTandon.) The ventral ganglia of the nervous system are much fewer than the segments of the body, and are bound together by two contiguous cords. The first and last of these ganglia are remarkable for their size. The first sends filaments to the lips, the second to the caudal sucker. Each eye-speck composed of a transparent cylindrical body, a little attenuated and rounded at its inferior extremity, while the opposite one causes the skin to bulge out like a cornea. Its remaining portion is enveloped with a layer of black pigment. The intestinal canal varies very much, especially as to the number and volume of its appended cæca. Its very narrow anal opening is upon the back above the pedal sucker. The blood-vessel system resembles in plan that of other Annelida. Beside two median vessels, there are distinguished two lateral ones, which intercommunicate by very numerous transverse vessels. From the contractions of these vessels, the blood is driven sometimes forward and sometimes backward, and oscillates from side to side through the transverse canals. With the Hirudinea the two sexes are always united in the same individual. The sexual organs consist of testicles, vasa deferentia, and vesiculæ seminales; then ovaries, oviducts, and the male and female copulatory organs. The latter are upon the ventral surface of the anterior part of the body and behind the male organs, so that two individuals, by placing together their anterior ventral surfaces in an inverse position, can be mutually impregnated. 


\section{ENTOZ0A (Internal Parasites).}

Parasites may be either vegetable or animal.

Among the former may be mentioned, Achorion schönleini, Oidium albi. cans, Sarcina ventriculi, Penicillium glaucum. Animal parasites chiefly belong to the articulate type. Divided into Entozoa and Ectozoa.

Ectozoa, see pp. 151, 156, 157, 158.

Entozoa divided into-

$\begin{aligned} \text { Helminths. } & \left\{\begin{array}{l}\text { Nematoidea. } \\ \text { Trematoda. } \\ \text { Cestoda. }\end{array}\right. \\ \text { Protozoons. } & \left\{\begin{array}{l}\text { Parasitic Infusoria. } \\ \text { Psorospermiæ. } \\ \text { Gregarinidæ. }\end{array}\right.\end{aligned}$

Nematoidea. Body elastic, hollow, sub-cylindrical. Alimentary canal simple. Head but slightly protractile. (Diesing.) A fine chitinous cuticle invests the body to be shed twice a year. A water-vascular system exists in the form of two long tubes, ending cæcally at each end and traversing each lateral thickening of the dermis. Toward the anterior end of the body each tube gives off a small branch, and these two branches uniting together open externally by a small pore. The nervous system may be said to consist of an œsophageal ring, with three ganglia-two lateral and one ventral, the latter being far the largest. Nervous fibres are continued backwards along the ventral side of the body to the anus; and several nervous fibres are said to run forward from the œsophageal ring. No sensory organs have been discovered besides the papillæ of the mouth, except in free forms, which are provided with eyespots. The alimentary canal is of variable form. The Nematoidea were supposed to be all diœcious by Schneider; but the Anguillidæ inhabiting putrefying snails have an ova-testis, and the same structure has been said to exist in an Ascaris. Males smaller than females; each has a long vas deferens opening below, in the front wall of a sort of cloaca, while its cæcal upper end furnishes sperm cells, the complete development of the spermatozoa only taking place inside the female. The oviduct of the latter is similar in form to the male tube just mentioned, and ova are secreted at its cæcal upper portion. (Huxley.)

Trichina. 
T. spiralis. Body rounded and filiform; usually slightly bent upon itself, rather thicker behind than in front, especially in the males; head narrow, finely pointed, unarmed, with a simple, central, minute oral aperture. Male possesses a bi-lobed caudal appendage, the anal aperture situated between its lobes; penis, consisting of a single spicule, cleft above to assume a $\mathrm{V}$-shaped outline. Female stouter than male, bluntly rounded posteriorly; genital pore at anterior fifth of body.

Measurements.-Male, $\frac{1}{1{ }^{\prime \prime}}{ }^{\prime \prime}$ long; female, $\frac{1}{8}{ }^{\prime \prime}$.

Habitat.-Intestine of man and hog.

Development.-The mature female inhabiting the intestine, after producing active young, dies and is removed with the ejecta. But the embryos remain within the host, very soon to penetrate the walls of its intestine. After assuming the desired position among the tissues they become encapsuled and remain quiescent. When a portion of flesh thus inhabited is consumed by another animal the larvæ again become active within its alimentary canal, and soon take on the sexual form. Coition now occurring, the female brings forth broods of larvæ as before. The conditions attendant upon the passage of large numbers of larvæ from the intestine to the surrounding tissues constitutes the disease 'Trichiniasis.

The most conspicuous instances of the disorder are seen when the infected flesh of the hog is eaten, either raw or imperfectly cooked, by man.

Strongylus. Body subcylindrical, rarely prismatic; attenuated at either end. Head naked, continuous with the body; rarely alate. Mouth terminal, orbicular limb not horny, naked or papillose. Caudal extremity of male with terminal entire bursa, truncate; with one or more radiated setæ. Penis filiform, contained within a bi-partite sheath. Genital pore of female placed anteriorly, rarely posteriorly. (Diesing.)

S. bronchialis, Cobbold. Caudal appendage with a bi-lobed membranous semi-bell-shaped bursa (supposed to be an accessory organ of copulation) which surrounds the cloacal outlet. Penis a double spiculum lying in cloaca. Female, tail sharply pointed, anus little in front or above the narrow part; body filiform, pale yellow color, $\frac{1}{35}$ of an inch broad; viviparous.

Measurements.-Male, $6^{\prime \prime \prime}$ long, ${ }^{\prime}{ }^{\prime \prime}$ " wide; female, $1^{\prime \prime}$ long, $\frac{1}{35}{ }^{\prime \prime}$ wide.

Dis. by Treutler, Germany, 1791, in the bronchial glands of an emaciated subject. Confined to the air-passages.

Tricocephalus.-Body subcylindrical, rather thick. Male mostly spiral; female straightish. Neck very long, gradually thickening posteriorly. Head scarcely distinct. Caudal bursa rarely unarmed, with a filiform penis withdrawn within a retractile sheath. End of tail of female straight and somewhat obtuse; genital aperture at base of neck. (Diesing.)

T. dispar, Rudolphi.-Male, long; neck, two-thirds length of body; skin with wart-like appendages on one side only; tail curved, emitting at extrem- 
ity a short tubular penis; sheath armed with minute retroverted spines; tail straight and bluntly pointed.

Measurement.-Male. $1 \frac{1}{2}{ }^{\prime \prime \prime}$ long; female, $2^{\prime \prime \prime}$ long. Eggs $\frac{1}{4 \frac{1}{8}}{ }^{\prime \prime}$ to $\frac{1}{4 \frac{1}{4}} 7^{\prime \prime}$.

Habitat.-Head of large intestine.

Ascaris.-Body subcylindrical, subequal at either end, rarely armed. Head subconical, continuous with body. Mouth terminal trilabiate, when closed assuming the form of a triangle. Caudal extremity naked or winged. Penis filiform, enclosed in a bipartite sheath with linear branches, sometimes very long. Genital pore of the female in front or posterior part of the body. Rarely viviparous. (Diesing.)

A. lumbricoides, Linnæus.-Body smooth, fusiform and elastic, marked by numerous fine transverse rings, and attenuated gradually toward either extremity, the anterior terminating in a much-produced tripapillated mouth, the posterior in a bluntly pointed tail ; female much broader than the male, having a diameter of $\frac{1}{4}$ of an inch and a circumference of $\frac{3}{4}^{\prime \prime \prime}$; male reproductive organs furnished with a double speculum or peuis, extremity of body arcuate; female genital pore at lower part of the anterior half of the body. Measurements. - $\delta$ from $4^{\prime \prime}-6^{\prime \prime}$ long; $q 10^{\prime \prime}-14^{\prime \prime}$ long. (Cobbold.) Intestine terminates in a cloacal cavity which opens by a transverse slit at a short distance from the end of body. Skin of two layers: external, chitinous; internal, granular. Spermatic tube $3^{\prime}$ long in most specimens; oviducts $4^{\prime}$. Gullet long, somewhat triangular, with thickened walls; very narrow at its commencement, it gradually increases in size, and is then suddenly constricted. The stomach consists of two globular dilatations; its walls are thinner than those of the œophagus. The intestine is straight, and presents some slight bendings; it becomes narrower toward the vent. The canal appears to be surrounded by white vesicles suspended in the cavity of the body. The anus is near the posterior extremity of the animal, and has the form of a transverse opening. The nervous system composed of two white cords running along the sides of the body; no ganglia apparent. The testicles and spermatic cords are filiform, and surround the alimentary canal. Vagina narrow, uterus short, provided with long flexible horns. These become continuous with the ovaries, which are long, and twisted upon themselves around the alimentary canal.

Development imperfectly known. Eggs are deposited in water. The embryo subsists for a long time active within the egg capsule. (Moquin-Tandon.)

Habitat._Small intestine.

A. mystax, Rudolphi.-Moderate size; alaeform appendages, one on either side of head; mouth trilobate. Male $2 \frac{1^{\prime \prime \prime}}{2}$ long; tail arcuate; body coiled; spicules $2-\frac{1}{2} 0^{\prime \prime \prime}$ long. Female 4 inches long; less coiled. Eggs measure $310^{\prime \prime}$.

Habitat.- 
Oxyuris.-Body subcylindrical, rather thick; caudal extremity acute; head continuous with the body; mouth terminal, naked, or papillose; caudal extremity of the male with a thorn-like process; penis filiform, enclosed within a tubular sheath; female awl-shaped, with the genital pore at the anterior part of the body. Oviparous. (Diesing.)

O. vermicularis, Bremser.-Male: caudal extremity obtusely pointed; head truncated; mouth with three papillæ; œsophagus triangular; penis single, very small. Female : tail long, tapering, terminating in three points. Eggs oblong, asymmetrical, $\frac{1}{1400}$ in length, $\frac{1}{90} \sigma^{\prime \prime}$ in diameter. The water vascular system composed of four vessels-one dorsal, one ventral, and one on either side.

Measurements.-Male, $\frac{1}{6}$ "long; female, $\frac{1}{3}-\frac{1}{2}$ "long.

Esophagus with thick muscular walls, dilates into a kind of crop at its junction with the stomach; the latter is short and globular. The commencement of the intestine is enlarged, so that the alimentary canal has the appearance of three stomachal dilatations. The intestine is nearly straight, uns in the length of the animal, and preserves a uniform diameter up to the rectum. It becomes enlarged at the posterior part of the body, forming a short rectum, to again gradually narrow like the tail of which it fills the cone. The anus, placed at the middle part of the base of the tail, is a transverse slit. Development not known.

Habitat.-Large intestine.

Sclerostoma.-Body subcylindrical, attenuate at either end; head subglobose; mouth terminal, margin subcorneous, toothed or papillose. Male caudal bursa entire or lobed, multiradiate; penis enclosed in a bipartite sheath. Female straight; genital pore either in anterior or posterior part of body. (Diesing.)

S. duodenale, Cobbold.-The oval papillæ four in number asymmetrically arranged, uneven, horny (probably chitinous), conical converging; head slightly pointed; tail blunt, partially inflexed; bursa cup-shaped, supported by eleven chitinous rays-ten simple, odd one bifurcated at summit.

Female.-Tail sharp, conical; genital orifice (?); oviparous; eggs (?). Females more numerous than the males.

Measurements.-Male, $\frac{\frac{1}{3}^{\prime \prime}}{3}$ long ; female, $\frac{1^{\prime \prime}}{3}$ long.

Dracunculus.

D. medinensis (Guinea-worm), Cobbold.

Male unknown. Body terminating in a more or less curved, reversed mucronate tail; head somewhat truncate or flatly convex, with a simple 
mouth surrounded by four papillæ; viviparous. The young almost fill the cavity of body. No anus. Cavity of body chiefly occupied by uterus, intestine being inconspicuous between it and integument.

Confined to old world-tropics of Asia and Africa.

Measurements. - $\mathrm{l}^{\prime}$ to 2 ' long; $\frac{1^{\prime \prime}}{10}$ thick.

The animal is parasitic only in the adult condition. The young exist in fresh water pools and mud of marshy districts. From such localities they gain access to the subcutaneous and intermuscular cellular tissues of man, dogs, and horses, most probably by penetrating the ducts of the sweat glands. The female thus lodged grows rapidly and produces large numbers of living young, which subsequently escape to pass the embryonic stage in or about water, as already stated.

Eụstrongylus. Body subcylindrical, conspicuously attenuate at either end. Head continuous with body. Mouth terminal, papillose. Bursa of male entire, neither radiate or furnished with appendages. Penis filiform, long, without sheath. Genital pore of female placed anteriorly or posteriorly.

E. gigas, Diesing.-Male. Body cylindrical, and more or less deeply tinged with red; head obtuse and furnished with a simple oral, surrounded by six papilliform, chitinous nodules; caudal extremity displaying a simple round cup-shaped bursa, devoid of any radiating appendages; penis consisting of a single spiculum. Female. Tail bluntly pointed, and pierced by the anal aperture; vaginal orifice situated on the ventral aspect, at a short distance below the so-called head; mode of reproduction probably viviparous. Eggs broadly oval.

Measurements.-Male, $10^{\prime \prime}$ to $14^{\prime \prime}$ long; $3^{\prime \prime \prime}$ wide. Female, $3^{\prime}$ long; $6^{\prime \prime \prime}$ wide.

Habitat.-Kidney.

Trematoda (Flukes), Rudolphi.-Animals solitary, for the most part hermaphroditic, rarely unisexual, and commonly furnished with median or lateral suctorial pores. Alimentary canal forkedly divided or ramose, very rarely simple. Generation rarely direct-alternate generation the rule. (Küchenmeister.)

Fasciola.

F. hepatica, Linn.-Body flat, anterior end abruptly constricted, produced, rounded and pointed, forming so-called head and neck; posterior extremity 
less acuminate, sometimes rounded, or even slightly truncated; margins smooth, occasionally a little undulate, especially toward the upper part; oral sucker terminal, oral rather smaller than the ventral (acetabulum), which is placed immediately below the root of the neck; reproductive orifice in the middle line, a little above the lower sucker; intromittent organ usually protruded and spirally curved; a central, light-colored space, extending twothirds of the body from above downward, marks the region of the internal female reproductive organs, being bordered on either side and below by a continuous dark band, indicating the position of the so-called yolk-forming organs; a small brown colored, rosette-figure, placed directly below the ventral acetabulum, shows the limits of the uterine duct; a series of dark lines, branching downward and outward on either side, marks the position of the digestive organs. General color of body pale brownish yellow with a slight rose tint. (Cobbold.)

Measurements. $-8-14^{\prime \prime \prime}$ long; $3 \frac{1}{2}-6^{\prime \prime \prime}$ wide. (Küchenmeister.)

Anatomy.-Mouth at apical or lower part of the cup-shaped cavity of anterior sucker. Esophagus divides into two primary intestinal divisions, the point of bifurcation being situated immediately above location of ext. reproductive orifices. These divisions pass down on either side to terminate at caudal extremity, giving off from the side a number of branches dicotomously dividing. The terminal branches are of nearly the same diameter as those which are first given off. Water vascular system a central long trunk, extending backward from the upper third of the body to the tail, where it terminates in a foramen. This central tube divides into three branches, which again more or less subdivide, anastomosing among themselves. The tubes during life are filled with a watery fluid, containing a number of small non-nucleated corpuscles, which are highly refractile. (Huxley.)

The Fasciola is hermaphroditic. Testes, one on either side, formed of a multitude of vermiform tubes, occupying one-half of the interior of the animal. The two vasa deferentia converge and unite in a single tube widened toward its outlet (receptalium seminis), finally terminating in a large spiral penis. This latter organ, in a state of rest, lies within a distinct sheath, and is covered with a fold of integument, furnished with a number of spines. Single ovary situated in median line at anterior third of body; emptying into it upon either side are the ducts of the yolk-bearing glands, - two large masses, placed one on either side of body, and partially enclosing the testis. The oviduct is short, uterine expanse of tube abrupt, convoluted, terminating in vaginal pore directly behind and on a line with that for the male organ; oviparous.

Habitat.-In bile duct and gall bladder of a number of mammals; rare in the human subject.

Distoma. Body depressed or slender. Head continuous or same as the neck. Mouth terminal or anterior, frequently acetabuliform. Genital pores 
approximate. Acetabulum single, ventral, sessile or pedicellate. Anus at termination of caudal extremity or placed dorsally. (Diesing.)

D. lanceolatum, Mehlis. Lancet-shaped, very flat, tolerably transparent, and of a whitish color. The oral sucker is proportionally larger than in preceding species and about the same size as the ventral sucker; they are both circular. Intestine straight, diœecious, unbranched; penis not spiral. (Moquin-Tandon.) The testes form two lobed organs, placed one in front of the other in the middle line of the body, and directly below the ventral sucker; the uterine canal is long, folded, occupying the central and hinder parts of the body. The yolk glands cover a small space near lateral margin of animal. The opening for water vascular system is terminal; it commanicates with a contractile vesicle, which passes upward, early dividing into two branches, which extend as far as the base of œesophagus to retrace their course a considerable distance backward. (Cobbold.)

Habitat.-In the bile passages and upper portion of small intestines of several mammals; rare in man. Has been detected in sole of foot and behind ear.

Measurement. $-2-6^{\prime \prime \prime}$ long; 1-2 $2^{\prime \prime \prime}$ wide.

D. opthalmobium, Diesing. Body lanceolate, oval form. Suckers circular; posterior farther from cephalic extremity than in the other species, being nearly in the centre of the body. (Moquin-Tandon.) Intestine bifurcated. as in D. lanceolatum.

Measurements. $-\frac{1}{4}-\frac{1}{2}$ "' long ; $\frac{1^{\prime \prime \prime}}{6}$ wide. (Diesing.)

Habitat.-Four species found by Gescheidt between the eye and its capsule in a child five months old. Von Ammon found eight in the same position,

D. crassum, Busk. Pointed in front, rounded posteriorly; testes form two bulky, lobed organs, situated below ventral acetabulum. The uterine folds occupy only the front part of the body, the margins of which also display two yolk glands, one on either side of the intestinal tube; water vascular duct rudimentary. Habitat not given. Measurements.- $1^{\prime \prime} 6^{\prime \prime \prime}$ to $3^{\prime}$ long; $8^{\prime \prime \prime}$ wide.

D. heterophyes, Von Siebold. Body pyriform; obtusely rounded behind; body compressed, armed with minute spines; hinder sucker much larger than anterior; œsophagus long; intestinal tube simple, gradually widening below and terminating near posterior margin; supernumerary sucker in neighborhood of reproductive orifices; eggs red.

Measurements. $-\frac{1}{2}-\frac{3^{\prime \prime}}{4}$ ' long ; $\frac{1}{4}^{\prime \prime \prime}$ wide.

Habitat.-Egypt; in small intestine of man.

Bilharzia.

B. homatobia, Cobbold. $\delta$ Cylindrical, vermiform, $6^{\prime \prime \prime}$ long; $q$ longer, narrower, $10^{\prime \prime \prime}$ long; $\delta$ tuberculated and furnished with a gynocophoric canal in which the female is lodged in copulation. Intestinal canals reunite, after a short separation, to form a broad, central, spirally twisted tube extending down the middle of the body; yolk-and oviducts uniting to form a single 
canal, which is expanded at its lower portion, finally to open near the inferior margin of the ventral sucker; eggs pointed at one end. (Cobbold.)

Habitat.-Egypt : man and monkey. Found in the blood-vessels; the eggs may act as thrombi, yet no pyemic symptoms are seen.

Tetrastoma. T. renale, Della Chiaje. This imperfectly known parasite possesses an oval flattened body, $5^{\prime \prime \prime}$ long, having 4 suckers at caudal end.

Habitat.-Kidney; very rare; only one case recorded.

Hexathyridium. Body oblong or lanceolate. Head continuous with the body. Mouth placed anteriorly, subterminal. Suckers six, behind the variolar margin. Genital pores of the body, ventral, approximate, superposed, the larger in form of a sucker. (Diesing.)

H. pinguicola, Treutler. Body oblong, convex above, concave beneath, acuminate anteriorly, truncated posteriorly. Suckers six in number, arranged in the form of a semicircle at base. Genital pores near one another in the neighborhood of the greater sucker.

Measurements.- $8^{\prime \prime \prime}$ long; $3^{\prime \prime \prime}$ wide.

Habitat.-Ovary of human subject; rare.

$H$. venarum, Treutler. Body obtuse, lanceolate. Suckers arranged in two longitudinal rows.

Measurements. $-2-3^{\prime \prime \prime}$ long; $\frac{1}{2}-2^{\prime \prime \prime}$ wide.

Habitat.-Sputa of hæmoptysis and blood from tibial vein.

\section{DEVELOPMENT OF TREMATODA.}

The impregnated egg of Fasciola and Distoma hepatica undergoes complete (?) segmentation. The embryo escapes as an oblong, ciliated planula. The subsequent stages of development have not been traced in the species found in human subject, but in other 'Trematoda - as, for example, the species of Distoma infesting an aquatic snail (Limnous stagnalis) - the development has been carefully studied, and it is reasonable to suppose that it is not materially different from that of the other species. The interior of the planula produces independent larval forms, probably by a process analogous to that witnessed in Aphis. But the larvæ, instead of at once escaping, remain within the parent larva case (König's gelbliche Wurm), as in Cecidomyia. This enclosed brood, as it may be termed, escaping, have evolved from within their bodies a second larval brood (Cercarioe). Each zooid possesses peculiar Distoma-like features, viz., two suckers and an intestinal tube bifurcating in advance of a ventral sucker, but differs from Distoma in the possession of a row of hooks about the position of mouth, in the presence of a long natatory tail, as well as in the absence of organs of generation. The cercarial larvæ in their turn escape from their encasement, and swimming freely about, attach themselves to the integument of the snail to be infested, and endeavor, by their hooks, to effect an entrance into its tissues. This 
having been accomplished, the hooks and tail drop off, and each larva passes into the pupal afterward to assume the sexual form.

In Bilharzia the eggs are of an elliptical shape. They develop minute ciliated planulæ. Their subsequent development has not been investigated.

Cestoda (Tapeworms), Rudolphi. Composed of animals joined generally for a long time to the nurse larva-elongate and multiarticulate. Larva (head) furnished with two to four pits or suctorial mouths commonly armed with hooks; mature joints destitute of external organs, bringing forth embryos armed with hooklets; alimentary canal none.

Tænia (Slender tapeworm.) Head subglobose or quadrangular; suckers four, rarely six ; muscular, orbicular, opposite, symmetrical, strongly contractile. Proboscis imperforate, retractile and inverted in scolex, but in mature form protrusile. Armed with a simple double or multiple crown of hooks. Body for the most part plane, white, depressed, bilateral, or triangular, strobile articulate. Mature segments hermaphroditic, separating successively. Each segment (called proglottis) resembles a Trematode. Water vascular system transparent. Genital pores lateral, for the most part alternate. Male pore larger and anterior, the female smaller and posterior. Genital organs perfect. Embryo small, active, and armed with little hooks; in those which go through the 'cysticercus' form, oval, very small, ciliated, yellowish; in other larger, smoother and more transparent. (Kiichenmeister.)

T. solium (Hooked tapeworm), Linn.-Head about the size of a pin-cap, globular, but produced in front to form a short conical proboscis armed with double row of hooks, from twenty to twenty-eight in each circular row; head furnished with four sucking disks, and succeeded by a very narrow neck nearly half an inch in length, the latter being continued into the anterior portion of body, in which traces of segmentation at first appear in the form of fine transverse lines, which gradually becoming more and more widely separated, leave brief interspaces. The earliest formed joints are narrow; the proglottides commence at about the 450 th segment, the total number of joints in a worm ten feet long being 800 . The integument contains a number of calcareous particles scattered through it, as well as a small quantity of chitine.

A longitudinal canal extends laterally along both margins of individual. They are in reality not continuous, but the canal of each segment is in a degree complete. It pertains to a water vascular system. An opening situated at the side constitutes the sexual aperture; the orifice is very distinct, and pierces a prominent papilla. The pore is placed sometimes on one side, sometimes on the other. In the centre of the projection is a small opening in which is found a perforate intromittent organ (spiculum), which is in connection with a tortuous vas deferens. The testicle is placed toward the middle of the segment. Behind the male orifice, and frequently confounded with it, is the opening of the female organs. The vagina passes parallel to the 
deferent canal. The ovary is a large irregularly lobed mass situated in the centre of the segment. (Moquin-Tandon.)

It is calculated that as many as 1200 proglottides may be passed in three months. The Tænia is oviparous; each segment may contain several hundred eggs.

Measurements. $-10^{\prime}-30^{\prime}$ long; $4^{\prime \prime \prime}$ wide.

Habitat.-Small intestine of man.

T. mediocancllata (Unarmed tapeworm), Küchenmeister. Head abruptly truncate at the crown, destitute of rostellum, and consequently also of a hook-apparatus; furnished with conspicuously large sucking disks, usually surrounded by a great quantity of dark pigment granules giving the head a blackish appearance. Ovary of the same type as in preceding species, but more complicated, presenting nearly double the number of lateral branches, which do not, moreover, branch out so dendritically. The terminal, 360-400 joints, may be mature. Joints apt to form monstrosities.

Measurements. $-36^{\prime}-40^{\prime}$ long; $5^{\prime \prime \prime}$ wide. (Küchenmeister.)

Habitat.-Small intestine of man.

T. echinococcus, Von Siebold.-Head with pointed proboscis armed with a double row of comparatively large rooted hooks from thirty to forty in number; the four suckers prominent, and succeeded by an elongation of the segments forming the neck; final segment when mature equalling in length the three anterior ones; ovary is placed in median line of proglottis, the oviduct having appended to it two distinct yolk glands modified near its outlet into a uterine chamber and receptacle. The genital pore is at the margin of the proglottis below the central line. The male organ consists of numerous sacs communicating with a vas deferens twisted upon itself, which terminates in a constantly protruded penis of large size.

Measurement.- $3^{\prime \prime \prime}$ long.

Habitat.-Small intestine of dog; larval form (hydatids) in man.

T. acanthotrias, Weinland.--Discovered in 1858. Cysticercal form; three rows of hooks. Known only in its larval form, which was found in muscle of man. (Wyman.)

T. flavopuncta, Weinland.-Proglottis short, with a 'yellowish spot clearly visible to naked eye, situated about the middle of each joint.' Reproductive organs occur on one side only. Known only from its strobile condition.

Habitat.-Intestine of man.

T. nana, Siebold. Head obtuse, large, and placed on a long, neck-like region. Segments proportionately broader than in other worms. Eggs globular. Known from proglottis. Obtained in considerable quantities from a child who died of meningitis.

Measurement. $-6^{\prime \prime \prime}$ long.

T. elliptica, Batsch. Head with conical proboscis, armed with several rows of minute hooks. An ovary or testicle upon either side of each segment, opening into a central lateral pore.

Measurement. $-6-8^{\prime \prime}$ long. 
Habitat.-Intestine of cat and dog; very rarely in man.

T. marginata, Batsch. Head subrounded, depressed, obtusely tentragonal; proboscis short. Segments short, square; terminal ones oblong. Genital pore upon alternate sides of the segments.

Measurements. - $1-2 \frac{1}{2}$ ' long; $1 \frac{3}{4}-3^{\prime \prime \prime}$ wide.

Habitat.-Intestine of wolf; rarely in man (Cobbold) in larval form ( $C$. tenuicollis).

T. lophosoma, Cobbold. Strobila 9 feet long ; breadth of each joint, $\frac{1}{5}$; length $\frac{1}{13}{ }^{\prime \prime}$; proglottides $\frac{1}{2}$ to $\frac{3}{4}$ of an inch; reproductive papillæ uniserially disposed at the margin on one side throughout the entire colony of segments; individual joints irregularly pentagonal in outline; average diameter of the eggs, $\frac{1}{8} \frac{1}{50} "$. Original specimen in Museum of Middlesex Hospital, London.

Bothriocephalus, Bremser. Cestodes furnished with two suctorial mouths or marginal oblong, or long opposite pits. Head subquadrangular, most part articulate. At the centre of under surface of each segment a conical papilla emits the intromittent organ. Behind this body is another smaller pore without a papilla. It is supposed to be the vulva, but is not always present. The penis is furnished with a sheath, and communicates with a tolerably long deferent canal, which is folded several times upon itself, gradually increases in thickness, and terminates in a vesicula seminalis, having the form of an oval pouch. The testicle consists of white granules, and is furnished with three slender ducts, which terminate in the above-mentioned vesicle. The female organs are somewhat more complicated; the ovaries are oblong and very distinct; the oviduct presents itself under the form of a tortuous canal, especially at the period when the ova are mature. The uterus has two pouches or diverging horns. (Moquin-Tandon.)

B. latus, Bremser (Broad tapeworm). Head oblong, unarmed, two marginal pits or fissures. Neck inconspicuous. Joints about 2000 ; mature joints broader than long, separating in groups. Genital pore placed in median line; male opening larger and superior, from which the broad and smooth penis is prominent. Quiescent scolex unknown.

Length $21^{\prime}-24^{\prime}$. Embryo with 6 hooks, in the ovule $0.008 \cdot 32^{\mathrm{m}}$. long, 0.002 broad; elliptic yellowish brown, included in a dehiscent operculum. (Küchenmeister.)

Habitat.-Intestinal caual of man.

B. cordatus, Leuckart. Head heart-shaped, or rather obcordate, and set on to the body without the intervention of a long neck. Segments increase rapidly, the anterior end becomes lanceolate: 50 joints immature; 660 joints in all. Smaller than B. latus; calcareous corpuscles in increased proportion; ' uterine rosette' smaller, longer, with larger number of lateral processes.

Habitat.-Intestine of $\mathrm{dog}$ and man; more frequently encountered with the former. So far as has been ascertained, peculiar to Greenland. 


\section{DEVELOPMENT OF CESTODA.}

Cestode worms without exception exhibit alternate generation.

The following terms will be used in its description:

Proglottis.-The mature segment, containing the organs of generation and the impregnated eggs.

Embryo.-The first larval stage.

Cysticercus.-The second larval stage. The head-like process to Cysticercus armed with suckers is known as the scolex. It is persistent in the strobilic form.

Strobile.-The segmented individual. The term is commonly applied to the scolex and immature segments.

In $T$. solium the proglottis escapes from the strobile and is voided from the intestine, the eggs soon afterward being discharged into the feces. In this position segmentation of the ova occurs; within each an embryo, having a subrotund form and furnished at one extremity with a circle of hooks resulting. The ova in this condition are taken up by the hog with its food and conveyed into the intestine. Here the embryo escapes, perforates the intestinal walls by means of its hooks to gain convenient positions within the various muscles or viscera of the body. Favorable conditions being afforded, the second larval form, or that of the Cysticercus, is assumed. The primal hooks are now lost, the larva being distinguished by the scolex, with its suckers and peculiar crown of hooks. In this stage it becomes inactive, while the integumental covering becomes rigid from the presence of a quantity of calcareous matter. The presence of large quantities of such capsules in the flesh of the butchered hog, where they appear as minute spots visible to the naked eye, constitutes 'measly' pork. Such meat, when eaten raw or imperfectly cooked, carries into the system numbers of infecting larvæ, each of which, when the essentials of development are presented to it, escapes from its encasement, becomes attached by its hooks to the mucous membrane, and, losing its bladder-like appendage, produces, by a process of gemmation, the features characterizing the mature worm. The terminal segments in succession produce the organs of generation in time to be converted into proglottides, subsequently to escape with their eggs.

In $T$. mediocanellata the development is the same, the sites selected affording the chief points of variance. The freed 'embryo' is swallowed by some ruminating animal, as the cow, and is received living within the alimentary canal of man, through the cossumption of raw or imperfectly cooked beef.

In T. echinococcus the larva is most commonly taken up by the cow or sheep, and the larval form (hydatid) lodged within its tissues. The third stage of development is attained by the dog devouring the infected beef, when the mature form is evolved within the alimentary canal. Or the larva 
itself may be consumed by man in his food and water, and carried within his tissues, very commonly to be permanently lodged within the abdominal cavity and brain. The mature form, in this instance, is of course never attained, anless through some rare mischance the man be devoured by the dog or wolf.

As may be inferred from the above statements, the $T$. solium is more common with pork-eaters, as the $T$. mediocanellata is with consumers of beef. Underdone meats, or raw sausages, partially smoked beef and hams are prolific sources of disease. In the case of $T$. echinococcus, filthy association with dogs favors the development of hydatids. In Iceland, where, in addition to such surroundings being very constantly present, the conditions are exceedingly favorable to increase of entozooic life, the ratio of occurrence of hydatids in the human subject is perhaps greater than in any other part of the world. It is calculated by $\mathbf{K}$ rabbe that one out of every forty, and by Schleisner one out of every seven inhabitants harbor hydatids.

In Bothriocephalus the scolex is formed as in Toenia, and lives in the intestinal canal of smaller aquatic animals, in the immature state. The strobile is found within rapacious aquatic animals, piscivorous birds and mammals. Proglottides very frequently separate in long conjoined series of segments. Embryos with six hooks. Coverings to ovules frequently colored. (Kïchenmeister.)

The following table is designed to show the localities of the larval and mature stages, as far as known, of the species of Tænia infesting the human subject.

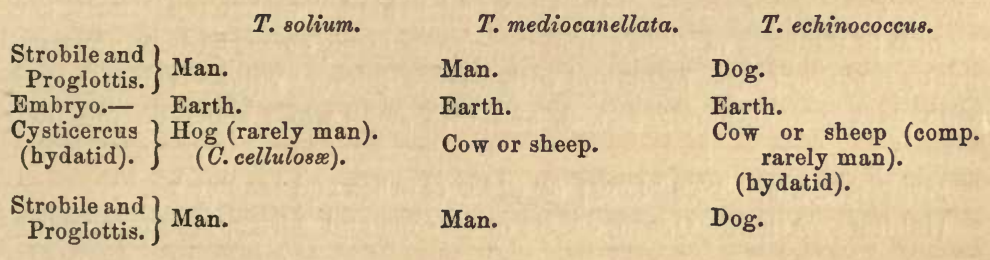

T. acanthotrias.

T. flavopuncta.

T. nana.

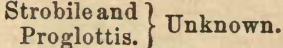 \\ Embryo.- Unknown. \\ Cysticercus.-Man. \\ Strobile and \\ Proglottis. $\}$ Unknown.}

T. elliptica.
Man.

Unknown.

Unknown.

Man.

T. marginata.

Dog and wolf.

Unknown.

Man (C.tenuicollis).

$\mathrm{D}$ og and wolf.
Man.

Unknown.

Unknown.

Man.

T. lophosoma.

Man.

Unknown.

Unknown.

Man. 


\section{MOLLUSOA,}

Sepra (Cuttle-fish). Cephalopoda.-Family Sepiadæ.

Body oblong, with lateral fins as long as itself, shell as wide and long as body, very thick in front, concave internally behind, terminating in a prominent point. (Forbes and Hanley.)

S. officinalis, D'Orbigny.-Body large, ovate, fleshy, depressed, rounded behind, with a rounded projection on the front of dorsal edge, surface of the body smooth. Fin narrow, lateral, bordering the whole side of the body, and separate behind. The ventral part of the mantle furnished with an oblique oblong tubercle fitting to a concavity in the sides of the lower part of the siphuncle. Head large, wider than long, with two elongated and some smaller beards above. Eyes large, with an inferior eyelid, and a lachrymal opening in the front of the folds of the eyelid. Ear at the lower part of the globe of the eye. Buccal membrane seven-lobed, the two lower lobes least marked. Arms short, strong, unequal ; order of length, 4, 3, 2,1 ; ring of cups smooth, entire. Tentacular arms much enlarged, with six alternating lines of cups, the five central cups much larger; ring of the larger cups smoothed, of the smaller ones toothed. Shell ovate, compressed, wrinkled above, semi-cartilaginous on the edge and behind, rounded posteriorly, embedded in the back of the animal. Siphuncle large, short, without any band at the junction to the head, and with a large internal valve. Back purple, with darker cross-bands, forked, and with small white spots on the side. (Howe.)

Measurements. $-8^{\prime \prime}-9^{\prime \prime}$ long; 6 " wide. (Forbes and Hanley.)

Habitat.-Atlantic Ocean, coasts of Europe and Africa, Mediterranean.

\section{PROTOZOA.}

Infusorra. Virgulina tenax.--Body elongated, membranous, transparent, somewhat thickened at its anterior part; it is furnished with a tail onethird or one-fourth shorter than body.

Measurement. $-\frac{2}{1000} "$ long.

Found in tartar of the teeth. (M. Tandon.)

Vibrio, Müller. Body filiform, more or less distinctly jointed from imperfect division ; vacuolæ distinct, globular hyaline ; movement undulatory. 


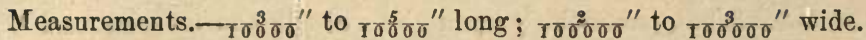

$V$. rugula.-Found in dejections of cholera patients. V.bacillus and $\nabla$. lineola are found occasionally in mucus of mouth. $V$.cyanogenus and $V$. xanthogenus at times found in milk. V.-(?) has been found in the blood of patients affected with malignant pustule. (Wood.)

Paramecium, Body covered with cilia ; no eyespot; a papilliform tonguelike process present; aquatic; stellate contractile vesicle (q. v., p. 55) well seen. (Micrograph. Dict.)

$P$, coli, Malmstein.-A species found in the discharges of chronic dysentery. Very rare.

Cercomonas. Body rounded, or discoidal, tuberculated, with a variable posterior prolongation in the form of a tail, which is longer or shorter, and more or less filiform. (Micrograph. Dict.)

C. davainei, M. Tandon.-Body pyriform ; integument soft ; posterior prolongation rigid, straight---serves to fix the animal at times to surrounding objects. They are true parasites, which live in the intestine of man when certain conditions are present that are requisite for their existence. (Davaine.)

Measurement.- $3^{\prime \prime \prime}$ long.

Rarely found in cholera dejections.

C. obliqua (?), Davaine.-Resembles above, but smaller, more oval ; candal filament arises somewhat from the sides. Rarely found in typhoid fever dejections.

Trichomonas, Duj. Body ovoid, or globular, becoming drawn out when adherent to the slide, hence sometimes exhibiting a tail-like prolongation; an anterior flagelliform filament present, with a group or row of vibratile cilia.

T. vaginalis.-Body glutinous, nodular, unequal, frequently becoming agglutinated to other objects; movement vacillating. Found in morbid vaginal mucus. (Mic. Dict.)

Measurement.-Length $\frac{\Sigma^{\prime}}{50} \sigma^{\prime \prime}$.

Psorospermid-Microscopic, oval, depressed, for the most part spindleshaped corpuscles, with or without a tail, exhibiting no movements, and consisting of a tolerably firm outer coat covered with hair-like processes which exhibit a very delicate and peculiar structure. Such bodies may aggregate in cyst-like masses, the contents of which appear granular to low powers, and exhibit a division into numerous segments, but it is found to consist entirely of minute bodies resembling one another, possessing very definite characters, being oval flattened, the body slightly curved laterally, with one extremity blunt and the other almost pointed. Sometimes they are embedded in a ramified sarcodic mass. (Micrograph. Dict.)

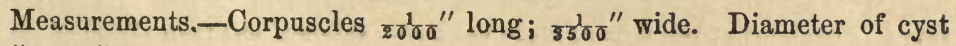
$\frac{1}{50} "$ to $\frac{1}{25}{ }^{\prime \prime}$. 
Habitat.--In fishes, particularly upon the gills, in the muscles, and between the coats of the eye, in the swimming bladder, etc. (Micro. Dict.) In the heart and voluntary muscles of mammals, such as the cow and sheep, they are often numerous. (Beale.) They have also been found within the muscles and viscera of the human subject. (Lindeman.)

Development.- The entire mass increases in size as the small bodies increase in size, probably by division and subdivision within the cyst. (Beale.)

It is believed by some that there is an intimate relation between these bodies and the causation of the cattle plague ; but other observers, while recognizing the frequency of the infection in animals dead of the disease, attribute no power to the Psorospermiæ. $\dagger$ The significance of their presence in man has not been ascertained.

Gregarinide, Dafour. Round, oval, fusiform, or cylindrical bodies, consisting of a smooth transparent cell wall, enclosing a granular, more or less liquid mass, with one or more nuclei and nucleoli. Sometimes they exhibit a contraction in the middle, or are divided by a transverse septum. In some a process resembling a head is situated at one end, and may be either naked or armed with hook-like processes. Motion slow; cilia obscurely seen both upon the outer and inner surface of membrane. One or more long filaments sometimes arise from the outer surface.

Measurements.

Habitat.

Development.

Two individuals coming into contact by corresponding portions of the body become shortened and firmly united. A transparent capsule is next formed around the two individuals, which encloses them in a cyst; the adjacent portions of the cell membranes are absorbed, and the substance of the two bodies become ultimately fused. Globules or cells are then formed in the contents of the cells, which subsequently assuming the form of the genus Navicula (boat-like bodies) have been called pseudo-naviculæ. These, the young Gregarinæ, escape from the cell to complete their development after a method unknown. In some cases it appears that the contents of the two cells in conjugation remain distinct until the pseudo-naviculæ are

* "In my investigation upon the muscles of animals destroyed by the cattle plague, I found these bodies in enormous numbers. While they are ordinarily found largely in the muscular fibres of the sheep's heart, and to a less extent in that of the ox, they are not to be detected in the best beef and mutton. On the other hand, in almost every specimen of cattle plague beef which I have examined, these entozoon-like bodies were present, and in many cases in immense numbers." (Beale.)

$\dagger$ "In the heart of a healthy sheep which I afterwards ate, I calculated there were about 1000 parasites to the cunce, and in the heart of a healthy bullock, which likewise served me for a hearty meal, the number were rather in excess of those in the sheep. Altogether at two meals I could not have swallowed less than 18,000 of these psorospermiæ." (Cobbold.) 
formed; but it is not certain whether each single cell in these instances has not arisen from the fusion of two others. (Micro. Dict.)

Sponara (Sponge), Linnæus. Sub-class.-Spongidæ characterized as follows: Fixed, aquatic, polymorphous animals; inhaling and imbibing the surrounding elements through numerous contractile pores situated on the external surface; conveying it through internal canals or cavities, and ejecting it through appropriate orifices; having an external flexible or inflexible skeleton. (Bowerbank.)*

Order Keratosa.

Spongia is distinguished as follows: Skeleton kerato-fibrous; fibre solid, cylindrical, aspiculous; rete unsymmetrical.

S. officinalis, Linnæus.

The Spongice Ciliatce are held by Prof. H.J. Clark to belong to the same family with the Infusoria Flagellata, the connecting form being secured in || 1 the genera Codosiga and Leucosolenia.

* The other divisions of the Spongia are:

Halisarscidx.-Most elementary forms, in which a system of water cavities has not been demonstrated.

Clionidx, or sponges, which bore into shells by means of their siliceous spicula. Indications of their existence extend down to the Silurian strata.

Petrospongidæ.-A group of organisms known only in the fossil state and abounding in the chalk. They can only be said to be probably sponges.

Tethyidx.-Undoubted sponges, but of very hard texture, and furnished with very long spicula which radiate from the centre of each organism to its circumference. (Huxley.) 


\section{ADDITI0NS.}

$P_{A G E}$ 12, paragraph 2.-Cilia present in alimentary canal of fishes. (Stan. nius.)

Page 22, paragraph 3.-Compsognathus, a genus of Dinosaurian reptiles; possesses in the construction of its posterior extremities features recalling those of the birds.

Page 25, paragraph 4.-Loxosoma, a genus of naked Polyzoa. (Clarapède.)

Page 30, second line from top.-The V-shaped bones placed below the bodies of the caudal vertebræ are more properly recognized as "chevron bones."

Page 37, paragraph 3.--Invertebrata is a term of convenience employed in speaking of animals not included within the Vertebrata. It is not considered to have any systemic significance.

Page 45, sixth line from top.-Paramecium may improvise an anus.

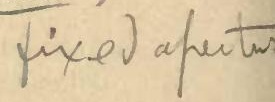




\title{
TABLE OF CLASSIFICATION,
}

\author{
INCLUDING THE NAMES OF ANIMALS MENTIONED IN THIS WORK.
}

\section{VERTEBRATA.}

Mammalia (mamma, the breast).

Placentalia ( placenta, a flat cake).

QUADRUMANA (quatuor, four, manus, a hand.)

Gorilla.

Semnopitheeus.

Cheiroptera ( $\chi \varepsilon i \rho$, the hand, $\pi \tau \varepsilon \rho 6 \nu$, a wing).

Corynorhinus.

Pteropus.

IxSECTIVORA (insecta, insects, voro, to devour).

Erinaceus.

Talpa.

Carnivora (carnis, flesh, voro, to devour).

Canis.

Felis.

Herpestis.

Lutra.

Machairodus.

Phoca.

Ursus.

Viverra.

Vulpes.

Ruminantia* (ruminare, to chew the cud).

Camelus.

Cervus.

Camelopardalis.

Hyæmoschus.

Moschus.

Tragulus.

OMNIVoRA* (omnis, all, voro, to Sus.
Perissodactyla ( $\pi \varepsilon$ pínoos, redun-

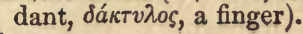

Equus.

Hyrax.

Rhinoceros.

Proboscidia (proboscis, a trunk, fero, to carry).

Elephas.

Rodevita (rodo, to gnaw).

Cavia.

Castor.

Lepus.

Mus.

Sciurus.

Edentata (edentula, toothless).

Bradypus.

Dasypus.

Manis.

Myrmecophaga.

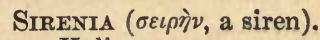
Halicore.

Cetacea ( $\kappa \ddot{r}$ tos, a whale).

Balæna.

Catodon.

Phocæna.

ImPlaCentalia (im, neg., placenta).

MARSUPIALIA (marsupium, a pouch).

Dasyurus.

Didelphis.

Macropus.

Phascolomys.

Monotremata ( $\mu$ òvo $\varsigma$, single, $\tau \rho \tilde{\eta} \mu \alpha$, a hole).

Echidna.

Ornithorhynchus.

* The orders Ruminantia and Omnivora are by Owen included in a single group, Artiodactyla (aprios, perfect, dakrvios, a finger). 
Ares (avis, a bird).

Anas.

Anser.

Archæopteryx.

Columba.

Cuculus.

Cygnus.

Fringilla.

Gallus.

Hirundo.

Otis.

Pelicanus.

Perdix.

Phasianus.

Psittacus.

Rhamphastos.

Struthio.

Reptilia (repto, to creep).

Dinosauria (deivos, wonderful,

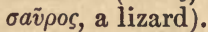

Iguanodon.

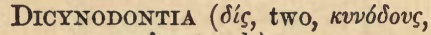
a canine tooth).

Dicynodon.

Lacerturia (lacerta, a lizard).

Chameleo.

Amphisbæna.

Chelonia ( $\chi \varepsilon \lambda \omega \nu \eta$, a tortoise).

Crocodirra (crocodilus, n.p.). Alligator.

Crocodilia.

OpHIDIA ( $\delta \phi \iota s$, a serpent).

Ancistrodon.

Caudisona.

Cerastes.

Crotalus.

Deirodon.

Hydrophis.

Naja.

ICHTHYOPTERYGIA (' $\chi$ Ө $\pi \tau \varepsilon \dot{\varepsilon} v \gamma \delta$ s, a fin).

Ichthyosaurus.

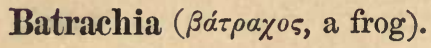

Alytes.

Amblystoma.

Cystignathus.

Osteocephalus.

Proteus.

Rana.

Salamander.
Pisces (pisces, a fish).

Pharyngobranchiata ( $\phi a ́ \rho v \gamma \zeta$, the throat, $\beta \rho a ́ \gamma \chi \iota a$, gills).

Amphioxus.

Marsipobranchiata ( $\mu a ́ \rho \sigma \iota t \pi o s, a$ Myine.

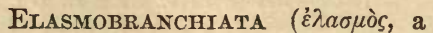
plate, $\beta \rho a ́ \gamma \chi \iota a$, gills.)

Selachia ( $\sigma \varepsilon \hat{\varepsilon} \alpha \chi \chi \varsigma$, n.p. of Aristotle, $\sigma \varepsilon \lambda a \varsigma$, brightness).

Carcharias.

Cephaloptera.

Chimera.

Lamna.

Mustela.

Squalus.

Squatina.

Zygæna.

RAIDE (from ray, n.p.).

Torpedo.

GANoIDEI ( $\gamma a ́ v o s$, splendor). Acipenser.

Lepidosiren.

Lepidosteus.

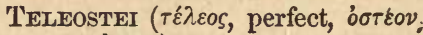
a bone).

Anableps.

Anguilla.

Aphredoderus.

Aspredo.

Blennius.

Bagrus.

Compostoma.

Clupea.

Cobitis.

Ditrema.

Gadus.

Gymnotus.

Hippocampus.

Malapterurus.

Perca.

Pimelodus.

Pleuronectes.

Salmo.

Scarus.

Scomber.

Tetradon.

Trichiurus.

\section{ARTICULATA.}

Insecta, n.p.

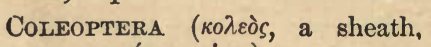
$\pi \tau \varepsilon \rho \sigma \nu$, a wing).

Calospasta.

Cysteodemus.
Epicauta.

Henous.

Lampyris.

Lytta.

Macrobasis.

Megetra. 
Meloe.

Mordella.

Nomaspis.

Photinus.

Photuris.

Pleuropompha.

Pomphopœa.

Pyrophorus.

Pyrota.

Tegrodera.

Tetraonyx.

HYMENopterA ( $\tilde{v} \mu \eta \tilde{v}$, a membrane, Apis. $\pi \tau \varepsilon \rho \delta v$, a wing).

Cynips.

LEPIDOPTERA ( $\lambda \varepsilon \pi i \varsigma$, a scale, $\pi \tau \varepsilon$ $o \delta v$, a wing).

Diptera ( $i \varsigma$ s, twice, $\pi \tau \varepsilon \rho \delta v$, a wing). Cecidomyia.

Musca.

Pulex.

NeUroptera ( $\nu \varepsilon \bar{u} \rho o \nu$, a nerve, $\pi \tau \varepsilon$ $\sigma v$, a wing).

Ephemera.

Lepisma.

Libellula.

Termes.

ORTHOPTERA ( $\rho \rho \theta \sigma s$, straight, $\pi \tau \varepsilon$ $\rho \delta v$, a wing).

Cicada.

Gryllus.

HEMIPTERA ( $\tilde{\eta} \mu$, half, $\pi \tau \varepsilon \rho \delta ́ v$, a wing).

Acanthia.

Aphis.

Coccus.

Nepa.

Notonecta.

Pediculus.

Prionotus.

Reduvius.

Myriapoda ( $\mu$ ofos, countless, $\pi o \bar{v} s$, a foot).

Iulus.

Octoglena.

Scolopendra.

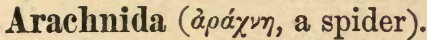

Acarus.

Buthus.

Demodex.

Epeira.

Galeodes.

Gamasus.

Phrynus.
Sarcoptes.

Trombidium.

Thelyphonus.

TARDigrada.

Emydium.

Crustacea (crusta, a shell or crust).

Cyclops.

Gammarus.

Homarus.

Lepas.

Lernæa.

Limulus.

Lucifer.

Lupa.

Oniscus.

Palæmon.

Zoe.

Annelida (annulus, a ring).

Acoëtes.

Autolytus.

Eunice.

Hirudo.

Lumbricus.

Nemertes.

Sanguisuga.

Serpula.

Terebella.

Torrea.

Entozoa ( $\varepsilon \nu \tau \delta \varsigma$, within, $\zeta \tilde{\omega} o \nu$, an animal).

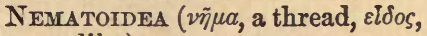
like).

Ascaris.

Dracunculus.

Eustrongylus.

Gordius.

Sclerostoma.

Strongylus.

Trichina.

Trichocephalus.

Trematoda $(\tau \rho \eta \mu a \tau \omega \delta \delta \varepsilon$, possessing holes).

Bilharzia.

Distoma.

Fasciola.

Hexathyridium.

Tetrastoma.

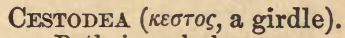

Bothriocephalus.

Tænia.

Rotifera (rota, a wheel, fero, to bear).

Asplanchnia.

Melicerta.

Rotifer. 


\section{MOLLUSCA.}

Polyzoa ( $\pi \circ \lambda \tilde{u} \varsigma$, many, $\zeta \dot{\omega} o \nu$, an animal).

Plumatella...

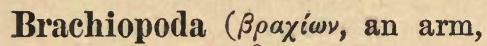
$\pi o \bar{v} 5$, a foot).

Crania.

Lingula.

Terebratula.

Waldheimia.

Tunicata (tunica, a coat).

Ascidia. .

Boltenia.

Pyrosoma.

Salpa.

Lamellibranchiata (lamella, a small plate, branchioe, gills).

Anodonta.

Cyclas.

Mytilus.

Ostrea.

Unio.

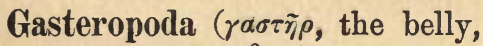
$\pi \circ \bar{v} s$, a foot).

Aplysia.

Bulla.

Chiton.
Dentalium.

Doris.

Eolis.

Fulgur.

Helix.

Janthina.

Limax.

Limnæa.

Natica.

Nerita.

Paludina.

Phyllidia.

Phyllirhco.

Strombus.

Tritonia.

Pteropoda ( $\pi \tau \varepsilon \rho o ́ v$, a wing, $\pi o \bar{v} \varsigma$, a foot).

clio.

Hyalea.

Cephalopoda ( $x \varepsilon \varphi \alpha \lambda \eta^{\prime}$, the head, $\pi \circ \bar{v} s$, a foot).

Dibranchiata ( $\delta^{\prime} \zeta$, two, $\beta \rho a ́ \gamma \chi \iota a$, gills).

Hectocotylus. Sepia.

Tetrabranchiata ( $\tau \varepsilon \tau \rho \alpha$, four, $\beta \rho a ́ \gamma \chi \iota a$, gills).

Nautilus.

\section{RADIATA.}

Echinodermata ( $\varepsilon^{\prime} \chi^{i}$ os, a spine, $\delta \varepsilon \rho \mu a$, the skin).

Astropecten.

Auricularia.

Bipinnaria.

Brachiolaria.

Comatula.

Echiurus.

Holothuria.

Ophiopholis.

Ophiuris.

Pentacrinus.

Pluteus.

Sipunculus.

Spatangus.

Synapta.

Toxopneustes.

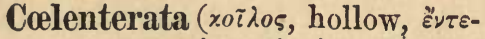
oov, intestine).

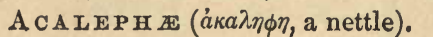

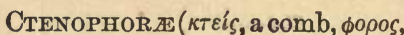
bearing).

Beroë.

Pleurobranchia.

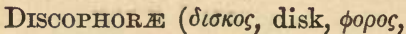
bearing).

Aurelia.

Cyanea.

Ephyra.

Geryonia.

Medusa.

Physalia.

Scyphostoma.

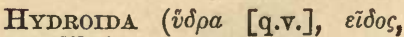
like).

Campanella.

Campanularia.

Coryne.

Cordylophora.

Dicoryne.

Eucope. 
Eucoryne.

Hybocodon.

Hydra.

Nanomia.

Perigonimus.

Rhizogeton.

Sarsia.

Syncoryne.

Tubularia.

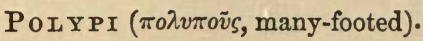
Actinia.

Alcyonium.

Astrangia.

Gorgonia.

Isis.

Laomedea.

\section{PROTOZOA.}

Infusoria (infusus, an infusion). |Spongidæ, n.p.

Acineta.

Bodo.

Cercomonas.

Codosiga.

Dysteria.

Monas.

Paramecium.

Stentor.

Stylonchia.

Trichodes.

Trichomonas.

Vibrio.

Virgulina.

Vorticella.

Leucosolenia.

Spongia.

Tethya.

Rhizopoda ( $\iota_{\iota} \zeta \alpha$, a root, $\pi \circ \bar{v} \varsigma$, a foot).

Amøba.

Eozoon.

Noctiluca.

Nummulus.

Sphærozoum.

Thallasicolla.

Psorospermiæ ( $\psi \omega \dot{\omega} \rho \alpha$, itch, $\sigma \pi \varepsilon \rho-$ $\mu a$, seed).

Gregarinidæ (gregarius, a flock). 
a 


\title{
INDEX AND GLOSSARY.
}

\author{
[n.p. = nomen proprius. $]$
}

Acanthis (ăkav $\theta a$, a sting), 151.

Acarus, n.p., 49, 59.

Achorion, 161.

Acineta (åıฑros, immovable), 123.

Acipenser, n.p., 37, 42, 70, 116, 145.

Acoëtes (ä̌xortns, husband?), 35, 40.

Actinia (akriv, a ray), $14,16,45,110,122$, 123.

Alcyonium (Myth., Alcyone, the daughter of Eolus), 14.

Alligator, 43.

Alytes (dìurrns, an executioner), 108.

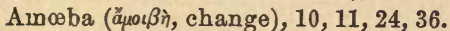

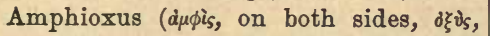
sharp), 20, 21, 38, 42, 53, 59, 60, 63, $76,98,116$.

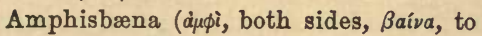
walk), 50.

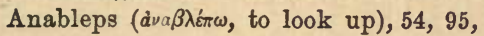
$108,116$.

Anas, n.p., 79.

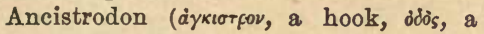
tooth), 144.

Anguilla (dim. of anguis), n.p., 64, 70, 71, $78,116$.

Anodonta (iv $6 \delta$ vros, without teeth), 129.

Anoplotherium ( $a$ priv., $0 \pi \pi \lambda o v$, defence, $\theta \eta \rho$, an animal), 139.

Anser, n.p., 50, 102.

Ant-eater, 52.

Aphis, n.p., 120, 132, 153.

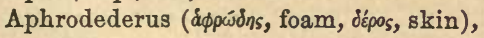
49.

Apis, n.p., 107, 132, 154.

Aplysia (a priv., $\pi \lambda \hat{v} \omega$, to wash; the aplysia of the Greek fishermen were sponges unfit for washing), 39, 46, 57.
Apterospasta (a priv., xтербv, a wing, onáoros, a blister), 148.

Archæopteryx (ápxaĩos, ancient, $\pi т \varepsilon \rho \partial v$, a wing), $23,42$.

Argonauta (Myth.), 75, 102, 103, 107, 113.

Armadillo, n.p., 71 .

Ascaris, n.p., 105, 163.

Ascidia (døkíov, a little bottle), 69 .

Asplanchnia (a priv., $\sigma \pi \lambda d \gamma \chi x \alpha$, the vis. cera), 102.

Aspredo (asper, rough), 107.

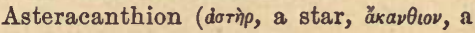
spine), $17,45,56,73$.

Astrangia, 88.

Aurelia, n.p., 14, 68, 92, 120, 126.

Auricularia (dim. of auris, ear), 127.

Autolytus, 131.

Axolotl, n.p., 61, 134.

BAGRUS, n.p., 108.

Balæna, n.p., 41, 81.

Barnacle, 13, 48.

Bat, 51.

Bear, 43, 119.

Beaver, 44, 71, 119, 139.

Bedbug, 151.

Bee, 107, 132.

Beroë (Myth., the mother of Bacchus), 26,45 .

Bilharzia (Bilharz), 167, 169.

Bipinnaria (bis, double, pinna, a leaflet), 127.

Blennius (from $\beta \lambda \varepsilon v \nu \alpha$, mucus), 54, 108, 116.

Bodo, n.p., 10.

Boltenia (Bolten), 69.

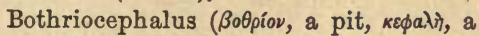
head), 171. 


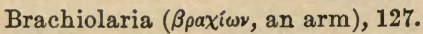

Bradypus ( $\beta$ padis, slow, noṽs, a foot), 22, 62.

Bulla (bulla, a bubble), 39, 93.

Bustard, 50.

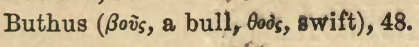

Calospasta (kados, beauty, oragtos, a blister), 149.

Camelopardalis (camelo, camel, pardalis, leopard),

Camelus, n.p., 102.

Campanella (dim. of campana, a bell), 126.

Campanularia (ibid.), 124.

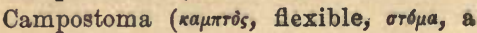
mouth), 49,60 .

Canary, 79.

Canis, n.p., 103, 119.

Cantharis, n.p., 147.

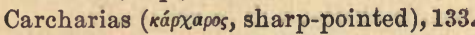

Castor, n.p., 44, 71, 92, 119, 139.

Cat, 43.

Caudisona (cauda, tail, sona, to sound), 87, 143.

Cavia, n.p., 119.

Cecidomyia ( $\kappa \dot{n} \kappa \iota d o s$, an excrescence, $\mu$ viı a fly), 120, 132.

Cephaloptera ( $\kappa \varepsilon \phi a \lambda \eta$, head, $\pi \tau \varepsilon p \delta v$, wing), 95.

Cerastes, n.p., 144.

Cercaria (ке́ркоs, a tail), 168.

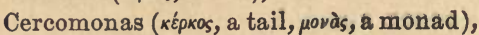
175.

Cervus, n.p., 103, 138.

Chameleo, 50.

Chimera, 89.

Chiton, 57.

Cicada, n.p., 102, 131.

Civet, 119, 139.

Cleopatra's asp, 144.

Clio, 47, 112.

Clupea (Pliny's name for a small fish), 116.

Cobitis, 54.

Cobra di capello, 144.

Coccus, n.p., 153.

Cod, 50, 145.

Columba, n.p., 50 .

Comatula (coma, a bunch of hair), 17.

Cony, 52, 141.
Copperhead, 144.

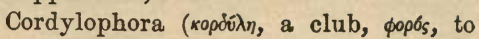
bear), 124, 125.

Coryne (кориiv, a club), 120, 124, 126.

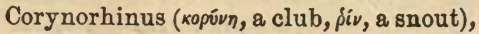
101.

Crab, 14, 122.

Crania (cranium), 128.

Cricket, 102.

Crocodile, 102.

Crocodilia, n.p., 91 .

Cuckoo, 51.

Cuculus, n.p., 51.

Cyanea (xváveos, dark blue), 88.

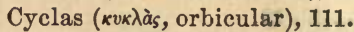

Cyclops ( $\kappa \dot{\kappa} \lambda \omega \psi$, cyclops, literally, roundeyed), 58, 107.

Cygnus, n.p., 50 .

Cynips, n.p., 107, 155.

Cysteodemus (кúorı, a bladder, dénas, a body), 147.

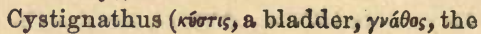
jaw), 102.

Damax, 119, 141.

Daphnia, n.p.; 48, 94.

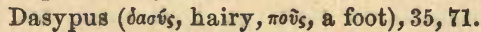

Dasyurus (davv́s, hairy, ov้ $\rho a$, tail), 81.

Deer, 103.

Deirodon, 42.

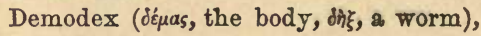
158.

Dentalium (dens, a tooth), 22.

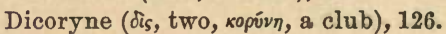

Dictylium, 153.

Dicynodon (dis, two, kvvodov̀s, canine tooth), 43.

Didelphis ( $\delta i_{\varsigma}, t w o, \delta \varepsilon \lambda \phi v_{\varsigma}$, a womb), 118, 119.

Distoma ( $\delta$ is, two, $\sigma \tau \sigma \mu a$, mouth), 166, 168.

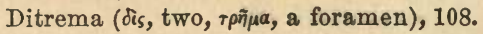

Dog, 103, 119.

Dogfish, 50.

Dolphin, 119.

Doris (Myth.), 24, 47, 51, 57, 74, 107, 129.

Dracunculus (dim. of draco, a dragon), 164.

Dragon-fly, 115.

Duck-bill, 41, 80, 100, 118.

Dugong, 62.

Dysteria (Dyster), 39. 
EARThWORM, 113, 122.

Echidna ( $\check{x} \iota \delta v a$, a viper), 100, 180.

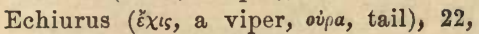
56.

Eel, 64, 70, 71, 78, 116.

Electric eel, 49 .

Elephant, 38, 52, 80, 92, 119.

Elephas, n.p., 38, 52, 80, 92, 119.

Eolis (Myth.), 4, 129.

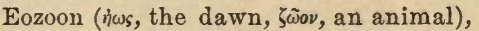
24.

Epeira (imeifopal, I examine), 48, 59, 104.

Ephemera, 59.

Ephryra (Myth.), 126.

Emydium (غ̇ws, a turtle), 59.

Epicauta (غ̇ì, upon, кav́w, tail), 149.

Equus (equus, n.p.), 43, 51, 52.

Erinaceus, n.p., 119.

Eucope, 120, 124, 125, 126.

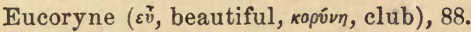

Eunice (Myth., daughter of Nereus and Doris), 58.

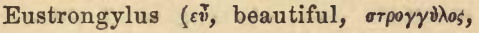
rounded), 165 .

Fasciola (dim. of fascia), 165, 168.

Felis, n.p., 43.

Fiber, n., 119.

Flounder, 116.

Fowl, 37, 62.

Fox, 80.

Fresh-water shrimp, 14.

Fringilla, n.p., 79 .

Frog, 42, 53, 54, 61, 64, 71, 76, 78, 99, 103, 117, 134.

Fulgora (fulgeo, to shine), 107.

GADUs, n.p., 50, 78, 145.

Galeodes ( $\gamma a \lambda \varepsilon \omega \dot{d} \eta \bar{s}$, weasel-like), 48.

Gall-fly, 107.

Gallus, n.p., 37, 62, 102, 118.

Gamasus, n.p., 49.

Gammarus, n.p., 14.

Gar, 61.

Geryonia, Myth., 97.

Gillaroo trout, 49.

Giraffe, 52.

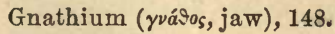

Goose, 79.

Gordius, Myth., 107.
Gorgonia (Myth., a daughter of Phorcys, whose locks were changed into serpents by Minerva), 35 .

Gorilla, n.p., 119.

Gryllus, 102.

Guinea-pig, 119.

Gymnotus ( $\gamma \nu \mu \nu$ s, naked, vஸัros, back), 83.

HADDOCK, 78 .

Halicore ("̈ $\lambda_{s}$, sea, $\kappa o ́ p$, a maid), 62.

Hammer-headed shark, 50.

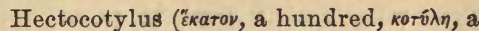
sucker), 113.

Hedgehog, 119.

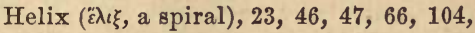
106, 112, 122.

Henous, 147.

Herpestis (" $\varepsilon$ $\rho \omega$, I creep), 119.

Herring, 116.

Hessian fly, 120, 132.

Hexathyridium ( ${ }^{\prime \prime} \xi$, six, ovpısiov, a little door), 168.

Hippocampus ("inos, a horse, $\kappa \alpha \mu \pi \eta$, a bending), 60, 108.

Hirudo, n.p., 48, 58, 159.

Hirundo, 62.

Holothuria ( $\delta \lambda_{0}$ Oovpı $a$, sea-tail), 17, 22, 46, $55,56,104,110,111,122$.

Homarus, n.p., 48, 58, 75, 94, 97, 104, 107, 114.

Horse, 43, 51, 52.

Hyæmoschus ( $v_{\varsigma}$, hog, $\left.\mu \sigma \sigma \kappa \sigma_{\varsigma}\right)$, n.p., 139.

Hyalea (Myth., Hyale, a nymph in the train of Diana), 39.

Hybocodon (vंos, a hump), 126.

Hydra (Myth., vipa, a fabled monster with many heads), $14,38,45,88$, $101,110,120,122,123,124$.

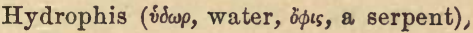
145.

Hylodes ( $\dot{v} \lambda \omega \delta \eta \bar{\zeta}$, sylvaticus), 108.

Hyrax (vpak, a rat), 52, 119, 141.

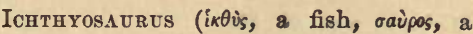
lizard), 95.

Iguanodon (Iguana, a genus of Saurian reptiles, odov̀s, tooth), 43.

Isis (Myth., an ancient goddess), 35.

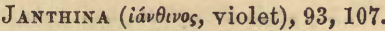

Julus, n.p., 104. 
KANGAROO, 51, 118, 119.

King-crab, 41.

LABYRINTHODON ( $\lambda a \beta \dot{v} \rho \iota \theta_{0}$ s, a labyrinth, odoús, a tooth), 23, 42,71 .

Lamna, n.p., 63.

Lampyris, n.p., 87.

Isancelet, 42, 59, 76 .

Laomedea (Myth., one of the Nereids), $104,124$.

Lernæa, 58.

Lepas ( $\lambda_{\varepsilon}^{\prime} \pi a_{\zeta}$, a small dish), 13, 48, 58.

Lepidosiren, 23, 76.

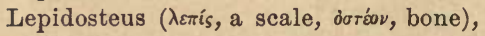
35,61 .

Lepisma ( $\lambda \varepsilon \pi i s$, a scale), 131.

Lepus, n.p., 100.

Libellula (dim. libella), n.p., 95, 115.

Limax, n.p., 66.

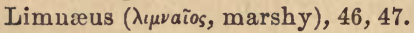

Limulus (dim. of limus, sideways), 41, 48.

Lingula (lingua, n.p., dim.), 46.

Loach, 54 .

Lobster, 75, 94, 104, 107, 114.

Locust, 102, 131.

Louse, 127, 131.

Lucifer (lux, light, fero, to bear), 97.

Lumbricus, n.p., 48, 58, 113, 122.

Lupa, n.p., 14, 122.

Lutra, n.p., 101, 119.

Lytta, n.p., 149.

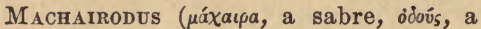
tooth), 43.

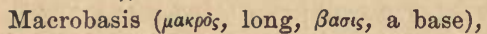
148.

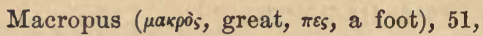
$118,119$.

Malapterurus ( $\mu$ a入os, soft, $\pi \tau \varepsilon \rho \delta v$, a wing, ovipa, tail), 84.

Manis (manus, the hand), 42, 71.

May-fly, 59.

Medusa, n.p., 97, 124.

Megetra ( $\mu \dot{\varepsilon}$ yas, great), 147.

Melicerta, n.p., 47,

Meloë, n.p., 147 .

Mite, 59.

Mole, 95, 101.

Monad (novàs, a unit, a minute protozoon), 9.
Mordella (mordeo, I bite), 95.

Moschus, n.p., 137.

Mud-fish, 61, 76.

Musea, n.p., 94, 131.

Musk-rat, 117.

Mus, n.p., 102, 103.

Mussel, 74, 103, 104, 107.

Mustela, n.p., 50.

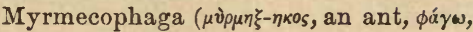
to eat), 42,52 .

Mytilus, n.p., 74 .

Myxine ( $\mu v \xi \xi_{\omega}$ os, slime-fish), 98.

NAJA, n.p., 144.

Nanomia, n.p., 124.

Natica, n.p., 93.

Nautilus (vavrînos, nautilus), $47,58,75$, $87,93$.

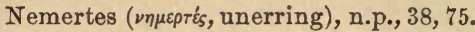

Nemognathus ( $\nu \tilde{\eta} \mu a$, a thread, yvá $\theta 0 s, \mathrm{jaw})$, 148.

Nepa, n.p., 104, 153.

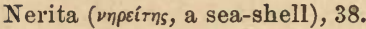

Noctiluca (nox, night, luceo, I shine), 86.

Nomaspis (voro; law, doris, a shield), 147.

Notonecta (vĩros, the back, vвктo, to swim), 152 .

Nummulus (nummus, a coin), 24.

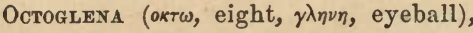
40.

CEthalium, 11.

Oidium (ordś $\omega$, to swell), 161.

Oniscus, n.p., 104.

Ophiopholis ( $\delta \phi i s$, a snake, $\phi o \lambda i s$, a scale), 17.

Ophiura, 45, 56, 122.

Opossum, 118, 119.

Opuntia (Opus, a city of Locris), 154.

Oreodon (öpos, a mountain, odovis, a tooth), 139.

Ornithorhynchus (opvis, a bird, jórxos, snout), 23, 41, 100, 102, 110.

Osteocephalus (oor'ov, a bone, $\kappa \varepsilon \phi a \lambda \eta t$, the head), 108.

Ostrea, n.p., 46, 57, 69, 74, 111.

Ostrich, $37,118$.

Otis, n.p., 50.

Otter, 101, 119. 
Oxyuris (oł̌vs, sharp, ovjpa, tail), 39, 163. Oyster, 74, 111.

Paldemon (Myth., Palæmon, a sea-god), 97.

Paludina (dim. Palus), 54, 57, 108, 112.

Pangolin, 42, 71.

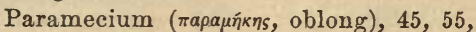
$110,122,175$.

Parrot-fish, 42.

Partridge, 37.

Pediculus (pediculus, a louse), 131, 156.

Pelicanus, n.p., 50.

Penicillium (penicillum, a pencil), 161.

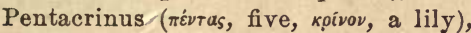
$35,46$.

Perca, n.p., 63, 116.

Perch, 63, 114, 116.

Perdix, n.p., 37.

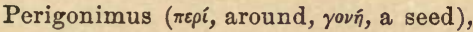
125.

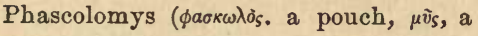
mouse), 51, 52,81 .

Phasianus, n.p., 37.

Pheasant, 37.

Phoca ( $\phi^{\prime}$ ḱ $\eta$, a seal), 35, 62, 95, 101.

Phocæna, n.p., 51, 68, 119.

Phodaga ( $\phi \dot{u} d \varepsilon s$, pustules, ă $\gamma \omega$, to cause).

Photinus ( $\phi \omega \tau \varepsilon เ \nu o_{s}$, shining), 87, 102.

Photuris ( $\phi \omega \bar{s}$, light, ov่pa, tail), 87.

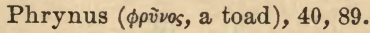

Phthirius ( $\phi \theta \varepsilon i \rho$, a louse).

Phyilidia ( $\phi v \lambda$ is, a leaf), 57.

Phyllirhœ ( $\phi v \lambda \lambda i_{i}$, a leaf, $\rho$, , the wave), 112.

Physalia ( $\phi$ ṽ $\sigma$, a bladder), 24, 45, 88.

Pillbug, 104.

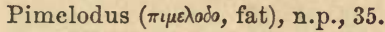

Plant-louse, 132.

Pleuronectes ( $\pi \lambda \varepsilon v \rho i v$, the side, $\nu$ in $\kappa r \eta s$, to swim), 116.

Pleurobranchia ( $\pi \lambda \varepsilon v \rho \delta \nu$, a lung, $\beta \rho a \gamma \chi \iota a$, gills), 45 .

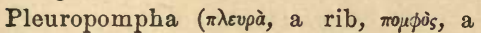
blister), 149.

Plumatella (dim. of plumata, feathered), 106.

Pluteus, 127.

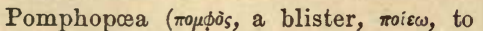
make), 149.
Porcupine ant-eater, 80 .

Porpoise, 51.

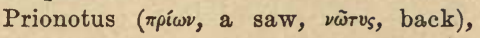
152.

Proteus (Myth., a sea-deity, son of Oceanus and Tethys), 53, 61, 91, 99, 117, 122.

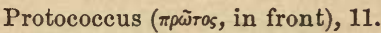

Psittacus, n.p., 62.

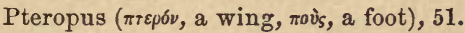

Pulex, n.p., 156.

Pyrethrum, n.p., 157.

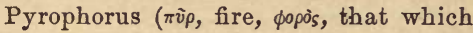
bears), 87 .

Pyrosoma ( $\pi \tilde{\nu} \rho$, fire, $\sigma \tilde{\omega} \mu a$, the body), 128.

Pyrota, n.p., 149.

RANA, n.p., 42, 53, 54, 61, 64, 71, 76, 78, $99,103,117,134$.

Rat, 103.

Rattlesnake, 142.

Reduvius, n.p., 152.

Rhamphastos ( $\rho \dot{x} \mu \not \circ$, a sharp snout), 62.

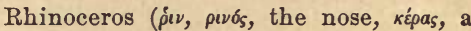
horn), 38, 52, 68, 72 .

Rhizogeton ( $\rho_{\iota} \zeta \alpha$, a root), 110, 125.

Rotifer (rota, a wheel, fero, to carry), 47.

SABre-toothed tiger, 43.

Salamander, 103.

Salmo, n.p., 37, 49, 78, 116.

Salmon, 37.

Salpa ( $\sigma a \grave{\lambda} \pi \eta$, stock-fish), 37, 69, 86, 108, 111, 128.

Sanguisuga (sanguis, blood, sugo, to suck), 48.

Sarcina ( $\sigma \grave{\alpha} \rho \xi$, flesh), 161.

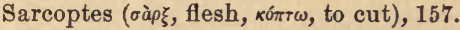

Sarsia (Sars), 126.

Scarus, n.p., 42.

Sciurus, n.p., 103.

Sclerostoma ( $\sigma \kappa \lambda \eta \rho \delta \varsigma$, rigid, $\sigma \tau \dot{\delta}^{\prime} \mu a$, mouth $)$, 164.

Scolopendra, n.p., 82, 83, 87, 159.

Scomber, n.p., 60 .

Scorpion, 48.

Scyphostoma ( $\sigma \kappa \grave{\phi} o_{s}$, a drinking-bowl), 126.

Sea-anemone, 16.

Sea-cucumber, 46. 
Sea-hare, 57.

Sea-lily, 46.

Sea-urchin, 45, 110, 111.

Seal, 35, 62, 95, 101, 119.

Semnopithecus ( $\sigma \varepsilon \mu \nu \bar{s}$, venerable, $\pi i \theta \eta$ kos, monkey), 51.

Sepia, 58, 87, 93, 106, 107.

Serpula (serpo, to creep), 48, 58,

Shark, 57, 102, 108.

Silver-moth, 131.

Sipunculus (siphunculus, a little watering-pot), 22.

Sloth, 22, 62 .

Snail, 23, 46, 47, 104.

Spatangus, n.p., 46.

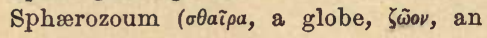
animal), 24.

Spongia, 177.

Squalus, n.p., 37, 76, 78, 102, 108.

Squatina (dim. of squatus, a skate), 63 . Squirrel, 103.

Starfish, 45, 73.

Stentor, n.p., 104, 122.

Strombus, n.p., 93.

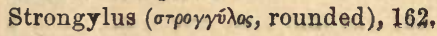

Struthio, n.p., 37, 118.

Sturgeon, 37, 42, 70, 116.

Stylonychia, 122.

Sus, 92.

Swallow, 62.

Swan, 50.

Syncoryne ( $\sigma v \nu$, with, кopv̀v, a club), 92. Synopta (бìvorros, conspicuous), 45, 110, 111.

TAenia ( faivía), 12, 107, 169.

Talpa, n.p., 87, 95, 101.

Tardigrada (tardus, slow, gradus, a step), 115.

Tegrodera, 149.

Terebella (terebra, an auger), 24.

Terebratula (terebra, an auger), 46.

Termes, n.p., 102.

Tethya (Myth., daughter of Uranus and Terrus), 109, 110, 123.

Tetraodon (те́трa, four, dҺớs, tooth), 85.

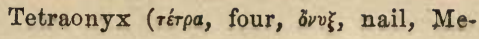
loides), 149.

Tetrastoma (т⿱㇒́трa, four, бтò $\mu a$, a mouth), 168.

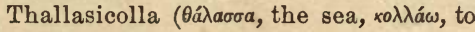
join together), 24.

Thelyphonus ( $\theta \dot{\eta} \lambda v_{s}$, a woman, фóvos, a homicide), 40, 89.

Torpedo, n.p., 82.

Torrea, 94, 97.

Toucan, 62.

Toxopneustes ( $\tau \delta \xi \circ \nu$, a bow, $\pi \nu \varepsilon v \sigma r a ́ \omega$, to breathe), 17,$35 ; 39,45,46,110,111$.

Tragulus (dim. of tragus), 138.

Trichina (тріх

Trichiurus ( $\theta \rho i \xi$, hair, ov $\rho a$, the tail), 85.

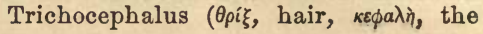
head), 162.

Trichodes ( $\theta \rho i \xi$, hair), 123.

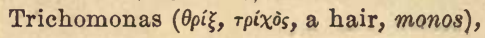
$45,175$.

Tritonia (triton, a weather-cock), 39 .

Trombidium (тро $\mu \beta \omega$ ios, timid), 49.

Tubularia (tubulus, a little pipe), 125.

UNIO (unio, a pearl), 38, 74, 103, 107.

Ursus, n.p., 43, 119.

Vibrio (vibrio, I shake), 9, 174.

Vipera, n.p., 144.

Virgulina, 174.

Viverra, n.p., 119, 139.

Volvox (voltere, to turn), 12.

Vorticella (vortex, a whirlpool), 38, 122, 123.

Vulpes, n.p., 80 .

Waldheimia ( Waldheim), 46.

Water-bear, 59.

Water-moccasin, 144.

Whalebone whale, $41,81$.

Wombat, 51, 52, 81 .

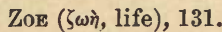

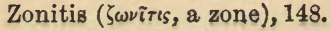

Zygæna, n.p. 50 . 




Evata
p.
0 
THIS BOOK IS DUE ON THE LAST DATE STAMPED BELOW

AIV IIVIIIAT

WILL BE ASSESSED

THIS BOOK ON THE FOR FAILURE TO RETURN WILL INCREASE TO DO CENTS. THE PENALTY DAY AND TO \$1.00 ON THE SEVE FOURTH OVERDUE.

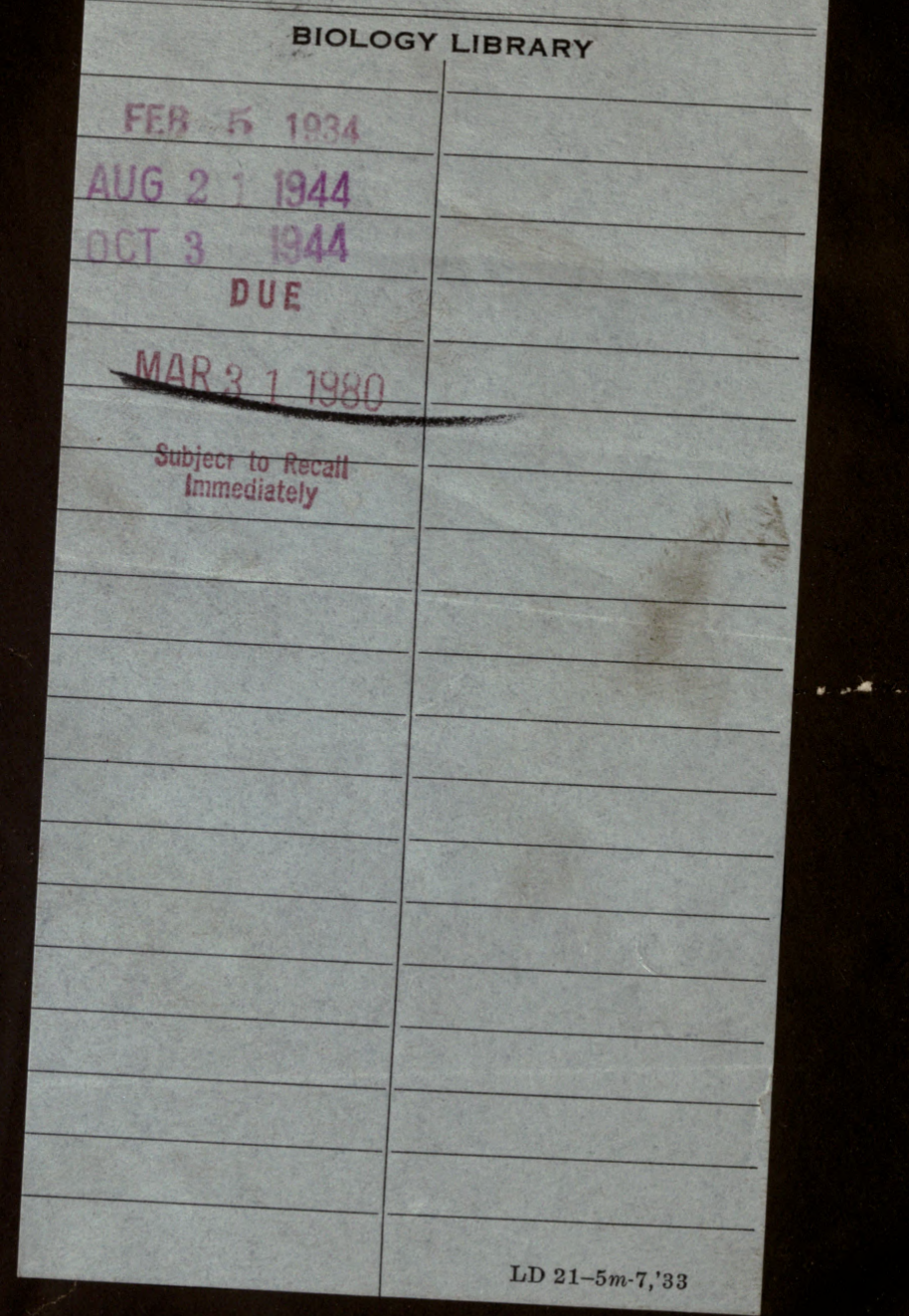


U.C. BERKELEY LIBRARIES

||||||||||||||||||||||||||||||||||||||||||||||||||||||||||||||||||||||||||||

C02616048?

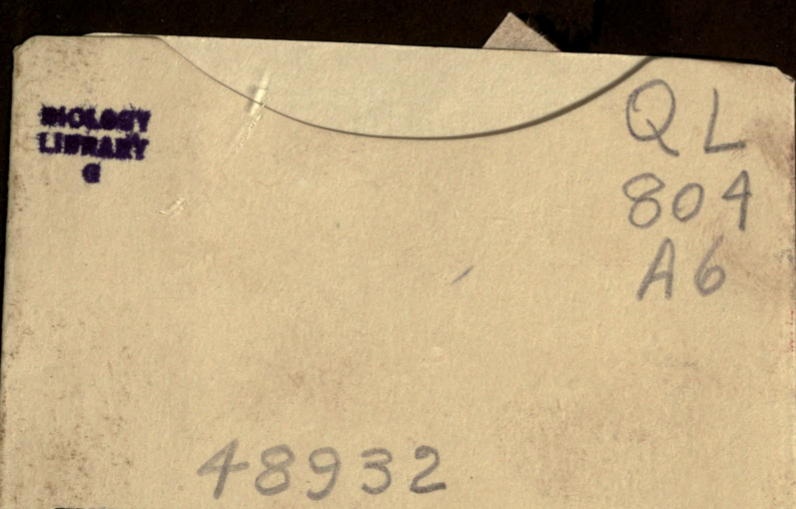

THE UNIVERSITY OF CALIFORNIA LIBRARY 
